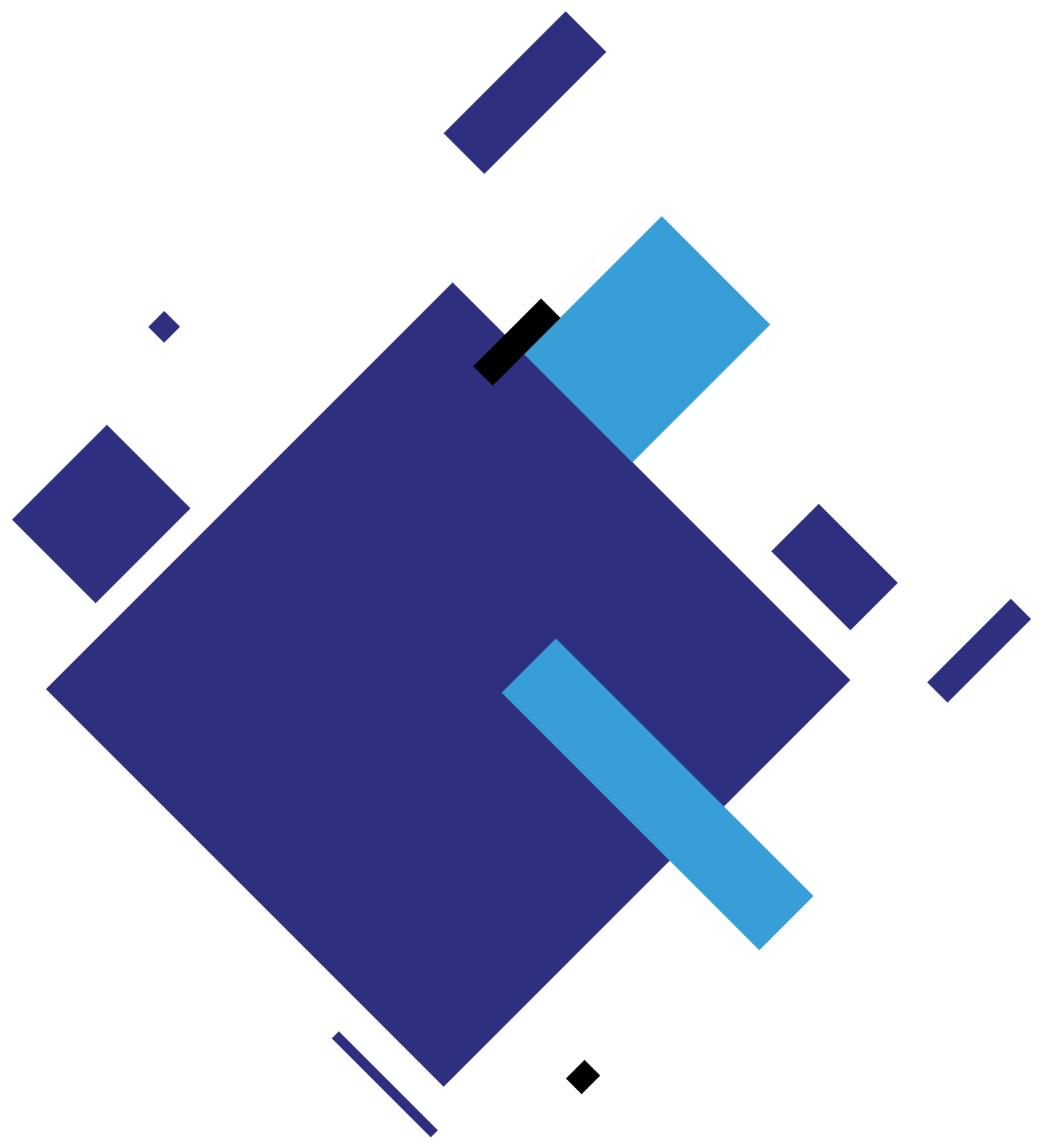

User-Tailored E-Health Services Jan-Willem van 't Klooster 


\section{User-Tailored E-Health Services}




\section{Samenstelling promotiecommissie:}

\section{Voorzitter \& secretaris:}

prof.dr.ir. A.J. Mouthaan

\section{Promotor:}

prof.dr.ir. H.J. Hermens

\section{Assistent-promotor:}

dr.ir. B.J.F. van Beijnum

\section{Referent:}

dr.ir. M.J. van Sinderen

\section{Interne leden:}

prof.dr. M. Vollenbroek

prof.dr.ir. L.J.M. Nieuwenhuis

prof.dr. D.K.J. Heylen

\section{Externe leden:}

prof.dr. P. Maret (Université Jean-Monnet, Saint-Étienne, Frankrijk)

prof.dr. B. Kröse (Universiteit van Amsterdam)

Het onderzoek beschreven in dit proefschrift is uitgevoerd aan de leerstoel Remote Monitoring \& Treatment, welke deel uitmaakt van de Faculteit Elektrotechniek, Wiskunde en Informatica aan de Universiteit Twente, Enschede.

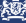

Agentschap NL

De promotieplaats van de auteur is mede gefinancierd door AgentschapNL.

Copyright (c) 2013 Jan-Willem van 't Klooster, Enschede.

All rights reserved. No part of this publication may be reproduced, stored in a retrieval system, or transmitted, in any form or by any means, electronic, mechanical, photocopying, recording, or otherwise, without the prior written consent of the copyright owner.

ISSN: $1381-3617$

ISBN: 978-90-365-3524-3

DOI: $10.3990 / 1.9789036535243$

Cover: Els van 't Klooster 


\section{USER-TAILORED E-Health SeRvices}

\section{PROEFSCHRIFT}

ter verkrijging van

de graad van doctor aan de Universiteit Twente, op gezag van de rector magnificus, prof.dr. H. Brinksma,

volgens besluit van het College voor Promoties

in het openbaar te verdedigen

op vrijdag 28 juni 2013 om 14:45 uur

door

Jan Willem Jaap Roderick van 't Klooster

geboren op 11 december 1984

te Leidschendam 
Dit proefschrift is goedgekeurd door:

De promotor: $\quad$ prof.dr.ir. H.J. Hermens

De assistent-promotor: dr.ir. B.J.F. van Beijnum 


\section{Summary}

This thesis describes a method to offer personalised healthcare. It is motivated by a desire for more efficient healthcare, as population ages and care demand and costs increase. Developing and testing individually tailored health services using ICT fits in this motivation, as it leads to more adequate information provided to care receivers and caregivers, a shift in tasks from caregiver to care receiver, and most of all: health services that empower as they are personalised towards individual needs.

In this research, a platform is realised and tested to provide user-tailored e-health services. Tailored means client-specific, i.e different care receivers can consume varying care services of different vendors from the same platform. $E$ health services are electronic health services, or recurring health applications involving communication, mediated by ICT to bridge time and/or distance. The services in the platform apply to care situations like alarming, reminding, taking vital sign measurements, and medication management. Moreover, activity management and interaction between (in)formal caregivers and care receivers are supported. The personalisation of these services can be performed by end users themselves. Hence, the e-health services are user-tailored.

To realise this platform, requirements have been elicited involving interviews with end users. Desires and needs have been translated into scenarios and scenario visualisations to discuss refinement. The technical design based on this requirements engineering process, has been implemented. Then it was tested in a nursing home. Finally we researched how, given such a system in use, data can be analysed and leveraged to monitor patients over longer time, to offer decision support and to provide insight into patient behaviour.

Results show that is possible to create a platform that enables patientspecific care. The platform provides useful applications in care. These applications can save time for caregivers, and increase self-management in patients. However, it requires investment in the learning process.

In sum, the work shows that this platform successfully integrates and tailors heterogeneous sensors, actuators and services from different vendor and 
technological origins. Moreover, the research shows how collected data can be leveraged for analysis and decision support. Adequate personalisation of selected e-health services saves time, increases health situation awareness, supports interaction and furthers patient empowerment. 


\section{Samenvatting}

Dit proefschrift beschrijft een methode om individueel aanpasbare (tailor-made) zorgdiensten te realiseren. Dat is van belang, omdat er behoefte is aan meer efficiënte zorg, door vergrijzing en stijging van uitgaven aan zorg. Het ontwikkelen en testen van individueel aanpasbare zorgdiensten past bij die zoektocht naar efficiëntieverbetering, omdat dit leidt tot betere informatievoorziening voor personeel en patiënt, verplaatsing van taken van personeel naar patiënt, en eindgebruikers op persoonlijke wijze ondersteunt bij het voeren van de regie over de gezondheid.

In dit onderzoek is een platform ontwikkeld en getest, om individualiseerbare zorgdiensten aan te bieden. Individualiseerbaar wil zeggen: patiëntspecifiek, dus verschillende patiënten kunnen uit hetzelfde systeem andere zorgdiensten afnemen, van verscheidene leveranciers. Zorgdiensten wil zeggen: terugkerende zorgtoepassingen waarbij sprake is van communicatie en overbrugging van tijd of afstand. De diensten richten zich op zorgsituaties zoals herinnering, alarmering, het uitvoeren van metingen van fysiologische parameters zoals bloeddruk, en ondersteuning bij het innemen van medicatie. Ook biedt het systeem mogelijkheden voor interactie tussen patiënt, familie en zorgverlener, en ondersteuning voor sociale activiteiten. De personalisering van al die diensten kan worden uitgevoerd door gebruikers zelf, daarom zijn ze 'user-tailored'.

Om dit platform te realiseren, zijn allereerst requirements geanalyseerd aan de hand van interviews met eindgebruikers. De wensen en behoeften zijn vervolgens vertaald naar scenario's en scenario-visualisaties ter verfijning. Het technisch ontwerp gebaseerd op dit requirements engineering proces, is geïmplementeerd en getest in een verzorgingstehuis. Tot slot is onderzocht hoe, gegeven zo'n systeem in gebruik, de gegevens kunnen worden geanalyseerd om patiënten te monitoren over langere tijd, zorgverleners bij beslissingen te ondersteunen en patiëntgedrag inzichtelijk te maken.

Resultaten tonen dat het mogelijk is een platform te maken dat zorgdiensten van meerdere leveranciers integreert. Het platform biedt zinvolle toepassingen in de zorg. De toepassingen kunnen zorgverleners tijd besparen en zelfmanagement van patiënten verhogen. Wel is een investering in het leerproces nodig. 
Het onderzoek bewijst dat het zorgplatform diensten, actuatoren en sensoren van verschillende leveranciers en technologische afkomsten integreert en personaliseert. Bovendien toont het onderzoek hoe verzamelde data kan worden benut voor analyse en beslisissingsondersteuning. Adequate personalisatie van geselecteerde zorgdiensten kan tijd besparen, interactie bevorderen en patiënten zelfbewust van de eigen gezondheidssituatie maken. 


\section{Contents}

Summary v

Samenvatting vii

1 Introduction 1

1.1 Background . . . . . . . . . . . . . . . . . . . . . . . . 1

1.2 Research Objective . . . . . . . . . . . . . . . . . . . . . 5

1.3 Methods . . . . . . . . . . . . . . . . . . 6

1.4 Thesis Outline and Credits . . . . . . . . . . . . 7

2 User-Based Requirements Engineering 9

2.1 Introduction . . . . . . . . . . . . . . . . . . 9

2.2 Methodology . . . . . . . . . . . . . . . . . . . . . . . 9 9

2.3 Results . . . . . . . . . . . . . . . . . . . . . . . . . . . . 13

2.4 Service Analysis $\ldots \ldots \ldots \ldots \ldots$

2.5 Service Requirements . . . . . . . . . . . . . . . . . . . 22

2.6 Conclusion $\ldots \ldots \ldots \ldots \ldots \ldots$

\begin{tabular}{lll}
\hline & Interactive Scenario Visualization & 27
\end{tabular}

3.1 Introduction . . . . . . . . . . . . . . . . . . 27

3.2 Background . . . . . . . . . . . . . . . . . . . . . . 28

3.3 Methodology . . . . . . . . . . . . . . . . . . . . . . 30

3.4 Results . . . . . . . . . . . . . . . . . . . . . . . . . . . . . 31

3.5 Evaluation $\ldots \ldots \ldots \ldots \ldots \ldots \ldots$

3.6 Discussion $\ldots \ldots \ldots \ldots \ldots$

3.7 Conclusion $\ldots \ldots \ldots \ldots \ldots \ldots \ldots$

\begin{tabular}{lll}
\hline & Realisation & 37
\end{tabular}

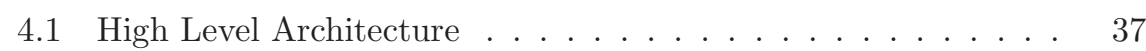

4.2 Behavioun . . . . . . . . . . . . . . . . . . . . . . . . . . . 39

4.3 Detailed Design . . . . . . . . . . . . . . . . . . . . . 41

4.4 Implementation Design . . . . . . . . . . . . . . . . 51

4.5 Discussion . . . . . . . . . . . . . . . . . . . 57 
$\begin{array}{lll}5 & \text { Evaluation } & 61\end{array}$

5.1 Introduction . . . . . . . . . . . . . . . . . . . . 61

5.2 Methods . . . . . . . . . . . . . . . . . . . . . 62

5.3 Results . . . . . . . . . . . . . . . . . . . . . . . . 64

5.4 Discussion . . . . . . . . . . . . . . . . . . . . . . . 74

5.5 Conclusion $\ldots \ldots \ldots \ldots \ldots \ldots \ldots \ldots \ldots$

$\begin{array}{lll}6 & \text { Decision Support } & 81\end{array}$

6.1 Introduction . . . . . . . . . . . . . . . . . . 81

6.2 Contribution of data mining . . . . . . . . . . . . . . . . . 82

6.3 Related work . . . . . . . . . . . . . . . . . . . 84

6.4 Case study description . . . . . . . . . . . . . . . . . . . . 85

6.5 Methods . . . . . . . . . . . . . . . . . . . . . . 85

6.6 Results . . . . . . . . . . . . . . . . . . . . . . . . . . . . . . . . 99 91

6.7 Validation . . . . . . . . . . . . . . . . . . . . . . 94

6.8 Conclusions and future work $\ldots \ldots \ldots \ldots$

7 Conclusions and Directions for Further Research $\quad 99$

7.1 Conclusions . . . . . . . . . . . . . . . . . . . . . 99

7.2 Reflection on the Research Questions . . . . . . . . . . . . . . 99

7.3 Research Contributions . . . . . . . . . . . . . . . . . . . 101

7.4 Directions for Further Research . . . . . . . . . . . . . . . 102

\begin{tabular}{ll}
\hline References & 111
\end{tabular}

Appendix

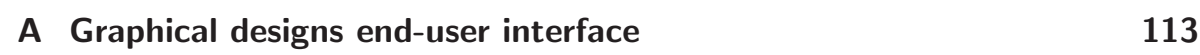

\begin{tabular}{ll}
\hline B Interview questions & 115
\end{tabular}

\begin{tabular}{ll}
\hline C Activities list & 119
\end{tabular}

\begin{tabular}{ll}
\hline D API reference & 121
\end{tabular}

\begin{tabular}{|ll|}
\hline E B-coloring example & 123
\end{tabular}

\begin{tabular}{ll}
\hline Dankwoord & 129
\end{tabular}

\begin{tabular}{ll}
\hline Biography & 131
\end{tabular}

List of publications 133 


\section{Chapter 1}

\section{Introduction}

To keep healthcare affordable and accessible in the near future, innovation is inevitable. In the coming decades, most western societies will have an aged population, less people trained and available to provide care and significantly increased healthcare costs. Hence, conducting research to find innovative yet effective healthcare solutions is necessary.

In this thesis, the focus is on innovation of health services. This thesis presents a services platform design that enables user-tailored healthcare. This approach enables caregivers to provide individualised care, tailored to personal care needs. This may need various services of different vendors, but they are all shielded from the caregivers; they can configure these services from one place regardless of the underlying working principles and technological origins.

This introduction first gives a general background on the current issues in healthcare. Thereto, section 1.1 provides an overview of relevant societal changes, as a motivation for this research and the context of the research project related to this thesis. Section 1.2 gives the research objectives and the research questions that will be answered in this thesis. Section 1.3 introduces the methods that are adopted to reach those goals. Section 1.4 finally gives an overview of the thesis structure and credits.

\subsection{Background}

The demographic trends in western countries are characterised by aging populations, growing life expectations, decreasing number of healthcare professionals, increasing cost pressure on healthcare systems, and urbanisation. In 2008, 84.6 million people $(>17 \%)$ within the EU were over 65 years of age, which will increase to 151.5 million (30\%) in 2060 31. Though people spend more years in good health condition, they will on average be older and reach higher ages by then, as shown in Figure 1.1. Average costs increase dramatically with age: Figure 1.2 shows that healthcare costs in The Netherlands are over $€ 10.000$ for men and women over 75 years of age, compared to $€ 4.200$ on average. 
In the coming decades, demand for healthcare professionals will increase 11. Whereas in 2008 in the EU there were 4 persons of working age (15-64 years old) for every person aged 65 years or over; in 2060 the ratio is expected to be 2 to 1 [26]. In rural areas this creates partial unavailability of healthcare, when specialised care is only available in urban areas.

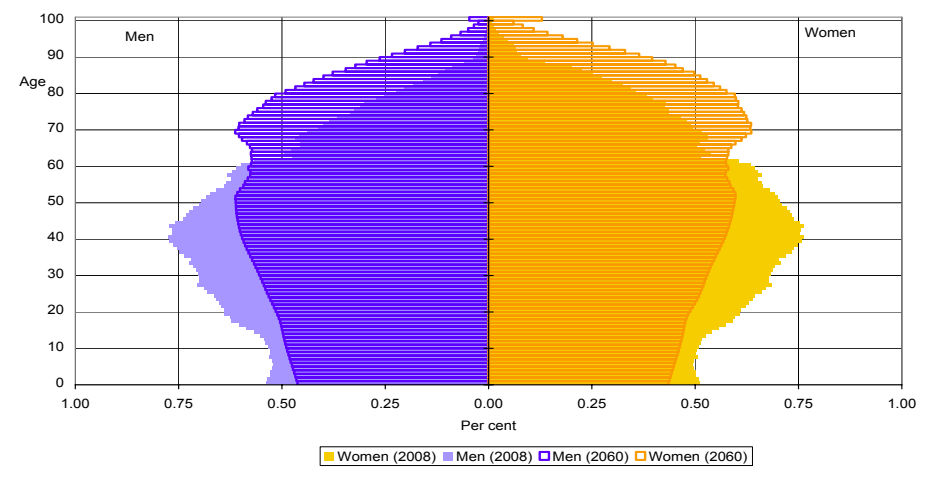

Figure 1.1: Population pyramid of 27 EU countries in 2008 and 2060 [31].

As the effects of these trends are undesirable from an economic and social perspective, it is important to innovate healthcare, to increase effectiveness and efficiency and to decrease costs. This is among others achieved by means of information and communication technology (ICT). ICT in healthcare is also referred to as electronic health (e-health) 28. E-health is an emerging field in the intersection of medical informatics, public health and business, referring to health services and information delivered, or enhanced, through the internet and related technologies. E-health differs from electronic care and telemedicine. E-health covers a wider range of applications and technologies than e-care (e-care focuses on care support) and telemedicine (distant patient treatment involving a professional). E-health is in a wider sense an enabler for patient empowerment.

\section{State of Art}

Most elderly want to age as independent as possible. However current enabling technologies such as e-health, are only used on limited scale nowadays, regarding their functionality, adoption, or both. Moreover, they can be quite expensive, not well integrated and not well tailored to specific care needs [25, 50, 71, Current state of art indeed shows this isolation of services and 'one-size fits all' approaches:

- 50plusnet is a popular match-making platform founded by the Dutch Institue for Public Health Promotion and Disease Prevention (NIGZ) to stimulate social activities and interaction among elderly. Having over 150 


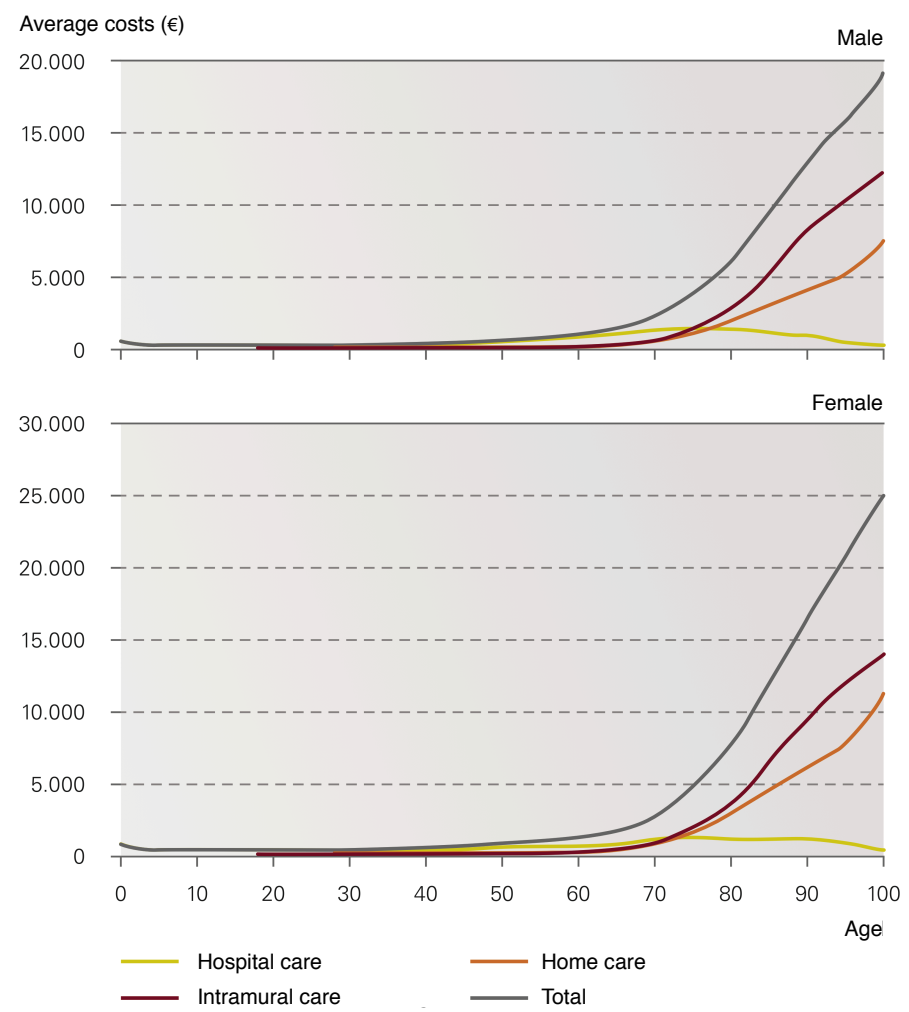

Figure 1.2: Average costs (in $€$ ) of hospital care (lime), home care (orange), intramural care (purple) and total cost (grey) over age, shown for men (upper figure) and female (lower figure). Adapted from 11.

active users simultaneously and over 30.000 registered users in total, it is quite well possible to meet new people with similar interests.

- Pal4 is a Dutch software platform for home care that also provides actualities, but also shopping services, entertainment and video contact. Standalone software running on intrusive touch screens was used initially, but currently it is rolled out using tablet computers. It is especially intended for independent elderly living at home. It does not collect, analyse, tailor, personalise or integrate health services.

- Care administration system such as ONS (Nedap N.V.) and augmented family portals like Caren offer care administration, information, health records, agenda and appointments, and secured interaction between caregivers and family of care receivers. 
- Various monitoring services are available on the market nowadays including medication monitoring, fall detection systems, remote monitoring of vital signs, and person alarm services connected to telephone centrals. To date, these are isolated and not used in integrated fashion. This implies that decision support based on fusion of data within these services is neither possible yet.

- Fusion of such data within single operator / vendor environment have been researched, among others in smart homes including the Gator Tech Smart House in Florida, Us, at DFKi in Bremen, Germany and at NICT in Osaka, Japan. Inspired by the networking possibilities of the 'Internet of Things' paradigm, domotics (i.e. home automation) and sensors systems are installed in testbed homes to execute living lab tests in the home. Although expensive to set up, these smart homes have catalysed innovation of in-home services. They also function as prototype showcases of the possibilities when homes are equipped with (in the future hopefully less) expensive sensors and actuators.

\section{Problem Analysis}

Current state of art is either focusing on small numbers of generic services (50plusnet: social activities and interaction, Pal4: video communication and leisure, care portals: administration and information services; isolated telemonitoring services) or on fixed location smart environments. There remains a need for integration and personalisation of health services from different origins and vendors, beyond a single place and beyond isolated services types. Fulfilling this need would allow personalisation, self management and better informed decision support.

This research focuses on the design of a platform that overcomes those issues. The thesis describes steps involved in the development and evaluation of a platform that enables user-tailored e-health services. The research is strongly related to the User-Tailored Home Care Services Platform (in short: U-Care) project described hereafter.

\section{U-Care project}

The U-Care project aims to develop a services platform for integrated care systems. The goal is to provide tailorable and non-intrusive care services. The U-Care platform will provide technology-independence, in the sense that it will shield users from underlying details and (vendor-specific) technologies. The U-Care platform is different from current platforms because it offers basic, context-aware functions that can be used as service building blocks. It utilises information derived from sensors for vital signs (activity level, heart rate, blood pressure, oximetry, weight, etc.), actuators (e.g. medication dispensers) and software systems used for e.g. alarms, agenda and video calls. The project focuses on wellness and healthcare applications and services to assist elderly 
people in their daily living and to increase their self management. The platform is validated using a pilot study in a nursing home testbed.

\subsection{Research Objective}

Most current e-health initiatives, as described above, are specific in function or isolated in location. They lack the ability to combine multiple generic services in a user-tailored way. This limits the advantages of such systems with respect to synergy, decision support and saving time. Hence, the goal of the research presented in this thesis, is:

- To develop and evaluate a system that provides user-tailored e-health services. The system should enable personalised care services, based on generic services from different vendors and technologies. Moreover, research will be conducted to find ways to leverage data available within the system. In this way, it is possible to perform modelling and to provide decision support.

The following research questions guide the different studies:

1. How to adequately elicit requirements from the different stakeholders involved in such a system? To date, a large corpus of research exists that reveals us that telemedicine implementations often fail because they are designed in a technocratic rather that a socio-technic way. To face this problem, user-based methods need to be studied and understood.

2. How to effectively gather comments and critique from stakeholders on the platform in an early stage of the design process? We are interested in the role of user-based methods to aid in the service design process. This question is studied as part of the design of the system.

3. To what extent are service oriented techniques beneficial to develop this platform? Since the platform should integrate and personalise different services from multiple vendors, service composition and orchestration are crucial factors. During the development of the system, we shall study architectural principles that enable the tailorability of the platform.

4. Is the system usable in daily care and is it effective? The system will be evaluated in practice. We will test suitability in daily care situations, and assess its technical merits.

5. How to leverage the data used in such a system to model patient behaviour and to provide decision support? We are interested in leveraging the synergy of services within such a platform. Given the 
data collected in such a platform, it becomes feasible to use data analysis techniques to model patient behaviour and to provide decision support. We will study how this can be achieved.

\subsection{Methods}

A health model and a general research framework are presented in this section to give a high-level overview of the research methodology. The specific studies, executed to answer the above-mentioned research questions, require specific methods and instruments. They will be presented in each chapter on a more detailed level.

\section{Health model}

First of all, we use the ICF (International Classification of Functioning, Health and Disability) as basis for our understanding of health. The ICF is developed and maintained by the World Health Organization (WHO); it is shown in Figure 1.3. This is a holistic health model as it describes and organises the biopsycho-social aspects of functioning of man. Besides a taxonomy of physiological and anatomical aspects of the health condition, it also relates activities and participation to health. The functioning of a person takes place in a context. Therefore, the ICF also contains environmental factors, next to (for each person varying) personal factors.

In Chapter 2, we discuss in more detail how the ICF is used to elicit requirements for health support. Since the ICF is used for this reason, the assessment of requirements for health support is set up in a broad way itself.

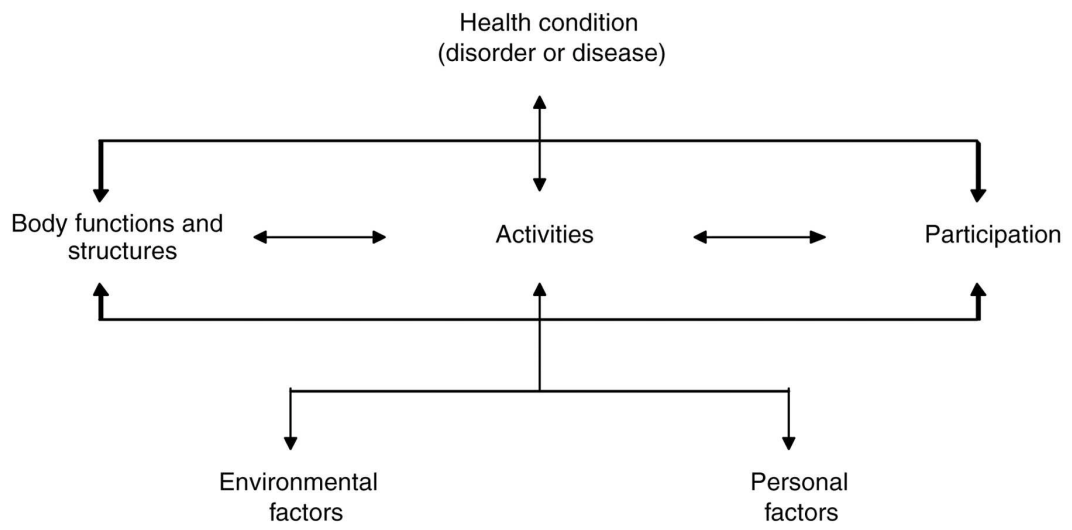

Figure 1.3: International Classification of Functioning, Health and Disability (ICF). 


\section{User-Based Design}

In the past decades, in has become clear that involvement of users is crucial in successful development, implementation and adoption health innovations 4, 5, 8, 54. As care innovation is a result of multiple disciplines (eg. engineering, clinicians, patients) working together [80, methods that synchronise their vocabularies and trains-of-thoughts are important to avoid miscommunication [10. In this research, a user-based design method is adopted involving scenario-based user need analysis (SUNA) [1, 3. Recurring user input and -reviews are guaranteed through frequent meetings, interviews sessions with experts, care professionals and elderly. They are executed in the requirements, development and testing phases of the design process. An evaluation is conducted to validate both usability and design. First, testing will be done to assure proper functioning in real life, then a pilot validation is conducted involving end users.

Scenario-based design involves 3 levels: organisation, application and technology. On an organisational level, it involves the understanding of people and their roles, the relevant activities they perform, their context and their rationale to use envisioned technology (PACT) [9]. On an application level, it involves requirements elicitation in terms of functionalities, interactions, information content, distributive aspects and quality characteristics of the service (FICS) 38. This steps aids the service decomposition on the technological level. This decomposition can be described in terms of model, view, control (MVC) [59]. The MVC-model, used widely in ICT development to manage, separate and re-use components, distinguishes the information model of a service, the logic or algorithmic (control) that controls the service, and the user interface (view) which represents (a state of) the information in the model. We adopt the Unified Modelling Language (UML) for modelling the decomposition.

The general framework, based on existing foundations of PACT, FICS and MVC, is shown in Figure 1.4. From left to right, it shows that a scenariobased design method can be used to iterate from abstract, user-centered PACTscenarios, via a system-oriented and more concrete FICS-scenarios, to a technical service decomposition. The result is a description in terms of information representation (model), user interface (view) and algorithmic (control) of the service. Iterations may take place both within and after the different steps involved. For example as a result of ambiguities, requirements changes or details becoming more clear along the process. Chapters 2, 3, and 4 discuss the PACT, FICS and MVC stages in depth, respectively.

\subsection{Thesis Outline and Credits}

The structure of the rest of this thesis relates to the research questions as follows:

Research Question 1: Chapter 2 presents the requirements engineering process that is used to elicit the requirements for the home care services 


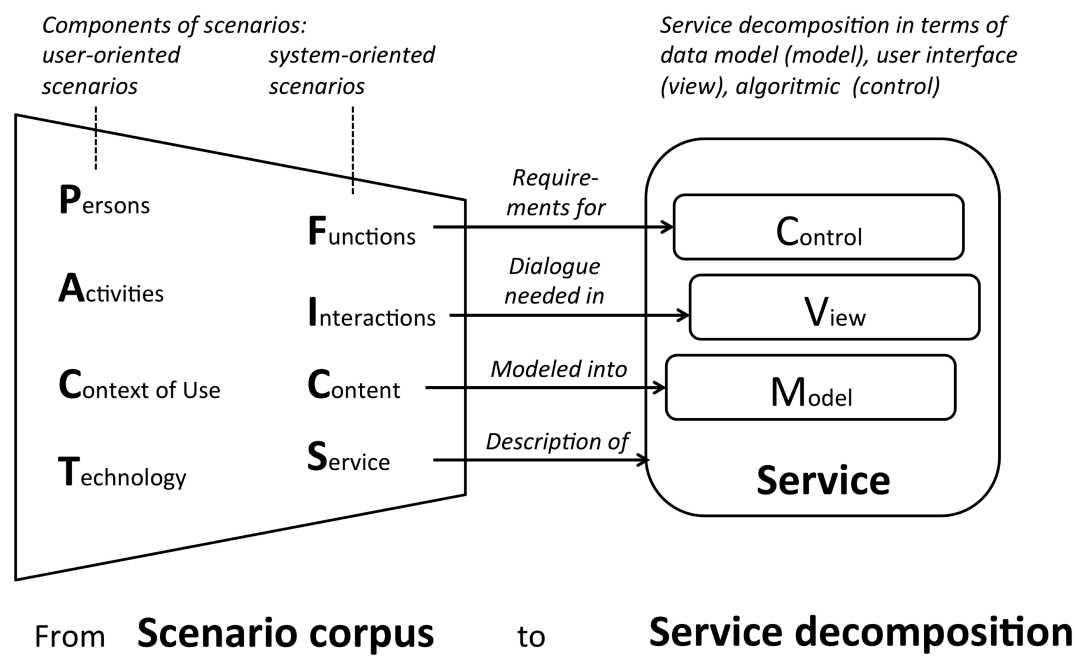

Figure 1.4: User-Based Service Design and composition involving PACT (Persons, Activities, Context of Use, Technology), FICS (Functions, Interaction, Content, Service description), MVC (ModelView-Control).

platform. This chapter is based on [71, [76] and [73].

Research Question 2: Chapter 3 presents interactive scenario visualisation as extension to scenario-based requirements engineering. As a case study, the home care services platform is visualised to gain stakeholder feedback. This chapter is based on 72 .

Research Question 3: Chapter 4 discusses the realisation of the home care services platform. Both the architecture and the implementation design are described and related to the requirements engineering process. The chapter is based on 74 and 75 .

Research Question 4: The system is evaluated in practice, using a longitudinal pilot study in a nursing home. The results of that study are presented in Chapter 5. It is based on 75.

Research Question 5: Chapter 6] describes how the data within the system can be used for monitoring, data analysis and decision support. To this end, a data mining module has been developed and validated. This chapter is based on 69] and 70 .

The thesis ends with conclusions, a reflection on the research questions and recommendations on future research in Chapter 7. 


\section{Chapter 2}

\section{User-Based Requirements Engineering}

\subsection{Introduction}

The contribution of this chapter is a systematic development of an e-health platform for elderly. To this end, a multidisciplinary and user-centric approach is followed where input is gathered and processed from care clients and caregivers using in-depth interviews, and input from other stakeholders are incorporated in the development process. This chapter discusses the requirements to be supported by the platform. The target population consists of elderly of 60 years and older, with varying levels of care needs, living independent or in open accommodations. We focus on the requirements and services of the technical platform rather than on the graphical user interface.

The remainder of this chapter is structured as follows. In section 2.2, the methods that were used for requirements gathering are explained. In Section 2.3. results of the interviews are discussed. Section 2.4 presents the proposed platform services analysis. Section 2.5 presents the requirements imposed on those services. Finally in Section 2.6. conclusions are presented.

\subsection{Methodology}

Our requirements elicitation process combines scenario-based user need analysis (SUNA) 1], and interviewing techniques guided by a health model constructed from the International Classification of Diseases (ICD), the International Classification of Functioning, Disabilities and Health (ICF), and their relationship as defined by so called core sets $[7,64,78,79$. Paragraph 2.2.1] gives an overview of the requirements elicitation process steps taken. Paragraph 2.2.2 discusses the health model. Paragraph 2.2.3 details the interview design and Paragraph 2.2.4 discusses the SUNA. 


\subsubsection{Overview}

The requirements elicitation process that we followed is shown in Figure 2.1. The boxes show the activities; the arrows denote the information used and produced for those activities. A health model and breakdown concepts [35] were used for interviews with clients and care professionals. Analysis of the interviews was used for scenario development purposes, both directly and involving a stakeholder workshop. The scenarios consequently imposed requiremen ts on the system. Hereafter details of each of the steps are given.

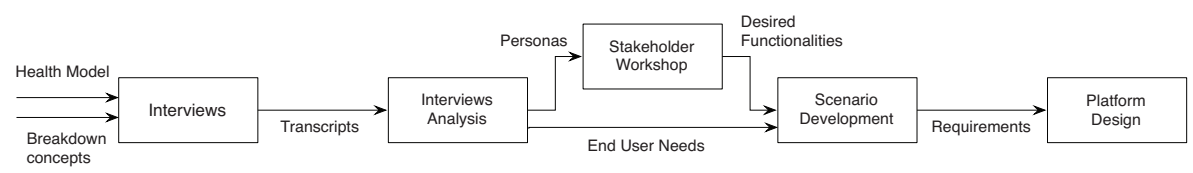

Figure 2.1: Steps taken to gather requirements for the e-health platform.

\subsubsection{Health model}

User interviews are the starting point of user-based requirements elicitation. In order to structure and guide the interviews, relevant health related issues need to be identifiable. To prepare, execute and analyse the interviews we adopted a comprehensive health model. The WHO has defined a holistic ontology for health, called the ICF 78. This ontology is a bio-psycho-social model of health, that can be used for many different purposes, among these the assessment of the health condition of man. The ICF defines the health condition as a composition of four components: body structure, body function, activity and participation. Each component comprises a set of categories. Example categories are: S4: structure of the cardiovascular, immunological and respiratory systems and D3: communication. Categories may be organised in a hierarchy of subcategories, for example: S4 includes amongst others the subcategories s410 structure of the cardiovascular system and s420 structure of the immune system. D3 includes amongst others communicating receiving (d310-d329) and communicating producing (d330-d349). Because of its bio-psycho-social model and its detailed description of both medical and social factors, the ICF is a holistic model. The ICF components are influenced by contextual factors, which can be either personal factors or environmental factors. The ICF defines the relevant categories for environmental factors. Using the ICF, we are able to assess a clients health status. Moreover it enables the structuring of interview sessions and the capturing of the essential clients needs and values related to all health aspects their chronic conditions (using the core sets described hereafter). Therefore we used the ICF as a theoretical basis of the interview protocol.

Most of the clients in our target group have been diagnosed one or more chronic diseases. A taxonomy of diseases is available from the WHOs ICD [79]. The qualitative relation between a (chronic) disease and the ICF categories 
potentially affected by this disease are defined by an ICF core set (Stucki et al., 2004). Core sets are continuously developed [7] and sofar have been defined for about 20 frequent chronic diseases [7, 64. For each of these conditions, relevant items of the ICF have been described and summarised in a core set cq. a brief core set. Hence while preparing interviews, these core sets enable to find relevant ICF categories for the chronic conditions client suffer from.

The conceptual schema of the ICF, ICD and core set is shown in Figure 2.2 in the Unified Modelling Language (UML).

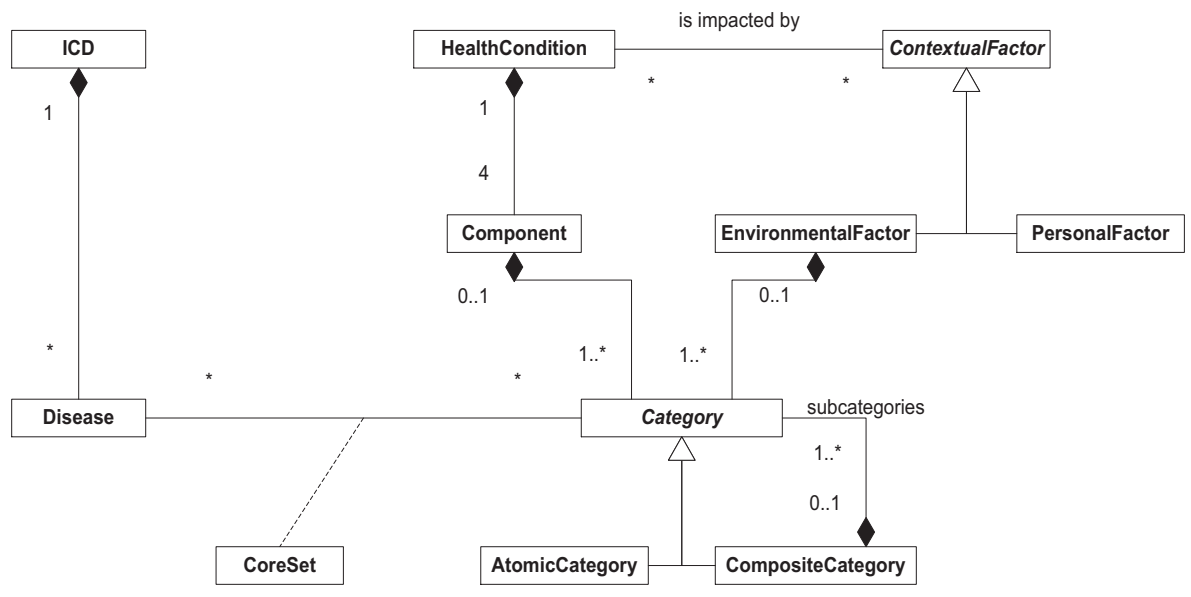

Figure 2.2: Comprehensive Health model based on WHO's ICD (International Classification of Diseases), Core Sets, and ICF (International Classification of Functioning, Health and Disabilities)

\subsubsection{Interviews}

Throughout 3 days, we interviewed 7 clients and 4 care professionals in the elderly care centre Parc Hoogveld in Sittard, the Netherlands. This centre encompasses 88 single and 6 double apartments with $24 / 7$ care, 64 service apartments, 124 'aging-proof' apartments as well as, e.g., catering, religious, shopping, relaxation and park facilities. Besides, there are 48 nursing home places mainly for dementia patients. The interview protocol was designed to get an in-depth understanding of the health status and living situation, and to elicit care values and needs. The protocol was tried out in advance in a test interview. The number of interviewees is low, and therefore does not deliver theoretical saturation [32. However, this is not the aim of this study. Instead it serves as a first iteration of end-user input for development purposes, and for an in-depth understanding of the behaviour of members in the target group. A second iteration of end-user input is discussed in the next section. Members of the target group are 60 years and older. They have 2 determinants in common: 
1. They have varying care needs due to varying health problems;

2. They make use of different care services from the care organisation.

For the interviews, elderly were recruited on voluntary basis by the care organisation. The care organisation assured those two determinants and representation of the inhabitants in the centre. Beforehand, we studied information about the clients health conditions and care services they use, by means of examination of their personal intake assessment, for which permission was obtained. Two of the interviewed care professionals were responsible for providing care services to clients. Since the two caregivers were interviewed after the client interviews, we were able to reflect and discuss the answers from the clients with the caregivers. The third care professional was responsible for client intakes and updates, to determine care services to be provided to the clients. The fourth care professional was specialised in information management in care centres with a strong care giving background. The clients were asked about a couple of items. Their health status was discussed, based on their intake assessment and the relevant ICF and Core Set categories. We also discussed their information needs, use of technology, care services received from the care centre or elsewhere, and wishes for novel functionalities that could be supported by means of technology. The caregivers were asked about their working procedures, information needs, use of technology, care services provided by the care centre and existing working practices. The in-depth interviews were held in a semi-structured manner and were recorded and transcribed. The interview protocol was based on the health model discussed in Paragraph 2.2.2, and on breakdown analysis. In breakdown analysis [35], the focus is on analysis of interrupted, not smoothly proceeding equipment use, e.g., technology equipment. We used breakdowns accordingly when asking the clients about their use of technology, and when asking the professionals view on this. In the interviews with professionals, we used breakdowns when they showed us their equipped working environment. The completed interviews were transcribed and then analysed. Analysis was conducted by identifying actualities in the answers and comparing these with other transcripts, so as to retrieve the key actualities. This grounded theory [18,32] based-analysis technique was used to retrieve the end-user values and needs discussed in the next section.

\subsubsection{Scenario-Based User Needs Analysis}

In situations where the use and purpose of a novel system are not clear a priori, usage scenarios are an appropriate technique for gathering these requirements [1, 36, 60, 65]. As this is the case in our project, SUNA [36] was used to elicit functional requirements. The interviews with end-users (clients and care professionals) were transcribed and analysed. Based on the key health problems, values and needs, three personas were constructed. Personas are fictional persons that serve as a vehicle to illustrate envisioned use of technology in scenarios [17, 58]. They represent role models of the target group 
of elderly. These personas were constructed blending idiosyncratic details of different interviewees into three persons with a combination of features that suited the main purpose to serve a role model in the workshop, clarifying and illustrating the key findings of our field work. To ensure this coverage, we checked whether the interviewee characteristics were represented in the personas. Once constructed, the personas were introduced in a multi-stakeholder workshop. The workshop centred around two multi-stakeholder focus groups with professionals from care, academia and home automation industry. All are members of our project consortium. The workshop identified a collection of functional elements of future ICT technology use for the targeted elderly. The interview analysis resulted in end user needs. These are presented in Section 2.3. The end user needs, prioritised by the consortium, and the functional elements, formed the input to develop three scenarios. They were drafted to present the proposed novelties in a coherent story around the personas. Then, the project consortium reviewed the scenarios to achieve consensus on the envisioned system. The requirements were grouped in basic (overall) requirements and requirements related to a specific function to be fulfilled by the system. For traceability purposes, we listed from which scenario each requirement was inferred. Finally, we checked whether the scenarios together covered the list of desired functionalities from the workshop, and whether the scenarios covered the needs expressed by the clients and caregivers.

\subsection{Results}

\subsubsection{Interview Results}

Table 2.1] summarises the needs and values put forward by the clients resp. care professionals during the interviews. These findings were not explicitly asked for, but mentioned spontaneously by the interviewed persons. One client and one caregiver emphasised the importance of finding new friends to conduct activities with. Three clients and four care professionals mentioned the importance of remembering and information on events. Six clients and two caregivers recognised medication support would be useful. Almost all clients (6) used, or wanted to use, some technology for hobby, such as cellphones, multi-button remote controls, dvd players, but also computers. For instance interviewee 1 said:

"Yes, I would like to learn how to handle a computer. I think I could do that ... from somebody, one-to-one. Not in a group, Im not really a group person. If that would be possible..."

The xct of learning how to operate the device is important, as addressed by interviewee 2 :

"My grandson then comes to explain me how to operate the dvd recorder." 
However not all interviewees want to use a computer, afraid that it consumes too much time learning. Interviewee 2 states:

"My son-in-law bought a new PC, with more capacity, and wanted to dump his old one on me. But I didnt want it. If you want to learn handling a computer, that is a lot of work, and I dont have the time to do that. I can handle the radio, the television, and the dvd recorder and thats all I need."

The use of technology indicates that the current generation independent elderly in our research do accept technology, but devices that perform computing tasks should preferably not look like a computer to receive higher acceptance. We observed that clients talked frequently about their communities, e.g., concerning family, neighbours or relations with the professionals. Five clients valued contact with family, not only for themselves but also for their relatives. Interviewee 3 mentioned:

For instance, my sister calls every evening at seven, and she talks for the better part of an hour. She can talk about the past, for example about the business that we used to have.

Though contact with family was not addressed in two interviews with caregivers, the other two valued it as important too. Two clients reckoned having a daily structure or aid for that is important; two caregivers did so as well. Almost all clients (6) valued support from and to neighbours and people in their community as important. Regarding this contact with the community, interviewee 1 said:

"It's a fine little street here. Yesterday we went in a van and a car to the hospital, all together, and then we drink coffee together and everyone is very happy."

"And in the morning I pour them a coffee. In our sitting corner, Im usually the first to be there, and then I ask everyone would you like a coffee? and then I give them one. There is nothing wrong with my hands, its only the legs that give problems."

Apparently, these communities are valued as an important part of their daily life. Also three caregivers mentioned this as important for their clients. Three clients mentioned that when they would be introduced to new technologies, assistance and explanation of the usage would be important. The caregivers did not address this. Interestingly, the clients did not talk spontaneously about monitoring or being monitored, but all the caregivers addressed monitoring functions as important for the clients safety. We think that this comes from the fact that for the caregivers monitoring of safety is an important aspect of the job (e.g., because of the possibly large impact after dangerous events such as a fall). On the other hand, for clients it is something they rather not think or talk about freely when it concerns their own situation. 
Table 2.1: Values and needs important to clients and care professionals (ordered ascending by clients, caregivers)

\begin{tabular}{lcc}
\hline Value / & $\begin{array}{c}\text { Nr clients } \\
\text { reported }(\mathrm{n}=7)\end{array}$ & $\begin{array}{c}\text { Nr. professionals } \\
\text { reported }(\mathrm{n}=4)\end{array}$ \\
\hline Monitoring for safety & 0 & 4 \\
Finding friends for activities & 1 & 1 \\
Providing daily structure & 2 & 2 \\
Aid in technology use & 3 & 0 \\
Information on events & 3 & 3 \\
Memorising events & 3 & 4 \\
Support for medication & 4 & 2 \\
Finding friends for activities & 5 & 2 \\
Contact with family & 5 & 2 \\
Technology use for hobby & 6 & 2 \\
Contact with community & 6 & 3 \\
\hline
\end{tabular}

Clearly, some of the needs and values found in the interviews can be supported by means of virtual communities 29. As there are various occasions in elderly healthcare in which different people interact because of a common problem or goal, different communities can be identified according to this definition. Because of their social nature, services for finding friends, information on events, memorising events, contact with family and contact with the community, are also good candidates for ICT-supported functionalities. Moreover, these services can be enhanced using the social graph of the member once this graph has been established. Finally, we refer to earlier work [57, 76] in which already scenarios related to monitoring for safety reasons are elaborated on and supported by means of virtual communities.

\subsubsection{Workshop results}

A project consortium workshop has been held in Enschede, the Netherlands, on 13 May 2009, to identify and select desired functionalities. The workshop participants (consortium members and external experts from care and ICT) discussed a range of functionalities intended for the personas. The proposed functionalities can be grouped under three service categories:

1. reminder and information services;

2. social interaction and activities services;

3. health monitoring and feedback services.

The workshop also yielded an idea for an information and communication system that should play a central role. This software system, which we call 
Julie, supports two-way (video) communication, is able to present content and (interactive) information, eventually on request. Moreover, Julie can run on various existing devices such as a TV, PC or smartphone. For each of the three service categories, scenarios are developed. They contain the desired functionalities and the needs addressed by the interviewees. Based on the scenario about social interaction and support services, functional requirements are elicited for a platform. Below one scenario is presented. In this scenario, the proposed technology becomes concrete through the use of the information and communication software system Julie.

"John Pieters is 78 years old. He lives alone in a care centre. He developed chronic obstructive pulmonary disease (COPD). The treatment of Mr. Pieters disease focuses on reducing symptoms and avoiding further deterioration of his condition. Some of his medicines work for the symptoms, but physical exercise is the key treatment. The original series of exercises was explained once at the doctors office. Since then, Mr. Pieters conducts them at his home. During the exercises, he uses a finger clip, which measures the oxygen level in his blood and his heart beat. Through the wall mounted communication system Julie, he gets feedback on how long he should do each exercise, based on those measurements. Thanks to this, Mr. Pieters dares to continue exercises for longer than he would do otherwise. A COPD nurse uses the two-way video to check-up on Mr. Pieters monthly.

After those check-ups, the doctor may adjust the exercise levels and medication, based on to the acquired measures and progress of the disease. The COPD nurse also adds the next check-up to Mr. Pieters calendar. Reminders for the exercises, the medication and the meetings are sent to Mr. Pieters through Julie, either at home or (when he is underway) through his tablet computer. This is useful, as his memory is getting worse.

Alice is a kind caregiver, who regularly visits Mr. Pieters. Alice not only helps with the housekeeping in his apartment, but also checks up on him once in a while via Julie to see how hes doing. Julie suggests activities and new inhabitants for him to meet in the care centre. One new inhabitant turns out to be a friendly man, and Alice arranges they can have get-togethers scheduled through Julie. Afterwards, Mr. Pieters and the new inhabitant meet occasionally for a walk or a coffee."

\subsection{Service Analysis}

This section discusses four services that interact with the user. These services are selected based on the interview analysis and results discussed in the previous section: 
1. Social interaction

2. Social activities

3. Medication intake and compliance

4. Health monitoring

These four services are proposed for the U-Care system. Schematically, they run on top of the physical infrastructure (actual devices, communication) and middleware (tailoring, composition, evolution). For each of these services, we describe the motivation, the objective, the service description, and the tailoring aspects.

\subsubsection{Social Interaction}

\section{Motivation}

Elderly people often experience problems in social interaction. There are many causes, e.g. relatives and family live at far distance, and over the year the number of friends may have decreased. This all can lead to social isolation, and in return it can lead to depression. From this perspective, support and stimulation of social interaction may add to the health condition of a person. We focus on the following three types of actors involved in this problem:

1. Inhabitants: These are the subject for whom an increase of social interaction is considered to be highly desirable.

2. Care personnel: Care personnel may be involved in detecting the social isolation, and may play a key role in stimulating social interaction.

3. Family/relatives/friends: They may play an active role in stimulating social interaction, for instance by taking an initiator role in social interaction acts.

\section{Objective}

The objective of this service is to stimulate and ultimately increase social interaction by elderly and in so far as considered highly desirable. This means that using the social interaction service by target subjects should lead to increased health status (for instance, inhabitant could feel less depressed). It may also lead to less dependability on caregivers for social interaction, as a social network is arising.

\section{Service Description}

Social interaction services can be classified in two distinct categories, these are: face-to-face encounters and ICT mediated encounters. Furthermore, social interaction services can be considered in terms of guiding or orchestration of 
social interaction encounters (hence, managing social interaction to occur), and in terms of social interaction services that realize social interaction encounters. Note that social interaction encounters should be interpreted broadly, that is: these can be synchronous (two or more persons interact now, and possibly at different location) or asynchronous (two or more persons interact each at different times at possible at different locations). The following is provided:

- Synchronous, mediated social interaction: this can be text based (e.g. Chat), voice based (Telephone, VoIP), video based (e.g. Skype or some $\mathrm{U}$-Care specific realisation).

- Asynchronous, mediated interaction: This may be text based (e.g. SMS, e-mail), voice based (voice message service) or video based (video message).

- Social interaction encounter management: to support the creation, publishing and subscription of synchronous (optionally ICT mediated) social interaction encounters. Possible involved roles are: inhabitants, family relatives and care personnel (in a steward or assistant role). At Orbis, get- together encounters may be organized by the caregivers responsible for this.

\section{Personalisation / Tailoring}

Personalisation is required as needs, preferences etc. differ per inhabitant. Personalisation / tailoring is primarily based on inhabitants preferences. Change of preference (over time) automatically leads to an adaptation of the HumanMachine interaction. Also, based on preference of the inhabitant, the service can assist in managing social interaction encounters (e.g. generate recommendations to participate in get-togethers). Health status may also affect the personalisation or tailoring of the service, for instance planned encounters may be brought under the attention of the inhabitant by means of notifications. Also, the health condition may favor a particular way in which the interaction takes place (e.g. voice is preferred over text or video).

\subsubsection{Social Activities}

\section{Motivation}

It has been identified that organizing social activities are important in the care process to provide clients with contact moments, relaxation, outings, etc. throughout the week. It is recognized as well that client may easily forget about the activities. Structural lack of social contact moments easily leads to social isolation and adds to the risk of depression. Alternately, with existing but minimal frequency of social contact moments, quality of life may reduce. Therefore, stimulation of participation in activities is important, for (a) maximizing effectiveness for all attendees and (b) for maintaining quality of life. 
Such stimuli can be given by care personnel, informal caregivers, family, and relatives in the (direct) environment. These processes can be facilitated through (in general) ICT support in general and (more specific) the envisioned social activity service.

\section{Objective}

The social activity service aims at facilitating, stimulating, and ultimately increasing organization of and participation in social activities organized by or for the inhabitants, and promotes remembering activities by opening up media about the event. To do so, the service should be used by care personnel, informal caregivers and family, and inhabitants.

\section{Service Description}

This service enables reminders for social activities. It uses a Publish / Subscribe mechanism [27,30] to issue notifications on the activities of interest. The notifications are available on a variety of resources dependent on the type of notification and preferences / context of the receiver. Various publishers are foreseen, who are able to publish content in an approachable manner. The service furthermore enables reissuing, accepting and viewing others interest in certain notifications. Caregivers and personnel can easily use the service to persuade inhabitants to frequent certain events by recommendation and (personalized) reminders. To enable remembering of the conducted activities, the service opens up media about the held events or activities, such that participants or others can re-experience it from another perspective in their own environment. It is foreseen that this form of content sharing increases the impact of the events. The service enables sharing of content related to activities, and offers notifications once the content is available. Clearly, some of the functional building blocks necessary to compose this service are shared with the social interaction service, especially with respect to ICT support for mediated encounters. Therefore, flexible orchestration / guiding of the process and flexible composition of building blocks is foreseen to be valuable.

\section{Personalisation / Tailoring}

The personalisation depends on the interests of the users. Taking these interests into account, only activities of interest are communicated. In addition to the previous service, personalized reminder settings are used.

\subsubsection{Medication Intake and Compliance}

\section{Motivation}

According to various studies, medication compliance is a major problem 47. Some sources mention that typical compliance ratios achieved are about $50 \%$. Increasing medication compliance is highly important in order for the maintain 
or improve the health condition. Not surprisingly that various approaches have been proposed, various hard- and software systems have been developed. One tangible type of realisation is the medication dispenser, often enhanced with monitoring and control (i.e. management) functionality. The basic idea all existing approaches have in common is that with the use of a medication dispenser and appropriate signalling and feedback, the users are (better) capable to take the right medication at the right dose at the right time. Also safety aspects so as to manage the medication prescription process are included. Typically, they involve physicians and pharmacists to minimise or exclude the possibility of medication prescription conflicts (considering medication, potential side-effect, health condition and diet). These solutions, although potentially extremely useful, are based on a number of assumptions that are not always fulfilled: people are capable and do indeed intake the medication from the dispenser, people are near their dispenser at the time the intake of medication is to take place, situational or circumstantial constraints are satisfied (for instance medication is to be taken before a meal or after a meal, possibly taking some time interval into account). In practice, and especially in care facilities, these assumptions may not be met for a substantial proportion of the inhabitants. The following real problems exists when looking at the current practice of medication intake:

- Inhabitant: inhabitant does not take the right medication or the right dose

- Inhabitant does not take the medication at the right time or not relative (before or after) a specific activity (e.g. a meal or going to bed).

- Inhabitant forgets or somehow deliberately does not take the medication.

- Nurse / healthcare professional: in order to solve the first or third problem (right medication or right dose, not taking medication), current practice is that a nurse gives local assistance to the inhabitant to take the medication. This way, correct selection of medication and right dosing is achieved, and visual cues give assurance that intake of medication occurs. This introduces potentially two problems: peak work load for the nurses, and potentially low compliance (i.e. not taking the medication at the right time).

\section{Objective}

The objectives are the following: to assure the right medication is taken in the right dose, to assure high medication intake compliance (with or without a medication dispenser, depending on the health condition of the person, with or without the local or remote assistance or guidance of a relative, neighbour and with or without the remote supervision of a nurse); to reduce current workload of care personnel. 


\section{Service Description}

The medical compliance service provides a single or multiple actor and partially or fully mediated ICT service to guide the intake of medication according to the medication prescription.

\section{Personalisation / Tailoring}

The medication compliance is a very good example of the personalisation / tailoring to be provided by the U-Care system. Personalisation / tailoring is to be supported in various ways. Firstly, depending on the actual health condition of the person, a tailored solution is configured which solves or gives support to the problems faced. These solutions may address any combination of the following problems: to take the right medication and dose (here the medication dispenser can play an essential role); to take the medication at the prescribed time, time interval or relative to a particular activity.Finally, tailoring in reaction to sudden or gradual changes in the health condition is to be addressed based on compliance judgment.

\subsubsection{Health monitoring}

\section{Motivation}

It is recognized that monitoring of the inhabitants health status can be improved for a variety of reasons, including:

- Time effort needed by personnel to perform measurements in the current situation;

- Information quantity; the actual frequency of measurements is not always equal to the desired frequency; improving this is a challenge;

- Caregivers indicate health monitoring is important (see Table 2.1 above);

- The desire for up-to-date health status information;

- Integrate and tailor monitoring services within care services platform.

\section{Objective}

The objective of the health monitoring service is to provide the ICT infrastructure and support for (remote) monitoring of a clients health and safety. To do so, ambulant monitoring for a variety of specific (yet coexisting) conditions will be provided, as well as the ability for clients to communicate on (sudden changes in) their health status. 


\section{Service Description}

The service will provide ambulant vital sign monitoring, exercise monitoring, diary- like remote questionnaires, alarm messages, access to the gathered information (for review by authorised parties) and data logging.

- For vital sign monitoring, a variety of physiological sensors must be supported to facilitate monitoring scenarios related to different conditions.

- The service enables web-based visualisation of monitoring data for authorised personnel and the clients involved.

- Data collected for the vital sign monitoring and representation is stored for reporting, visualisation and self-management purposes.

- Alarm-messages could be supported if appropriate, to extend the ambulant monitoring functionality with for instance a panic-button on the device.

\section{Personalisation / Tailoring}

Tailoring is important to showcase integration and customisation of monitoring services with respect to the U-Care platform. This holds for all points mentioned under the service description. Personalisation of this service is required to handle different chronic conditions. Also the GUI for direct feedback an indirect feedback is personalised, dependent on the end user service consumption.

\subsection{Service Requirements}

This section divides the envisioned services from section 2.4 further into functional units. Based on the computation tasks that compose the user facing services, this section presents a high-level functional decomposition of:

- Support for interaction;

- Support for activities;

- Support for medication intake and compliance; and

- Support for health monitoring;

The prioritisation is given using the MoSCoW-model, showing must haves, should haves, could haves and want to haves [1. Afterwards, non-functional requirements are shortly addressed. 


\subsubsection{Social Interaction Support}

Virtual communities (VCs) [76] will be deployed for socialization and clientcaregiver care-related interactions. The VC can be used to support these interactions and enables notifications from the personnel to clients. To do so, the following service components are required for this user-facing service:

- Content management function: the care organization must be able to perform general and content- related management functions in the $\mathrm{VC}$; such as member management, adding and editing content, events, and announcements;

- Video communication using the earlier introduced concept of Julie (see paragraph 2.3.2); video interaction between clients or between client and caregiver should be available;

- Support for organizing encounters must be given through the virtual community.

- The VC must support a place to find other people to interact with, based on profile information.

- Delegate / mandate function: the VC could allow for delegations and mandates, such as accepting or requesting connections to people or services on behalf of a user. For instance, an (informal) caregiver could be authorized to make a connection between two clients;

- Connection facilities with external services must be included to support (video) calls.

\subsubsection{Social Activities Support}

Reminder services must be deployed to assist the elderly. The functionalities are:

- Reminder services, such as showcased in the tailoring workshop, based on an agenda which can be filled by involved actors must be available;

- Tailoring of this service must be available w.r.t. interface modalities and personalisation of the reminders as they are presented to the users;

- Different kinds of actors, including (informal) caregivers and inhabitants should be able to publish information.

- Measuring if informing clients on activities results actually in successfully notified clients should be available;

- Regarding the reminders, different levels of intrusiveness should be possible as well as based on context information. 
- Registration of reminders and acknowledgements of these reminders must be available to show trends over a longer term;

\subsubsection{Medication Intake and Compliance Support}

The system must provide medication intake support and means to monitor and register compliance information.

- Medication supply services using a medication dispenser must be available. It is coupled to a reminder service to provide reminders,

- The service must enable both single- and multiparty use for independent intake as well as intake with assistance;

- It should guide intake of medication by means of a tailorable interface;

- The intake scheme must be coupled to the service to enable correct reminding; it is accessible at a distance.

- For taking medication, a sampling service must be deployed (managed by an authorized formal caregiver).

- A compliance service must be deployed to present compliance over time to clients and authorized formal caregivers; It provides backlogs and signalling of deviances in the intake.

\subsubsection{Health Monitoring Support}

Telemonitoring services must be deployed for vital sign monitoring. The goal is not to specifically aim at a single (chronic) condition. Part of the envisioned outcome is to show that different monitoring scenarios can be supported, using possibly a different set of sensors. The following functions must hence be available:

- Remote monitoring of (physiological) measures: the service has support for remote monitoring of vital signs;

- The functionality allows authorized parties (humane or artificial) to give feedback to the monitored subject;

- Measures include:

* Location or other context information;

* Activity;

* Oxygen saturation;

* Heart rate;

* Weight;

* Blood pressure. 
- Monitoring must be mobile and should be pervasive;

- Both immediate and longitudinal feedback should be supported within the platform.

- Presentation and storage (logging) of these data should be possible using the platform, and should be available to involved actors. The monitored data should be accessible to authorized parties, synchronously or asynchronously.

\subsubsection{Non-Functional Requirements}

All systems have qualitative concerns. These concerns are described using quality characteristics. As such, they reveal how the goals of the system are met -rather than which goals. For software systems, ISO standard 25010:2011 [55] defines a framework for software quality characteristics. It describes a product quality model that consists of functional suitability, performance efficiency, compatibility, usability, reliability, security, maintainability, and portability concerns.

For the U-Care system, these qualities are applicable as well. Specifically, they must be addressed as follows:

- Functional suitability: the functionalities provided should be efficient and effective. Efficient (the right things) because unused functionality means waste of resources, and inefficiency in functionality is contrastive to the desire of more care efficiency using such a system. Effective (the things right) in the way that the provided services should reach their intended goals.

- Performance: the time behaviour and resource utilisation (usage of resources) should be reasonable. Given the inherent delays in networked systems, the controllable performance should be as high as possible. The system should have a scalable capacity to accommodate utilisation of the system by large nursing homes in the future.

- Compatibility: the system should be compatible with current care solutions and with current health records when available. The system should not suffer from interference of other distributed systems.

- Usability: given the target group, the system should be as operable as possible. It should be easy to learn using e.g. a workshop with demonstration and exercises. It should have a pleasant, recognisable and easy to understand graphical user interface that limits possibilities to make user mistakes. Accessibility (including battery life, portability and sufficient sound volume) should be such that the system can be used for some hours a day. 
- Reliability: the system should be as reliable as current networked systems available on the market.

- Security: the system must preserve privacy of its users. The system must provide confidentiality, integrity, non-repudiation of data, authenticity of measurement and it should provide accountability of access.

- Maintainability: when operating, it should be easy to maintain the system for providing updates and new functionalities. As stated in the previous section, tailorability of the functionalities must also be facilitated.

- Portability: the system should be working on a variety of technical devices. Hence it should be portable across different specific implementations.

In chapter 5, the above mentioned qualities are evaluated using subjective (semi-structured interviews and questionnaires) and objective (log analysis) techniques. Chapter 4 pays special attention to usability concerns, as for the elderly, the user interface is a key issue.

\subsection{Conclusion}

In this Chapter, we showed how a systematic user-based requirements elicitation was conducted for ICT development in elderly healthcare. Our method uses the ICF health model, breakdown analysis, in-depth interviews with endusers, stakeholder prioritisation of functionalities, and scenario-based user needs analysis.

Secondly, we showed a scenario exemplifying these health and socialisation related needs in elderly healthcare. The example scenario was presented in Section 2.3.

Thirdly, we discussed the desired functionalities and requirements for the services proposed in the scenario. These functionalities and requirements will be addressed when the design and implementation of the system is discussed in Chapter 4. 


\section{Chapter 3}

\section{Interactive Scenario Visualization for User-Based Service Development}

This chapter discusses a novel approach to system development: scenario-based design augmented with scenario visualization. Using a case study, we demonstrate this principle using the home care services platform that is the subject of this thesis.

Scenarios are commonly used to develop new systems in multidisciplinary projects. However, written scenarios are sequential, not dynamic and often too abstract or difficult to understand for end users. The goal of this chapter is to extend the use of scenarios in design methodologies, using an interactive scenario visualization (ISV) approach. After discussing scenario-based design, we show that ISV can be used beneficially to develop new ICT systems and that ISV aids in reflection upon the design trajectory. Using a state of the art software toolkit, we found it was possible to develop such ISVs inexpensively, rapidly and with good visual quality. As a case study, we demonstrate the use of this thesis' home care telemedicine system, for which the requirements were elicited in Chapter 2. We created a 3D scenario visualisation of this system for discussion and development purposes. An evaluation among $n=22$ professionals shows that ISVs can prove useful in design, aid in clarification of new systems, are suitable to demonstrate system functionalities, and aid in articulating feedback.

\subsection{Introduction}

In situations where the exact use of a new system is not known a priori, scenarios are used to conceptualize and discuss the systems properties, the behavior of people interacting with the system or the interaction context [1,65]. Written 
scenarios may however be difficult to understand, especially when they concern abstract concepts. Moreover, their stories are sequential and non-interactive. Also, jargon and knowledge barriers may induce unfamiliarity with the proposed technologies, which hampers input of domain experts and end users [67. Finally, the visualization and imagination of the scenario has to be performed by the reader, based on the given (often lengthy) text. When multiple stakeholders are involved this easily leads to interpretation differences or incomplete understanding. In this study therefore, we describe interactive scenario visualization. It extends the use of scenarios in design methodologies. The goal of visualization is two-fold: to clarify the system to be designed and to facilitate discussion with stakeholders. This chapter discusses theses goals using a case study: a multi-disciplinary design effort to develop an ICT-mediated home care system for independent elderly living at home.

The remainder of this chapter is structured as follows. Section 3.2 discusses the use of scenarios and scenario visualization in the development lifecycle. Section 3.3 explains our interactive scenario approach. Section 3.4 discusses the results of the case study. Section 3.5 presents the outcomes of a small-scale panel evaluation, which is discussed in Section 3.6. Section 3.7 finally presents some conclusions.

\subsection{Background}

A scenario is a story about the concrete use of a (future) service or technology and the consequences of the usage [9, 10, 44]. Scenarios are especially useful in multidisciplinary development projects to perform needs analysis, to guide the development of novel systems [3, 36] and to articulate constraints from different stakeholders [80]. Hence, scenarios are used for understanding requirements and they aid in prototyping and evaluation of design concepts. The scenario product is a description of who does what for what purpose [46] on a specified abstraction level, depending on the goal of the scenario and the moment of delivery in the development lifecycle. In early design stages, the scenario takes on a user perspective revealing PACT (people, activities, context of use and technology used) properties 38. and hence how the usage process can be realised, without specifically dealing with application-level details.

As the development effort continues, the scenario corpus (i.e. the set of scenarios) increases. Scenarios become more detailed and system-oriented, reflecting the FICS [38, 80] properties (functions, interactions, content and service) of the system. The functions describe the functionalities or abilities of the system. Interaction properties describe the user interaction and the modalities in which the system is used. The content reveals what data, information and knowledge should be stored within the system. The service component describes the application-level service the system provides. These 4 properties impose functional and technical requirements on the system. They describe the system not anymore on the process level, but on the application level of the system itself, i.e. from the system perspective and not from the perspective 
of the organisational embedding of the system.

This scoping can be visualised as follows. From left to right, Figure 3.1 shows that a scenario-based design method can be used to scope from an abstract, user-centered PACT-scenario, via a system-oriented and more concrete FICS-scenario. Iterations may take place both within and after the different steps involved, for example as a result of ambiguities, requirements modifications or details becoming more clear along the process.

Components:

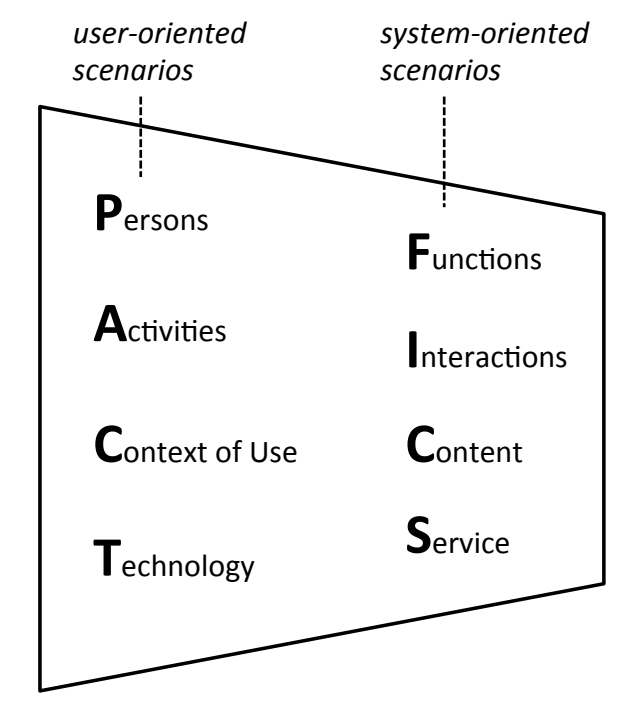

From User-oriented to System-oriented scenarios

Figure 3.1: Scenario scoping.

Scenarios are produced in different modalities: apart from a written storyline they can be in mockup, sequence of maps, animation, theatre, audio-visual or interactive format $[1,9,53,65$. Whereas visualized modalities have impact on understandability and consumability of the scenario 83 , they come at the price of translation and interpretation of the storyline. The resulting product may be less flexible: e.g. a video version is difficult to modify as the scenario evolves. Moreover, they tend to be time-consuming and expensive to produce or modify. This is also the reason that video productions sometimes are preproduced (pre-visualization) in virtual environments 41.

Interactive scenario visualizations, like audio-visual visualizations, also have interpretations of the storyline, but have interesting properties regarding understandability, dynamicity and, using current toolkits, limited production effort. In interactive scenario visualization, the story becomes dynamic and reversible, and may hence be traversed in the users order of choice, e.g. useful in educa- 
tional situations or serious gaming [45. The ISV tempts to activate its audience and is not consuming-only anymore. Like audio-visual scenarios, ISVs can be streamed over the internet to reach a large audience. Unlike movies however, interactive scenarios can be linked to data sources, web services and news feeds to increase the actuality of the scenario, to store metadata, or for reuse later in the development lifecycle. An example is the visualization of physical exercises, before using these visualizations in physical exercise software. Yet despite the common use of scenarios and the potential of ISV, ISVs for health-related development are still, as far as we know, very limited, although concepts related to serious gaming for health are starting to emerge and gain potential.

\subsection{Methodology}

This section describes the methods used to extend scenario-based design with ISV. Therefore this section recalls (i) the scenario creation, (ii) describes the software package used to develop the visualization, and (iii) review the content selection process to create the visualization itself. After the development, a validation has been conducted using questionnaires in small focus groups. This is discussed in Section 3.5 .

To develop the scenario, we have performed a user-based requirements elicitation process, as has been discussed throughout Chapter 2 Caregivers and caretakers were interviewed to find and clarify their desires for a new care system, containing services such as medication guidance, telemonitoring and an activity agenda. Their desires were formulated into a visionary scenario in Section 2.3 This scenario was validated by a stakeholder workshop, and visualised to illustrate the direction of development of the new system.

To develop the visualization of that scenario, we used Unity3D. Unity3D 68 has a steep learning curve but offers large flexibility in terms of graphics, story design and realistic representation of daily activities in $3 \mathrm{~d}$ virtual worlds. Behavior can be extended through adding $\mathrm{C \#}$ code. The package is intended for (serious) game design. In Unity, it is easy to produce interesting, high-quality and entertaining results. Hence it is widely used to create serious games, 3D games and visualizations.

The content of the ISV is based on the scenario corpus in [76]. The use of a telemedicine system in a nursing home is demonstrated, showing the graphical interface for both a caregiver and a caretaker. The story in the virtual environment is captured in a story board. Then, its interaction is defined in an interaction graph, or interactive story graph. The interaction graph represents the different parts of the scenario and define the choices that are available to follow the scenario using different routes. Interaction graphs ease the administration of choices in the story design and the tracking of logical sequences, moreover it serves as an aid to check if all relevant activities of the scenario text are captured for visualization. An example is shown in Figure 3.2. Diamonds (choices) refers to interactivity in the scenario; it represents user interaction with the scenario. By making choices, the user decides the sequence of the 
activities within the ISV and manages the control flow. The sequential (movielike) scenes start in the rectangle in the Figure, such as the 'take medication' scene. The scenes represent activities from the scenario corpus.

The control flow of the visualization becomes clear through setting up an interaction graph. Also it becomes easy to systematically check whether all activities of the interaction graph are correctly put in the ISV. The available options to navigate should be presented within the ISV itself in a consistent and clear way as well 49. Hereto, Unity3D offers different dialogue box designs.

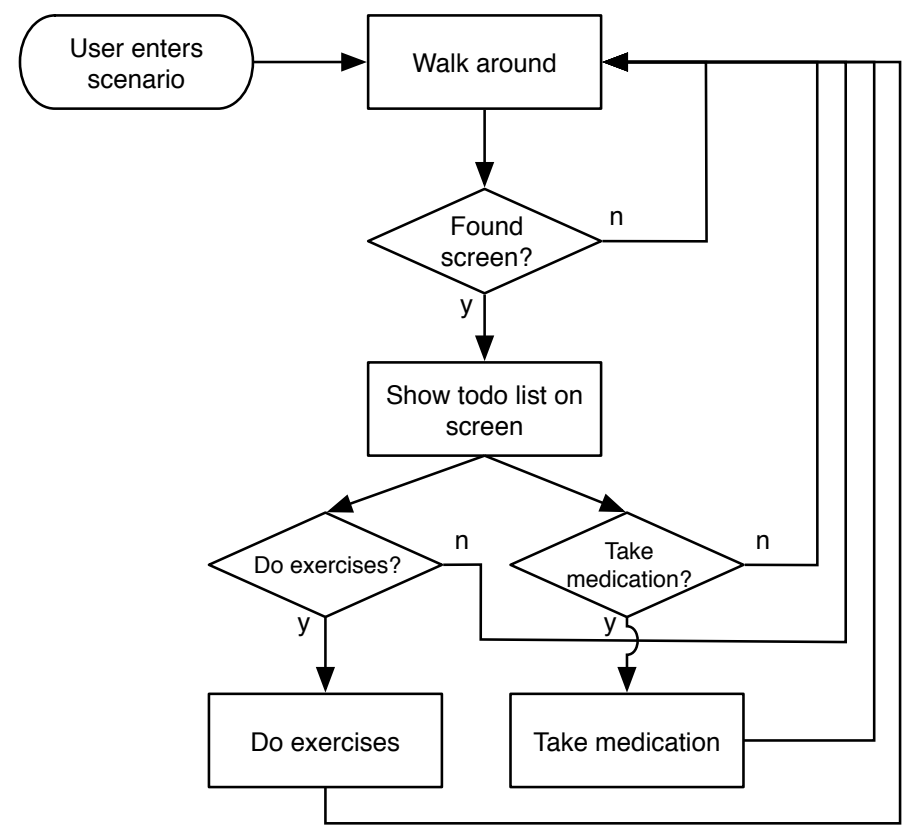

Figure 3.2: Simplified flow chart representing the interaction graph of the scenario visualization with choides (diamonds) and acts (rectangles). When the user finds a screen, a todo list is displayed with activities to conduct. The screen in the scenario visualization is visible in Figure 3.3, inset on the left.

\subsection{Results}

We developed an interactive virtual environment, inspired by the actual nursing home Parc Hoogveld in Sittard, The Netherlands. It can be accessed via http://rmt-server.ewi.utwente.nl/scenvis/.

It shows two elderly apartments, a nurse office and a corridor connecting these three spaces, as visible in Figure 3.3. This Figure shows the result of 
the development in Unity. The interactive scenario evolves around the role of one of the inhabitants in his apartment; he is able to use the installed home care system freely. The concept of this home care system is an easy to access touch screen on the wall, offering services like medication reminders, agenda, social interaction and aid in doing exercises. The system can also be accessed through the TV in the living room. These 2 screens both provide access to the system. Once the user is in the vicinity of one of the 2 screens, the options of the home care system become usable as shown by the Figures inset on the left. It provides the 4 service types analysed in Section 2.5 (Social Activities, Social Interaction, Health Monitoring and Medication Intake Support). The graphical interface in the virtual world is similar to the actually prototyped version, as found in Chapter [5] and 62.

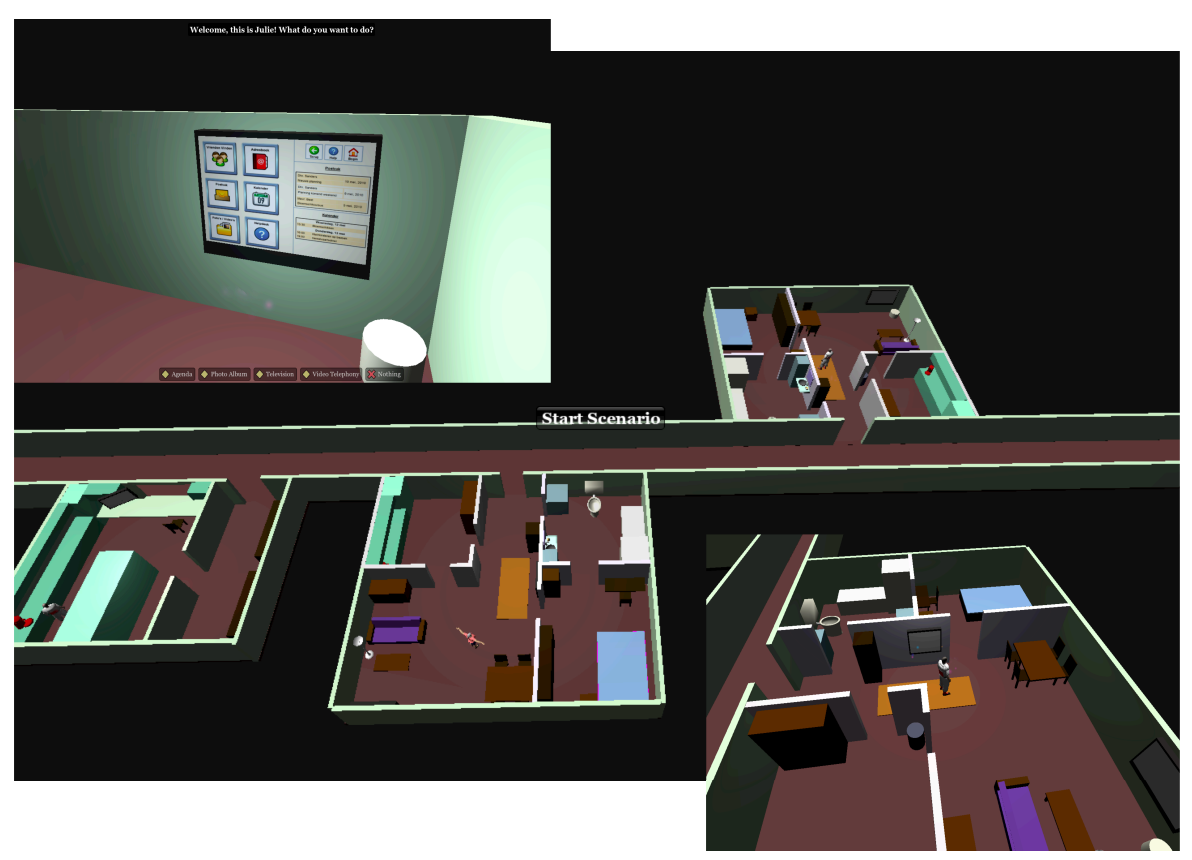

Figure 3.3: Virtual nursing home created in Unity. The large photo shows 2 apartments and a nurse office. The inset on the right shows 1 apartment, its inhabitant (the main character operated by the user) and the 2 screens ( 1 on the wall and 1 as TV in the lower right) of the home care system. In the inset on the left, the screen on the wall is active, showing Agenda, Photo Album, Television and Video Telephony options to b eexplored by the user.)

In the ISV, different functions of the home care system can be explored from the viewpoint of both care receiver and caregiver. Interactive parts are combined with sequential scenes to show these different perspectives. An im- 
portant point of attention in this regard is the self-explaining property of an ISV. Depending on the intended use of the ISV, the visualization should be self-contained: it should be explained using audio-visual clues.

\subsection{Evaluation}

We are interested in the perception of the extended scenarios-based design approach, using ISV as presented in this chapter. Hence, we performed an evaluation to validate the usage of interactive scenario visualization as a development instrument. The ISV made in Unity was presented in St. Etienne, France and Enschede, The Netherlands in small groups to $\mathrm{n}=22$ participants. They are working in healthcare development disciplines $((7)$ healthcare R\&D; (10) academia; (3) ICT consultancy industry; (2) healthcare management). All of the inquired people dealt with healthcare innovation on a daily basis, either from a development or from a practical perspective. They are asked because they can potentially apply the proposed method themselves, in contradiction to e.g. care receivers.

After an explanation and demonstration of the visualization, a questionnaire was handed out to get the opinion of the panel on this method and to find out how valuable they think it is over non scenario-based design methods. The ISV made in Unity was used in the evaluation.

Using a 5-point Likert scale (totally disagree codified 1 ; totally agree codified 5 ), we measured whether or not scenario visualization:

1. Clarifies innovative care scenarios;

2. Gives insight in the care platforms proposed functionality;

3. Gives insight in the platforms technical requirements;

4. Eases giving feedback on the development of the platform.

We also asked the professionals to write down both the perceived value of ISV over other techniques, as well as general comments. With respect to the 4 items that had our interest in this evaluation, non-negative outcomes were expected, except for (3). Question 1-3 relate to the FICS framework (clarification of interaction (1), functionality (2) and technical /service requirements (3)) whereas question 4 is used to assess the ability the ISV has to ease giving feedback.

The results of the evaluation are shown in Figure 3.4. Scores on construct 3 varied. This indicates the interviewees disagreed on whether such visualizations give insight in the technical requirements. This was not the aim either so it is not surprising. On the other hand, constructs 1, 2, and 4 (clarification, functionality and feedback) had positive responses: the ISV clarifies innovative care scenarios, gives insight in the proposed functionality and eases giving feedback on the development to better involve end-users and stakeholders in the design process. 


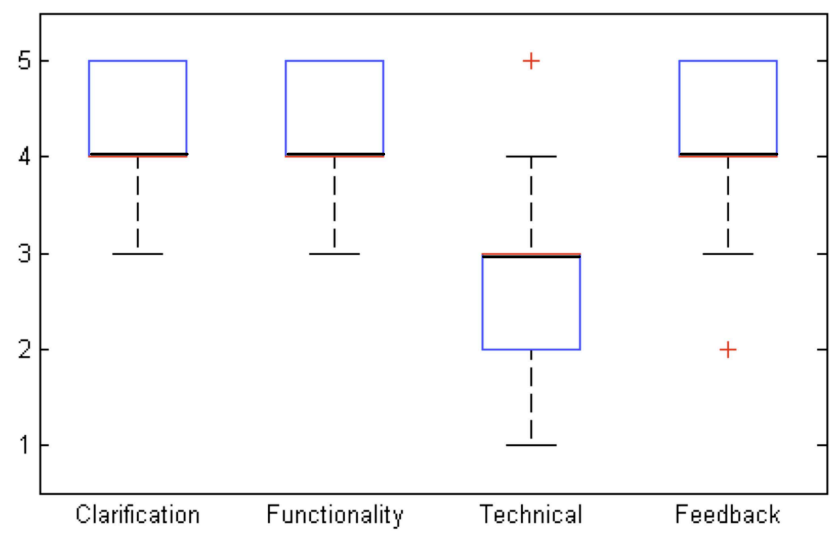

Figure 3.4: Results of ISV evaluation $(n=22)$.

Comparing the perceived value of ISV over other techniques, we asked how the professionals would use scenario visualization themselves:

- The most common answer (9 people) was usage for requirements elicitation and validation;

- 6 people said they would not use it;

- 5 said they would use it to articulate their design ideas;

- 2 people said they would use it for usability testing.

Remarks given by the evaluations subjects included the recommendation to also use the visualization for end users of the system (eg. nurses) and that it should be easy to create such a scenario. Indeed, visualizations are useful to clarify both conceptual and finished systems. The creation of ISVs is enabled by modern, model-driven software environments. Another remark concerns the fact that making a visualization potentially improves the scenario text, because one is forced to think about details and eliminate ambiguities in the storyline.

\subsection{Discussion}

According to 14 of 22 interviewees, ISV is useful to facilitate design (requirements elicitation and validation, usability, clarification of concepts). However, the right toolkit should be used. Unity3D 68 is such a toolkit. When developing the ISV, we investigated the use of Alice 2 but it was clear that Alice does not produce as high quality visualizations as Unity, so it was decided not to show it to the panel. 
The value of ISV over mockups seems to be that it shows more of the high level process steps and not only the interface. Hence besides application usage, organizational usage is shown too, eventually involving different actors. This is all not the case in mockups. In terms of MVC, it shows, in addition to the user interface (view), also the added value and working of the system (control). Showing organizational usage is also possible in movies, but only 1 storyline can be told. Besides, interaction lacks and production (especially modification) is costly. Using modern toolkits like Unity allow ISVs to be made in the order of days without actors or producers.

In short, benefits, based on this case study, seem to be clarification of a system to be designed, the functionality of such a system and the use for getting stakeholder feedback. ISV can prove useful in design. These ideas could be fortified using another study, in which a more detailed comparison is performed based on multiple scenario text vs. visualization comparisons.

\subsection{Conclusion}

This chapter proposes interactive scenario visualization (ISV) as an extension of scenario-based design. We showed how interactive scenario development can be used beneficially in the process to develop a new telemedicine system, presenting a methodology combines scenarios, PACT, FICS, and visualization.

ISVs make scenarios more dynamic in storytelling and they are more flexible than other visualization techniques such as mockups and movies. Scenario visualizations can be created rapidly nowadays, are appealing to work with, and can be extended or modified easily without the need of producers or experienced professionals.

After developing a case study ISV (based on the requirements elicited in Chapter 2), Unity shows to enable realistic visualizations, extensibility and good graphical possibilities. Unity, offering visual, model-driven design and scripting, however has a steep learning curve compared. ISVs can be made in the order of hours to days.

In the evaluation, we noticed that ISV was received well with respect to getting feedback, clarification and functional aspects: It seems to be promising to use interactive scenarios to clarify innovations, to give insight into system functionalities and to gain feedback of stakeholders. However discussing technical requirements of a system to be designed is more difficult; such discussions do not benefit from scenario visualization directly. Attention should be paid to the degree to which the ISV is self-contained: a visualization that runs autonomously requires more audiovisual guidance than the ISV developed in the present study. State-of-the art of software packages like Unity enable rapid design of scenario visualizations. Besides, they are an enabler for using ISVs to involve stakeholders in the design process efficiently. ISV can prove useful in design but is not directly comparable to mockups or movies: besides application usage, organizational usage is shown, involving different actors/viewpoints, unlike mockups. In contrast to movies, ISV provides interaction, facilitated produc- 
tion, modifiability and dynamicity. These considerations should be taken into account by designers when using scenario-based methods to get stakeholder feedback. 


\section{Chapter 4}

\section{Realisation}

A system has been realised to offer personalized care services to end users. This chapter briefly describes the realisation of the complete system and in more detail the realisation of one part, the Carereceiver Tier. First, the high-level and detailed architecture are given, then the main design and implementation aspects follow, divided over control, model, and visible aspects.

\subsection{High Level Architecture}

The high-level design of the complete tailoring system is presented in Figure 4.1 To separate concerns and provide modularity, its is divided in 3 physically and logically separated units, or tiers: the Caregiver Tailoring Tier, the Integration Tier, and the Carereceiver Tier.

\section{Caregiver Tailoring Tier}

Caregivers manage personalised medical processes and social activities for clients in the Caregiver Tailoring Tier. These actions consist of following a wizard through which service building blocks are composed into what is defined as a personalised service plan. Figure 4.2 shows an example of such a wizard, setting a blood pressure plan for a period of six months for a given client. This involves the following plan parts: setting the events in a calendar, defining thresholds, defining message communicated to the carereceiver, ands defining the escalation path in case of forgetfulness or threshold exceed. For each of these plan parts, service building blocks are available in the Integration Tier, discussed hereafter.

\section{Integration Tier}

The personalised service plans are submitted to the Integration tier. As the Integration Tier needs to keep the state of the plans, they are stored in a 


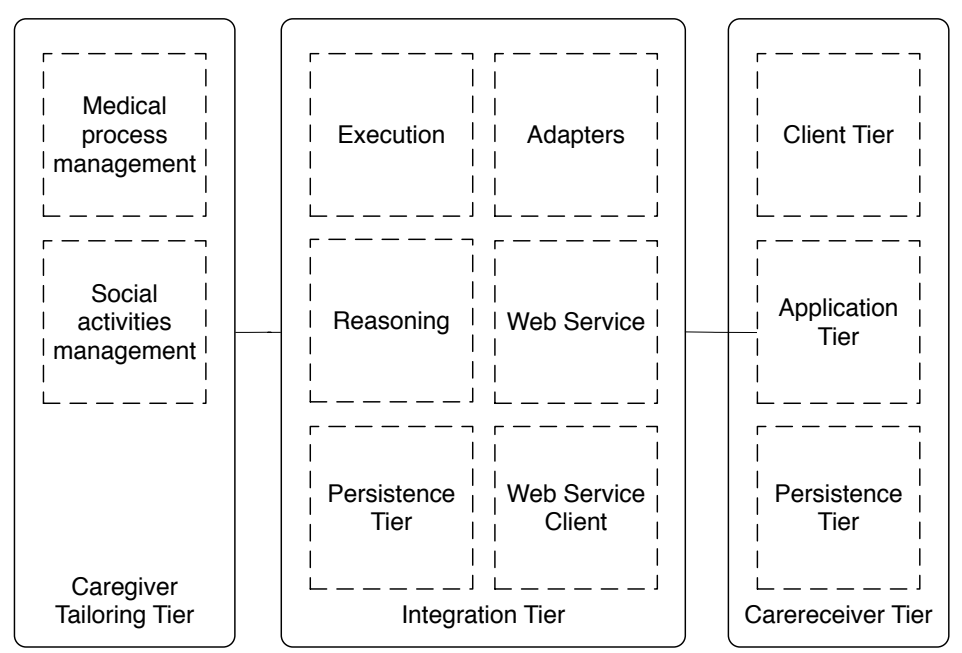

Figure 4.1: Architecture of the complete tailoring system

persistence subtier. In the Integration Tier, plans are executed by orchestrating all necessary plan parts as follows. If the execution of a plan needs external service building blocks (such as sensors), they are available through a set of Adapters. It is not always the case that a plan outcome is known in full at design time. For example, if a plan defines that an alert should only be sent if a measurement value exceeds a limit, this should be reasoned at runtime. Hence, a reasoning component judges actual activity within the system. To provide an interface for (i) the Carereceiver Tier or (ii) for external service building blocks, a Web Service component is available. The Web Service Client on the other hand, is the client the Integration Tier uses for accessing the API of the Carereceiver Tier, discussed in the next section.

\section{Carereceiver Tier}

The Carereceiver Tier system finally provides the application services defined in the service plan to the care receivers. In itself, it works standalone (i.e. asynchronously from the 2 tiers above) and hence needs to keep state. It consists of a Client Tier, an Application Tier and a Persistence Tier. Hence it is a typical Model-View-Control architecture with the Client Tier showing the View, the Application Tier managing the Control logic and the data and Information Model of the end users residing in the Persistence Tier. The detailed architecture of the Carereceiver Tier is presented in Figure 4.3.

The Client Tier shows the application state in a web browser to users on computers or tablets. Its graphical user interface considerations are further described in Section 4.3.3.

To manage user state, a user management part handles all requests that are 


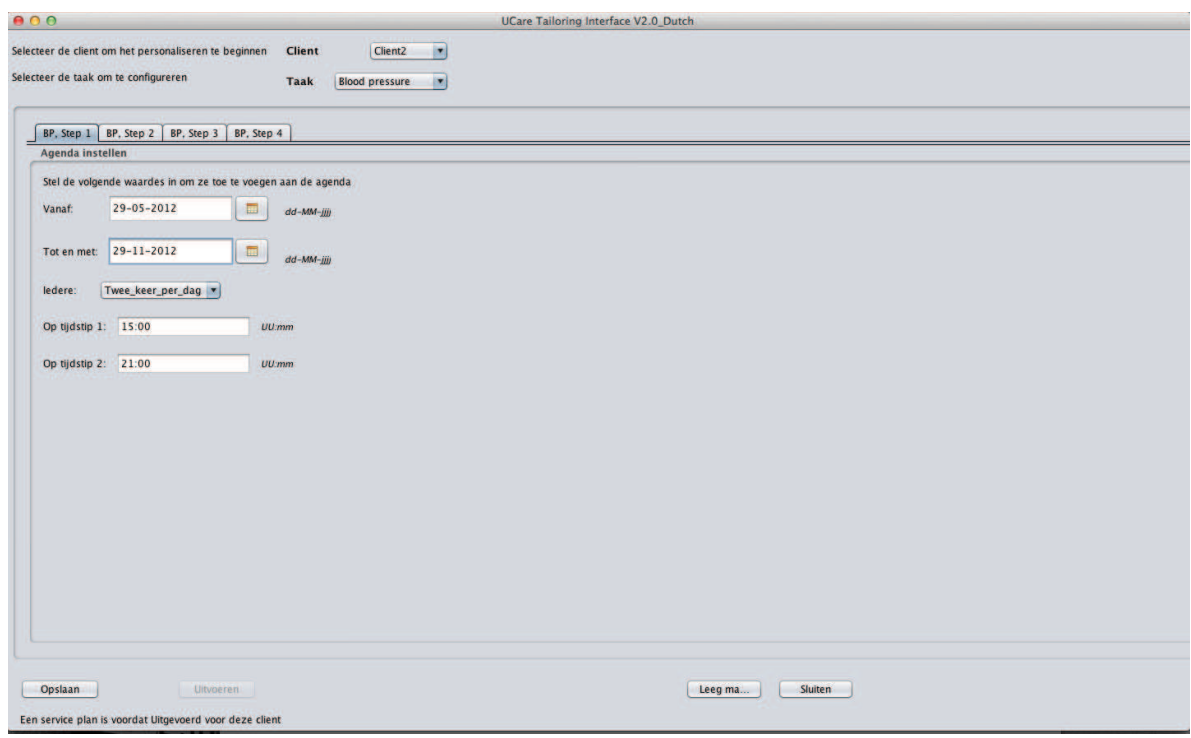

Figure 4.2: Caregiver tailoring software interface for defining health monitoring and medication-related service plans

specific to a user. This has been separated from device session management, as a user may have multiple device sessions (eg. on different device modalities).

Finally, there are 4 parts of the Application Tier that manage and communicate data. They consist of a web service client, a web service, a scheduler and entity representation. The Scheduler service is used to schedule events such as messages and agenda events. The entity representation manages an object model of relational data in the Persistence Tier. The Web Service and Web Service Client communicate with other system tiers. The Web Service exposes an API to agents that require services of the Carereceiver Tier. The Web Service Client connects to web services of the integration tier.

\subsection{Behaviour}

Before the details of the architecture are discussed, a usage example is discussed to illustrate the behaviour of the system. The following usage scenario corresponds to the sequenced behaviour of the Time Sequence Diagram in Figure 4.4 .

\section{Example 4.1 (Tailoring usage scenario)}

This example shows the scenario of defining self measurements for a care receiver, monitoring if they perform the measurement, performing the actual measurements, and fetching and showing the result. There are 5 agents within the system (Caregiver, Tailoring Tier, Integration Tier, Application Tier and 


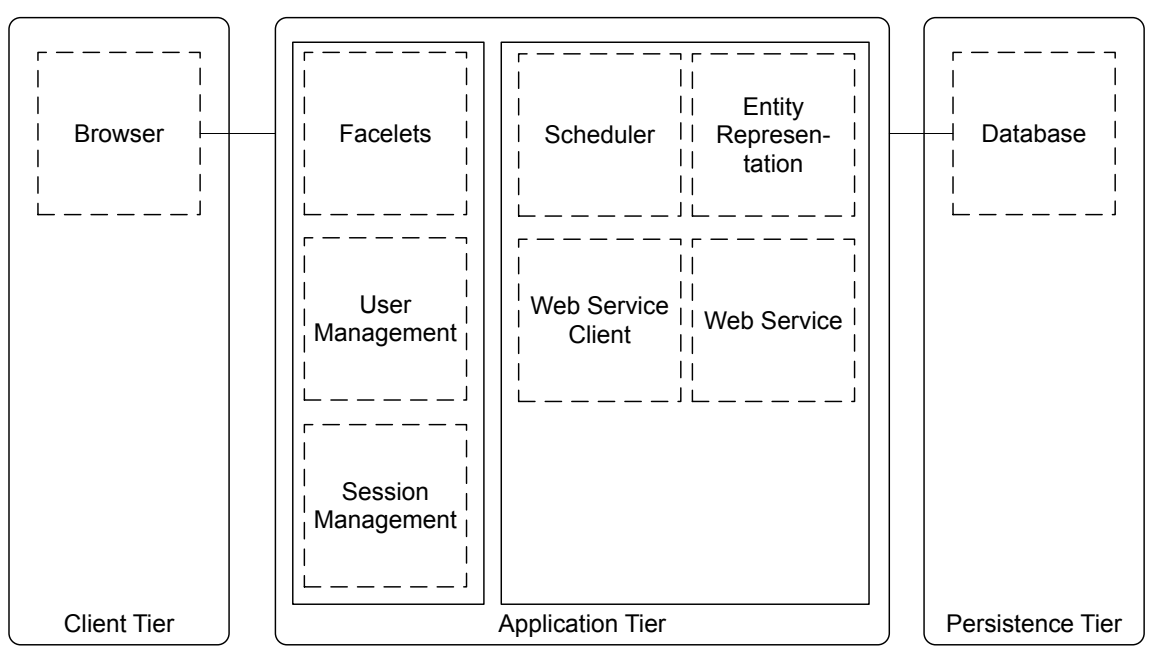

Figure 4.3: Architecture of the Carereceiver Tier

Care receiver) and one external agent (Mobihealth). Four use cases are sequenced in the diagram:

1. Scheduling. In the application shown in Figure 4.2, a caregiver sets a monitoring plan for a care receiver, e.g., perform a self-measurement on a given time. Once set,event of type blood pressure is deployed and the application tier calendar is updated with new event. For later usage, Integration Tier receives event identifiers.

2. Monitoring. When event to take blood pressure is due, integration tier is warned to check latest available measurement data. If not yet taken, care receiver is warned to perform a self-measurement.

3. Updating measurement values. Client performs a self-measurement using blood pressure device. Data is transmitted to third party (Mobihealth) tier, Integration Tier is notified about new data available.

4. View. Both client and caregiver may review the measurement data, in which case it is fetched, prepared and presented by the Application Tier.

This example shows just one measurement deployment, and just one reminder. In reality, multiple measurements are done one a frequent basis (e.g. daily) and reminders are sometimes repeated, to carereceivers and eventually to caregivers. 


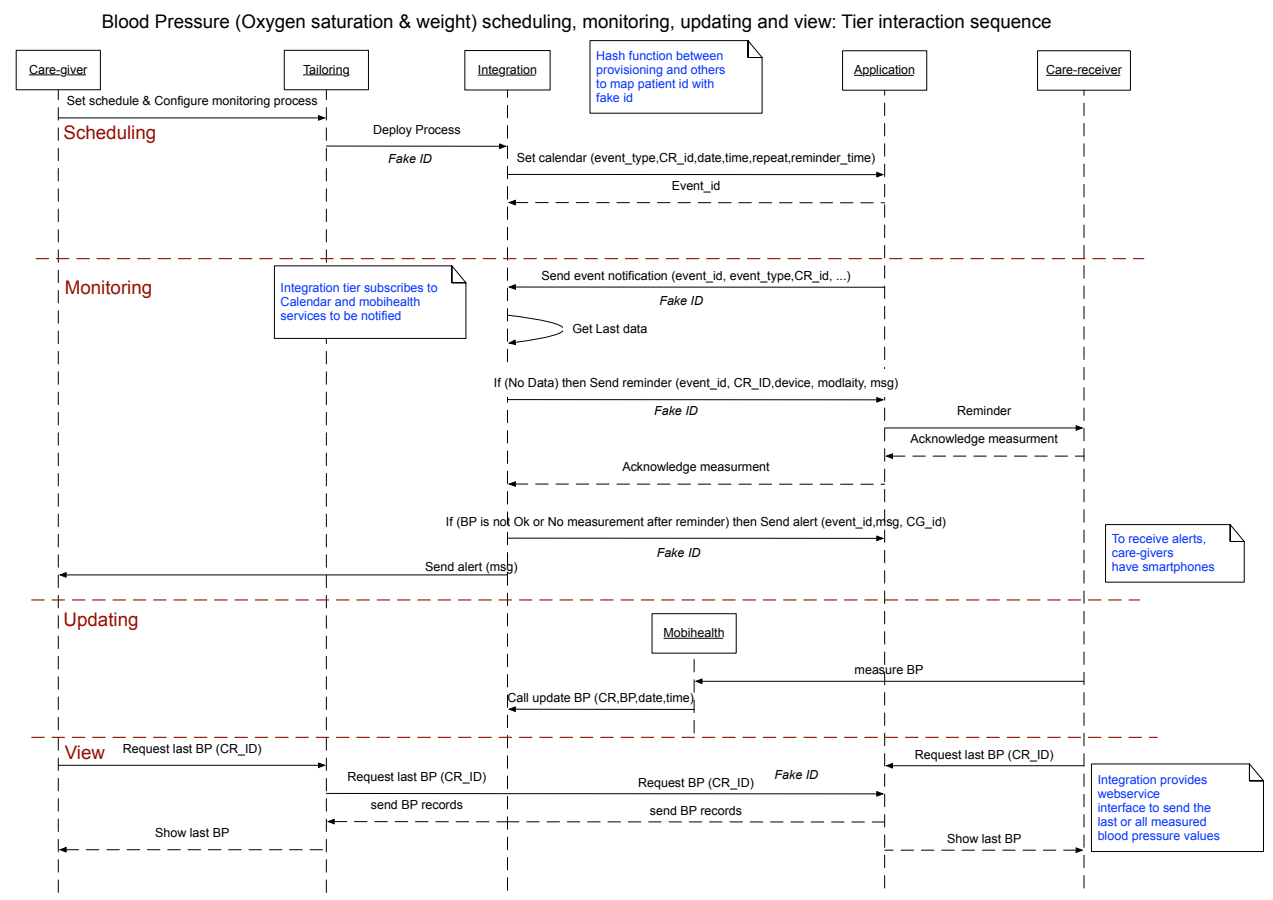

Figure 4.4: Interaction diagram showing the actor interactions related to blood pressure scheduling, monitoring, updating and view.

\subsection{Detailed Design}

In this section, the main design details of the Carereceiver Tier are described. Design details of the Caregiver Tier are discussed in [82]; those of the Integration Tier are described in [81. The discussion is divided over Model, View and Control aspects. The MVC-model [30,59, used widely in ICT development to manage, separate and re-use components, distinguishes the information model of a service, the logic or algorithmic (control) that controls the service, and the user interface (view) which represents (a state of) the information in the model. In the remainder of this section, the main service functionalities and control logic are described in 4.3.1. The information model is described in 4.3.2. and finally the visible design aspects such as physical appearance and graphical interface are described in 4.3.3. 


\subsubsection{Control: Controlling the application}

\section{Architectural separation of data processing and validation}

In a system of this magnitude, it is crucial to separate concerns. Separating MVC aspects on a high level is necessary, but a further separation is desirable by separating data validation from data processing. This means that whenever data enters the system through user input or via web services, checking of the validity of the data is separated from the actual low-level data processing in the persistence tier. This is achieved by 2 implementation choices that are described in section 4.4 being Java Server Faces (JSF) and Java Persistence API (JPA) 24.

\section{Hybrid session architecture}

From the scenarios described in Chapter 3, we know that care receivers may have multiple devices that (ii) should be kept synchronously up to date, also without user interaction. The latter requires a publish/subscribe mechanism, and the first requires a session architecture that handles multiple users and multiple devices per user. Figure 4.5 shows this layered separation of concerns concept. From top to bottom, a user may have multiple devices for which a device session is managed (device layer). The user-specific information is also stored in a user session (user layer). The information in the information model is a per-user information model (information layer). It shows information constructed from both data in a database, using Object-Relational Mapping, or from web service interaction with the Integration tier (both options are discussed in Section 4.3.2). We define this session architecture as a hybrid session architecture as we not only have a per-device session, but also a peruser session.

\section{Escalation Paths}

Three different types of escalation exist in the system. Each of them can be repeated, mapped to actual persons and turned on or off in the service plan for a care receiver.

1. Notify Care Receiver (NCR): An event occurs, and the care receiver should be notified;

2. Notify Information Tier (NIT): An event occurs, and the Integration Tier should be notified;

3. Remind Care Receiver (RCR): An event occurred, and the care receiver should be reminded;

4. Warn Caregiver (WCG): An event occurred, and a caregiver should be warned. 

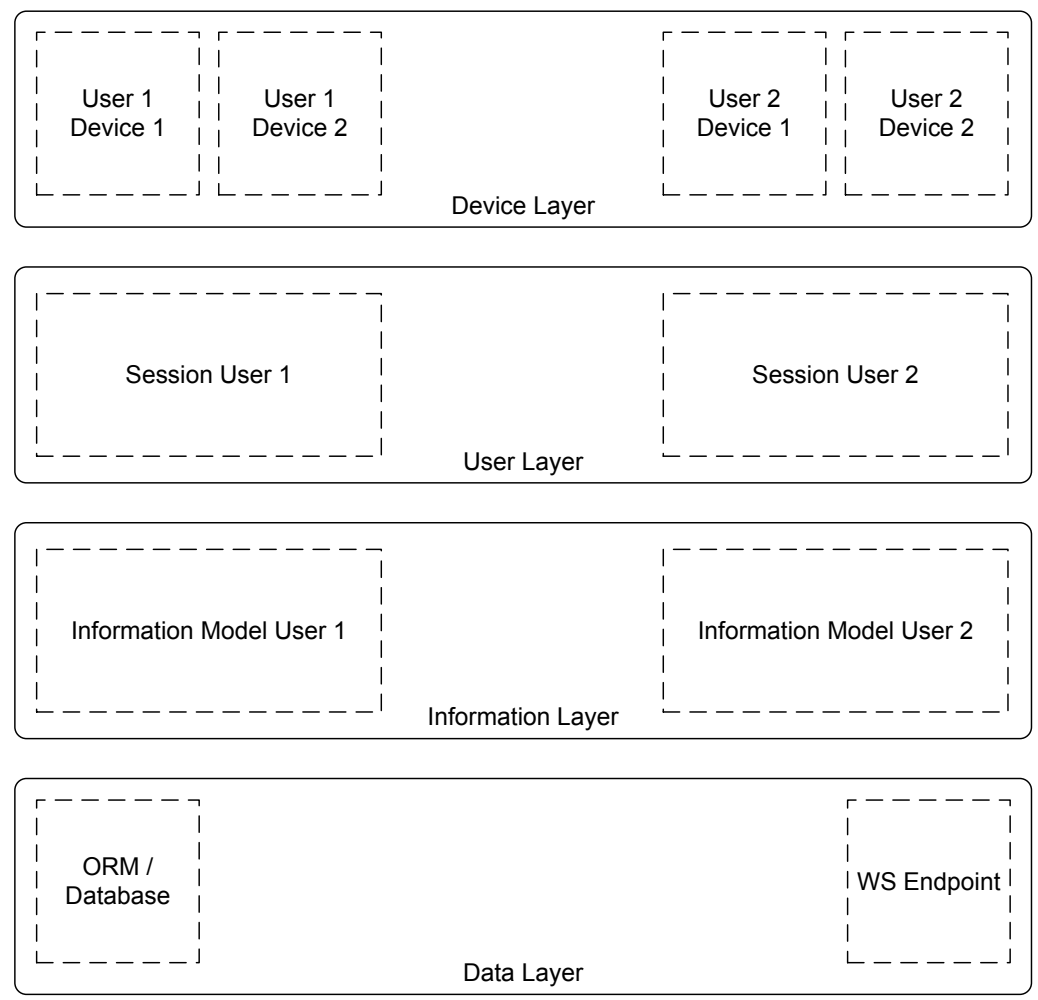

Figure 4.5: Separation of concerns in data, information, user and device management.

Whenever an event is due, option NCR is executed. If the care receiver has to perform an action using an external service, option NIT is executed to have the Integration Tier check whether these external service actually change state. If this is not the case, the care receiver may well be reminded again (for a number of times, according to parameter settings in the service plan) - option RCR. Finally, the escalation path 'last resort' is option WCG; the care receiver does not react so a caregiver is warned.

\section{Agenda}

An agenda functionality is designed which displays agenda items to users but also allows for item-specific escalation such as mentioned above and discussed in Example 4.1). Due to these specific requirements, it was chosen to develop the agenda ourselves.

To create agenda items, 2 options are available: caregivers can either set activities and their recurrence in the tailoring interface, after which all event 
items are persisted to the care receiver tier, or care receivers can add agenda items themselves. However, in most of the cases the caregivers will take responsibility for filling the agenda of the care receivers.

Agenda items are all stored in the scheduler service. This service initiates a timeout sequence each time an item for which a timer is set expires, to initiate the publishing of the item.

\section{Medication diary}

The medication diary is used to keep track of medication intake events. The diary not only shows future but also past events. Scheduled intake time is registered based on the settings per clients as entered by the caregiver. The actual intake time per medication event can be set in 2 ways: subjectively (the client confirms intake after alerting) or objective. In the latter method, an electronic medication dispenser measures if the client has taken medication from the dispenser and submits this to the client electronic record. A web service in the integration tier periodically enquiries the record and updates the medication diary using a webservice. Hence we know if the medication is taken out the device in an objective fashion (though we cannot be sure if the medication has been swallowed). Though, in many cases clients are still independent and free to decide whether or not to take their medication. On the other hand, subjective confirmation only tells us that clients confirm they are taking medication.

\section{Medication classification}

Based on the time difference between medication schedule time and medication intake time, a classifier has been built that has been trained with the help of personnel of the nursing home Hoogstaete in Sittard, The Netherlands. The goals are to show and improve medication compliance by assigning scores to medication compliance performance. There are 4 classes concerning the scheduled medication: (i) unknown, i.e. not taken or not confirmed; (ii) taken in time; (iii) taken in reasonable but improvable time; (iv) taken late. The definition of these classes is adjustable, but has been based on discussion with caregivers. The class of intake event $j$ with scheduled timestamp $j_{s}$ and confirmation timestamp $j_{c}$ is judged as follows, based on the difference in hours $h$ :

$$
\operatorname{class}(j)= \begin{cases}i & j_{c} \text { is unknown } \\ i i & \left|j_{c}-j_{s}\right| \leq 1 h \\ i i i & 1 h<\left|j_{c}-j_{s}\right| \leq 2 h \\ i v & \left|j_{c}-j_{s}\right|>2 h\end{cases}
$$

\section{Health info}

The health information section of the system displays the clients' measurement results as provided through coupled telemedicine devices. Even though the vital 
sign measurements can be measured using devices and services from different vendors, they are made available here and prepared in an user-friendly format, in one place by the care receiver tier. The web service component described below fetches the client data based on a salted and SHA-256 hashed request [ 6 , and receives the personal data from the integration tier to display it to the client. This happens both once new information is available, and upon request by the client.

\section{Social Activities}

The design of the activities service stems largely from the interviews conducted as part of the requirements engineering process described in Chapter 2. In nursing homes, many (recurring) social activities take place that are intended for single, groups or all inhabitants. The service is hence designed to enable single, groups or all care receivers to be notified about one or more (recurrences of) social activities. To this end, caregivers define and subscribe care receivers to activities similar to the process described in Example 4.1. The tailored activities appear in the calendar of the care receiver, and they are notified a set time in advance. Carereceivers may add events themselves as well.

\section{Social interaction}

The requirements analysis showed demand for community-driven functionalities to contact peers, family and caregivers. The system has an easy-to-use community built in that allows for discovery of neighbours and addition to an address book. The address book can also be filled with family contact details. Typical contact methods are telephone, messaging and Skype.

A different aspect of social interaction is the facility to use the agenda for social events to promote the actual participation and hence socialise. As found in the requirements engineering phase, informing clients about social events was inefficient and can be automised. Using the system, caregivers that organise activities can now input activities once and the items appear automatically in the clients' agendas based on their preferences.

\subsubsection{Model: the Information Model and Persistence}

This section describes the information model and the architectural storage choices (persistence). In the subsequent sections, specific attention is given to persisting personalisation settings, API functionalities and the mapping between objects and relations.

\section{Information Model}

Figure 4.6 shows the information model of the care receiver tier. The User at the centre contains user-related authentication information. clockwise from the top, the following objects are displayed: 


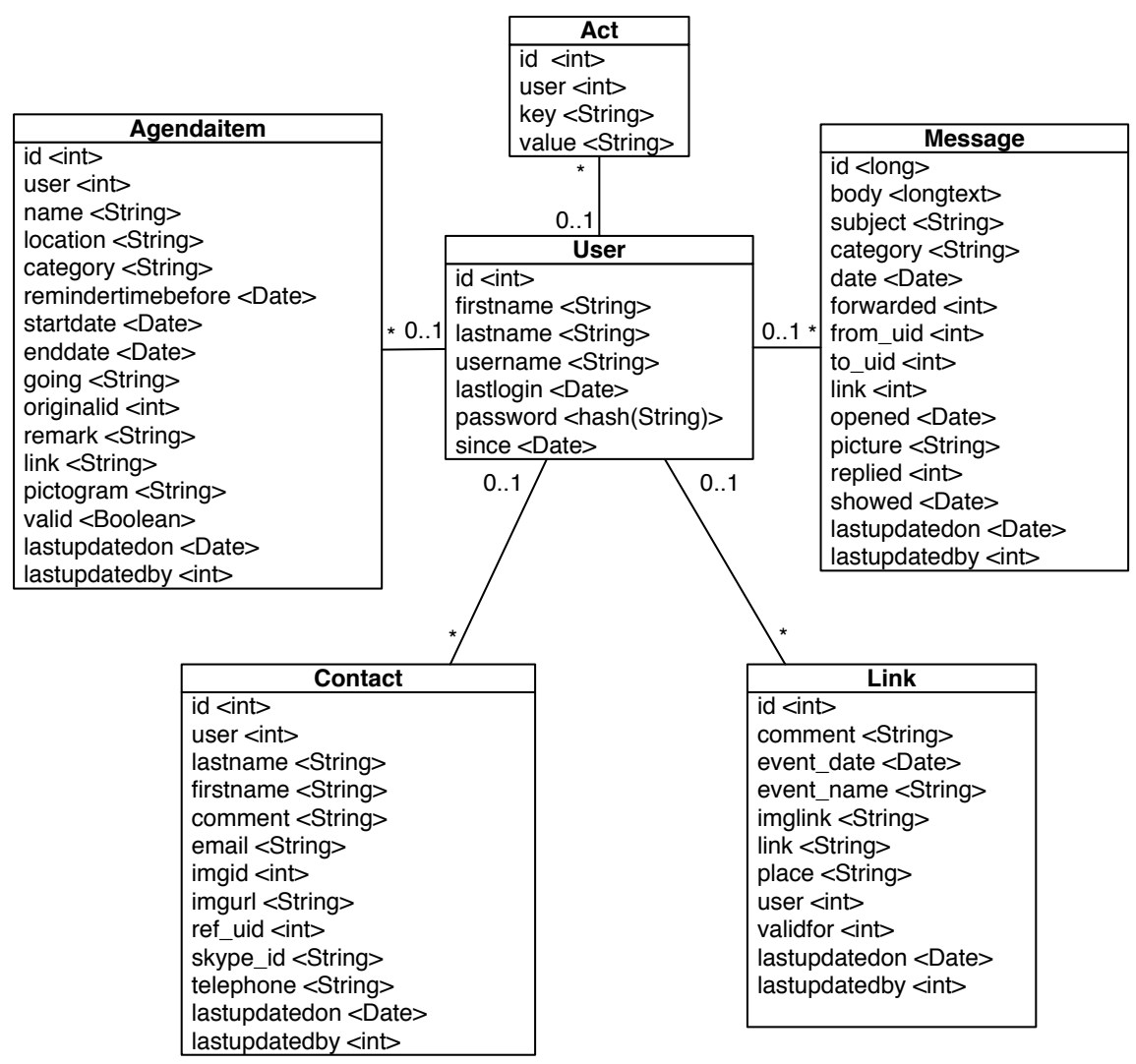

Figure 4.6: Carereceiver Tier Information Model

- Act, to define personalisation settings (discussed hereafter);

- Message, which contains the structure of messages between a sending user from_uid and a recipient to_uid.

- Link contains a structure to capture information about links, e.g. to refer to photos and videos.

- Contact contains contact details of persons added to the address book.

- Agendaitem contains events in the agenda of a user. It is discussed in 4.4 .3

\section{Personalisation mechanism}

To enable personalisation, an at design-time unknown number of parameters need to be tailorable and persistable. Hence we use a personalisation mechan- 
Table 4.1: Personalisation settings

\begin{tabular}{llr}
\hline Key & User ID & Value \\
\hline DisabledApp & 1 & manualintake \\
DisabledApp & 7 & healthinfo \\
XMPPNotify & 7 & ucare.client7@gmail.com \\
DisabledApp & 5 & healthinfo \\
DisabledApp & 5 & medication \\
\hline
\end{tabular}

ism in the system which consists of a persistence facility that allows uniquely identifiable key-values pairs for each client. This way we can store acts, or personalisation settings for each client and retrieve them when checking for user-specific settings. Among others, this mechanism is used to enable / disable apps for users, to set medication confirmation method, and to set XMPP alert and notification settings. These options are the key attributes, and how they are filled out for a given user is stored in the value attribute. The list of keys can be increased easily. Via WS, they can be retrieved and set. An example is shown below.

\section{Example 4.2 (Personalisation settings)}

See Table 4.1. From this table we find:

- User 1 cannot perform manual intake confirmation.

- User 7 does not have a health information service (i.e. there is nothing to measure for this care receiver). Their XMPP notification address is ucare.client7@gmail.com.

- User 5 does not have the health information service nor the medication intake service.

\section{Web-accessible API}

In order to communicate with other system tiers and for testing, an API is developed. Because the access of the system is web-based, it is obvious to expose this API through the web as well. Pautasso et al. 56. compare the 2 conventional approaches of exposing APIs through the web using either REST (Representational State Transfer) or Simple Object Access Protocol-based Web Services (WS). While REST is very suitable for fine-grained data access, WS is more suitable for coarse-grained, process-based access to application level functionality. Because this is the case in our system (e.g. securely adding agenda items, sending messages and notifications) we choose to use the WS approach. 
The web-based API is used for scheduling, to manage agenda items, send notifications, messages and alerts, to manage labels and personalisation settings, and for testing. On the reference side, a web service client is used to notify the integration tier concerning scheduled events, medication intake confirmations and to request vital sign measurement from that tier.

\section{Persistence using Object-Relational Mapping}

The system uses object-relational mapping (ORM) for persistence of all data within the system. The aim of this approach is to shield application developers from relational database-style persistence and querying, and to allows higherlevel tiers to talk in a generic object language rather than it low-level SQL. CRUD operations on data or object instances can now be performed in the business layer, while the underlying data manipulations are performed by the ORM manager.

\subsubsection{View: The Design of the Application and What the User Sees}

This section describes the graphical design process resulting in the View of the Carereceiver Tier. A sound design process is inevitable when designing for elderly: creating systems for this audience imposes different requirements compared to creating systems for common usage. The hardware and software considerations are discussed below.

\section{Hardware}

At the time the project started, commercial of-the-shelf (COTS) tablet computers were introduced at affordable prices. Hence the project was among the first scientific projects able to use these devices as end-user devices. Despite little literature being available on experience which such tablets in this area, two advantages over PCs were directly clear: no mouse, and less intrusivity. Computer mouses are reportedly difficult to handle by elderly, whereas tablets have touch screens. Providing end users a tablet instead of a PC is much less intrusive because of the size and mobility of the device. Next to that, clients may receive a blood pressure sensor, pulse oximeter, weight scale, step counter, or electronic medication dispenser. Service plans for these devices are defined in the caregiver tailoring interface. Figure 4.7 shows a possible set of devices end users of the U-Care system use. The device can be coupled through the adapter service as shown in Figure 4.1.

\section{Software Interface}

Designing the interface on the software means choosing in a smart way the best out of carefully designed alternatives. This was done in a user-centred iterative process [62], as shown in Figure 4.8 . 

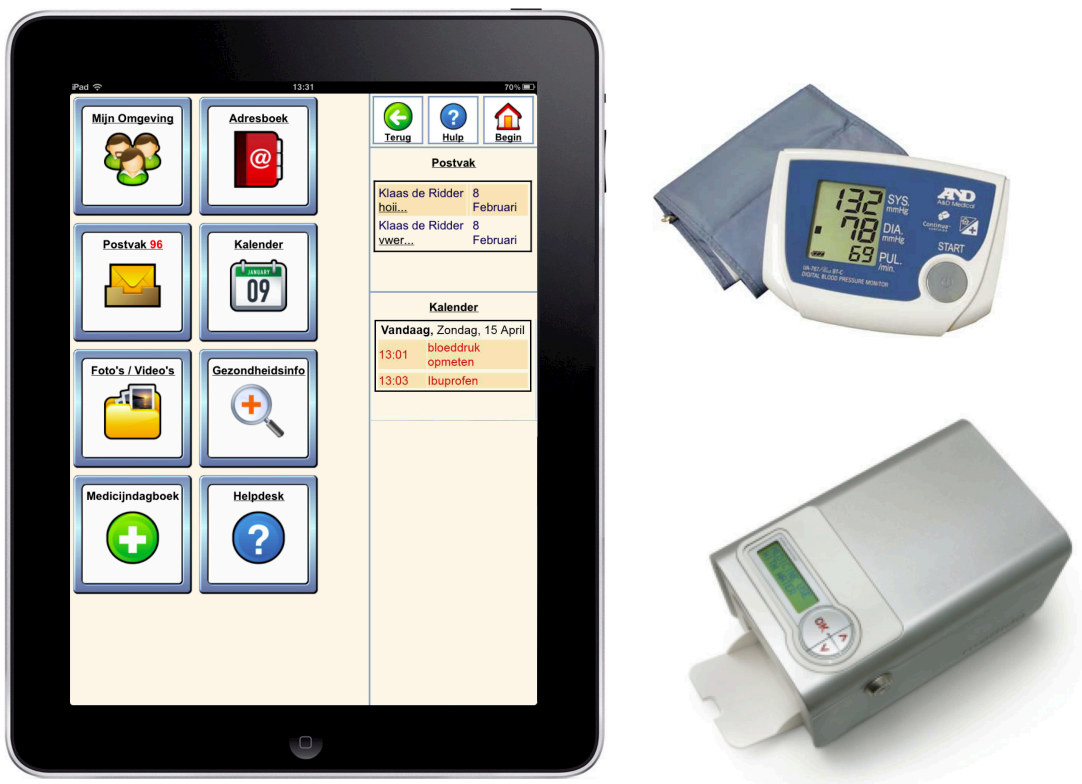

Figure 4.7: Set of devices for end users. On the left, tablet computer with graphical interface running. On the right, Bluetooth blood pressure monitor and electronic medication dispenser.

To find design goals, both interviews with stakeholders and literature review were conducted. These goals were input for a visionary scenario corpus, and analysed to find requirements. The scenarios were used in interviews with elderly to discuss the design in an exemplified and articulated fashion. Based on functional and non-functional requirements, different mock-ups (i.e. nonworking prototypes) were designed and evaluated with end users. These preliminate versions are shown in Appendix $\mathrm{A}$. Their remarks were used to create a working prototype, which was again evaluated in 62 .

\section{Key graphical design aspects}

The following list states the main graphical design guidelines followed for the interface design.

- Clear notifications. Actual attention-deserving item are clearly visible in a signalling colour.

- Panic button. To ease navigation and aid in case of navigational loss, a 'begin' button is visible in any part of the application.

- Aid. A help button is available in any part of the application, to facilitate seeking help with staff. 

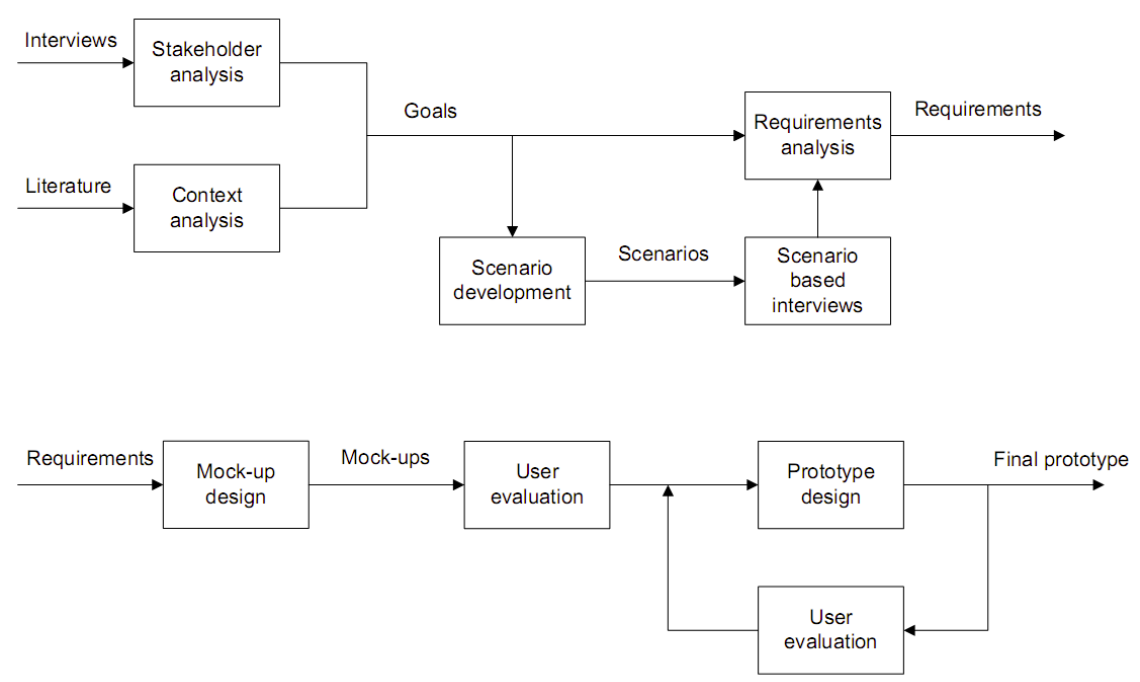

Figure 4.8: Design process to create graphical interface

- Works out-of-the-box. Pre-configuration of device is mandatory, making it afterwards easy for end users to start the application without configuration needs.

- Navigation. Buttons are large, and contain clear icons in natural pastel tinted colours.

- Operation speed. Pages appear and disappear at moderate speed, such that users can get adjusted to representational state changes.

- Consume only. The system is useable in a consume-only fashion, so without enterineg passwords or input of information. All important information is displayed on the main page.

\section{Display usage}

The prototype incorporates a design that is easy to extend upon by addition of buttons, lists, menus, actions, forms and functionalities. To accommodate for different screen resolutions, the layout has been designed in such a way that the menu bar is always visible (and hence also the home, back and help buttons). The additional room is used to display either two or three columns of application buttons, dependent on the screen resolution. For browsers that support it (i.e. WebKit on $\mathrm{iOS}$ and Android browser), fullscreen operation is possible to maximise the available room for content. 


\subsection{Implementation Design}

\subsubsection{Separation of data processing and validation using JSF}

J2EE6 allows for a well-defined separation between View and Control using Java Server Faces (JSF) 24. While the View is defined syntactically in XHTML, the inserted control logic results from Java Beans are strictly separated. Regarding the separation between information in the (information) Model and Control, JPA 2.0 enables another strict separation: the information model in the database is translated to a singleton object model, and the operations on the object instances are now fully controlled on object-level by the Control part of the system. The details of this mapping are discussed in the paragraph Persistence below. The main feature that forces the strict separation between these 3 parts is the JSF lifecycle. The JSF lifecycle has 6 phases:

1. Restore View. Render or create a server-side view of the components the clients views.

2. Apply request values. If necessary, update the view with what the clients alters in component values.

3. Process validations. Process conversion and / or validation of new component values.

4. Update Model Values. Update the server-side components with processed values.

5. Invoke Application. Invoke application tier with processed values.

6. Render Response. Render the new client view as backed by server-side view.

It is clear that checking of client input is separated from updating the information model. This not only reflects the separation of concerns within MVC, but also allows for checking which actions are allowed to authorised cq. unauthorised clients. Hence we are able to detect if clients are authorised to view or change the information model in step 3. When authorised, the next step is to set up a session for the client, which is the topic of the next paragraph.

\subsubsection{Hybrid Session Architecture and AJAX Push}

Using the @session Managed Bean facility in J2EE6, one is able to define sessionscoped Java beans that have the lifetime of a per-device session and reflect the authenticated users' information. Combining this with a publish / subscribe pattern yields the possibility to define per-user publish updates, even when the same user is identified in multiple device sessions. This is for example the case when multiple devices such as TV and tablet are logged in to the system on the users' behalf, and the system generates and publishes events 
such as notifications. This results in a user session update, propagating to all device sessions. If the user interacts on one device, the Document Object Model (DOM) is updated again, and all device session of the user render the new state.

The AJAX Push [40 that is necessary to push such DOM updates to all device sessions, is facilitated by using ICEFaces API [40. Each time a user logs in, it is registered in a push group based on their user id. Subscription is done utilising the PushContext from the javax.servlet.ServletContext. Having this context available, we are able to subscribe and publish. The method

$$
\text { pushContext.addGroupMember (userId, pushId); }
$$

is used to add a device session (identified by a pushId) for a given user, to a userId. Publishing is done using

$$
\text { pushContext.push (userId); }
$$

which results in on-the-fly updates of all devices for a user, using AJAX. This does not require reloading and rendering of the whole page. The cleanness of this approach is that it leaves the information model of the system intact whilst transferring state change immediately. In order to maintain client-server connection over unreliable network routes, a heartbeating mechanism is used to ensure that DOM updates can be pushed from server to client.

\subsubsection{Agenda implementation}

The agenda described above is implemented in format as described in Table 4.2. The 'Category' field allows for category-specific escalation paths, and filters medication events to display in the medication diary. After the scheduler service 24] gives a timeout for an event, the category field is used to either notify the Integration Tier to let it check if demanded measurements are actually perform, or to notify the care receiver in case of social activities, based on the escalation path. Because of this case-specific escalation path requirement, it was chosen not rely on calDAV standards (although mapping to a CalDAV server for compatibility should not be difficult as all CRUD operations are supported per agenda item).

\subsubsection{Medication implementation}

For the medication diary, per medication event 2 timestamps are important: the prescribed intake moment and the actual intake moment. As the agenda implementation covers a superset of these, it can be used for the medication diary. Whenever the category is 'Medication', the item appears in the medication diary. Care receivers entitled to an automatic medication dispenser regime cannot enter intake times themselves. Instead, the Integration Tier receives the 
Table 4.2: Agenda item parameters

\begin{tabular}{|c|c|c|}
\hline Item & Type & Remarks \\
\hline Id & (int) & Event identifier \\
\hline User & (int) & Event Adressee identifier \\
\hline Name & (String) & Name of the event \\
\hline Location & (String) & Location of the event \\
\hline Category & (String) & Event category (e.g. medication) \\
\hline ReminderTimeBefore & (Date) & Timestamp to start escalation path \\
\hline StartDate & (Date) & Timestamp of event start \\
\hline EndDate & (Date) & Timestamp of event stop \\
\hline Going & (String) & $\begin{array}{r}\text { Indicates if user does/doesnot/maybe } \\
\text { attends event }\end{array}$ \\
\hline OriginalId & (int) & $\begin{array}{l}\text { Head event Identifier, } \\
\text { in case of recurring event }\end{array}$ \\
\hline Remark & (String) & Remarks for event \\
\hline Link & (String) & URL for this event \\
\hline Pictogram & (String) & Pictogram URL for event \\
\hline Valid & (Boolean) & Indicates event validity \\
\hline LUO & (Date) & Last Updated On timestamp \\
\hline LUB & (String) & Last Updated By \\
\hline
\end{tabular}

timestamp from the dispenser through the wrapper service, and updates the event end-date in the Carereceiver Tier through a web service call. In case the care receiver should manually confirm intakes, the event end-date is stored directly after confirmation and the Integration Tier is notified to stop the escalation path. In both cases, a classification judgement is calculated for decision support purposes, as described in Equation 4.1. An example of manual intake confirmation is shown in Figure 4.9. The classification for medication that has not been forgotten is annotated with red, orange or green labelling. The last column is empty, because the snapshot was taken after November, 2nd. Only medication for the same day is allowed to be confirmed. If the client would be entitled to an automatic medication dispenser regime, the last column would not be shown because the confirmation time would be fetched from the electronic dispenser.

\subsubsection{Health info}

The health information service currently implements a service for the following types of health-related measurements: oxygen saturation, blood pressure (systolic / diasystolic, pulse rate), steps (within a time period), weight, heart rate. These items are measured using the Mobihealth vital sign monitoring service, which consists of an internet-connected smartphone and one or more BlueTooth connected sensors dependent on care receiver needs. Figure 4.10] 


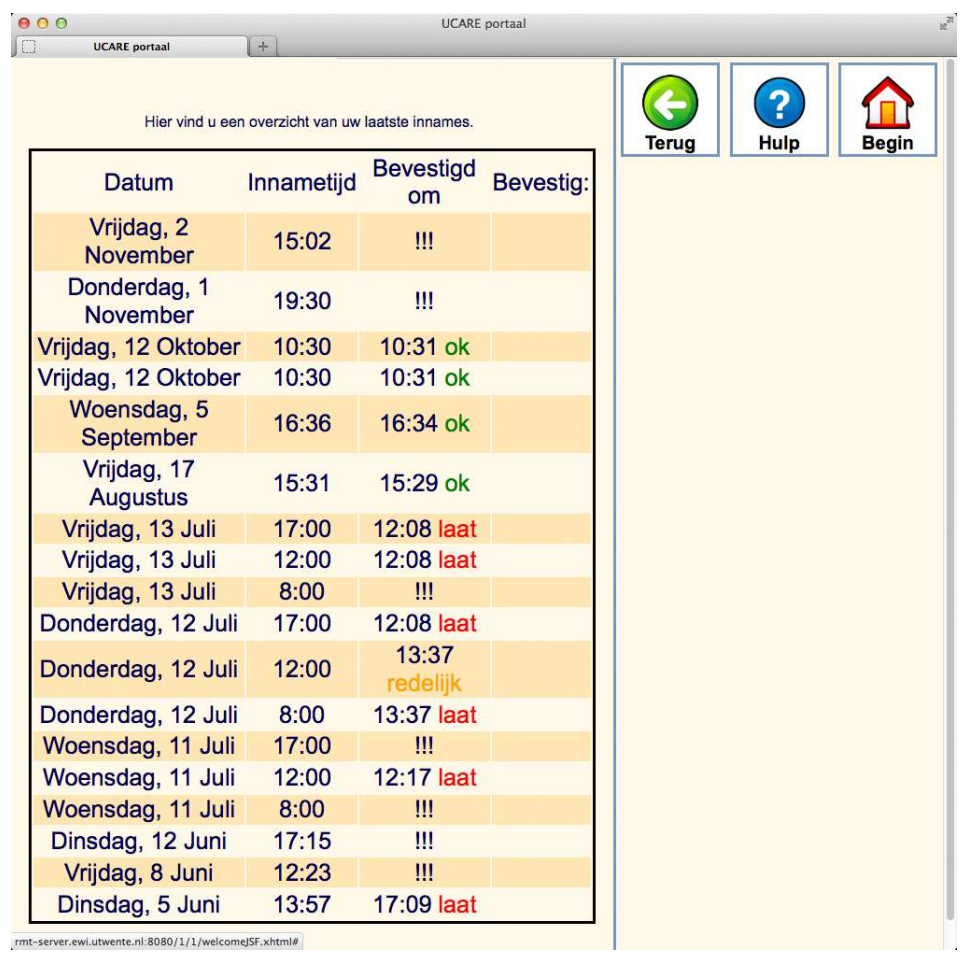

Figure 4.9: Medication diary example for manual intake confirmation. Columns: Date, prescribed intake time, confirmation time and score, confirmation action.

shows an actual measurement taking place. When WLAN is available in the nursing home premises, there is no need for a more expensive cellular connection. As soon as a measurement is performed, the integration tier is notified as shown in the use case 'Updating' in Figure 4.4. Care receivers can review their results themselves in the medication diary, such as shown in Figure 4.11.

\subsubsection{Social activities}

The implementation of the social activities service is implemented through having the caregivers responsible for activity management filling out the agenda in the caregiver tailoring tier. Here, they define activities, activity recurrences, location and they define which care receivers should be notified about the activity types they are interested in. This is shown in Figure 4.12. The agenda of care receivers is then automatically updated according to the events they are subscribed to. An example is shown in Figure4.13. The 'Agenda implementation' subparagraph above described the further event handling. 


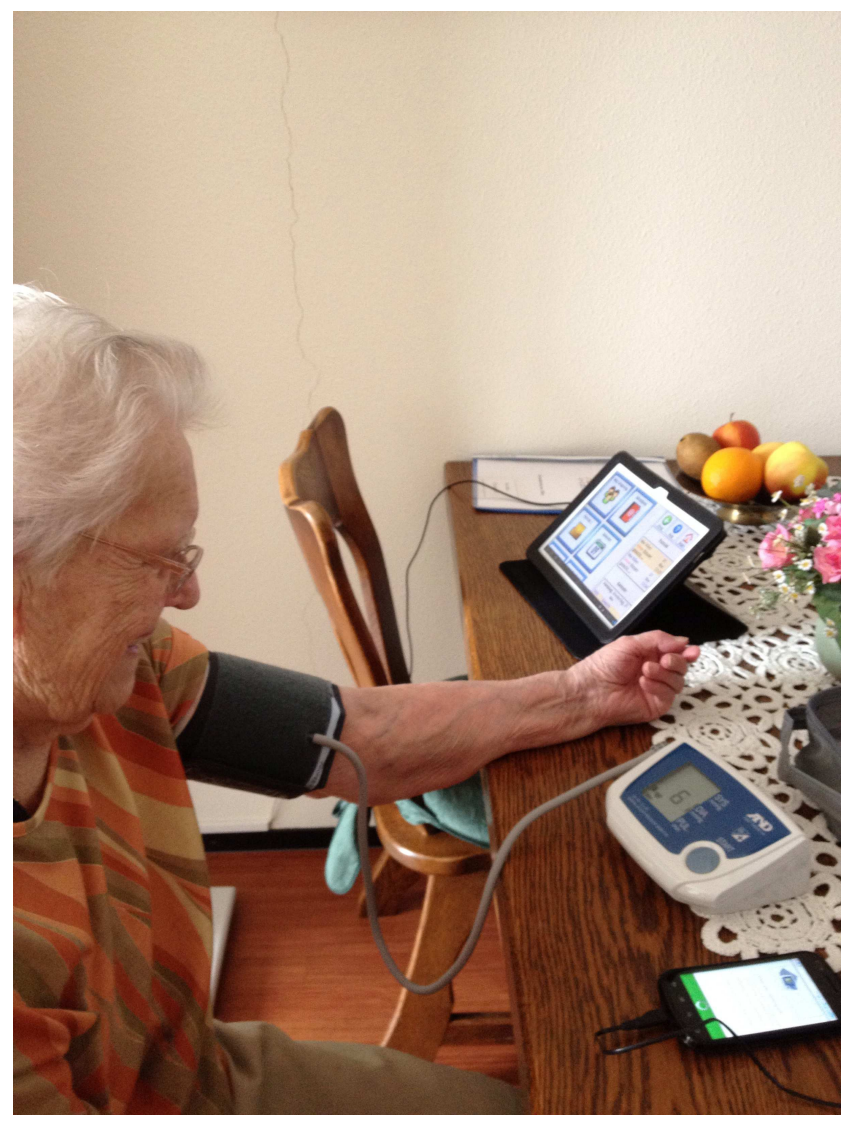

Figure 4.10: Care receiver performing blood pressure measurement

\subsubsection{Social interaction}

For the care receivers, VoIP accounts are installed on the tablet computers to enable voice and video conversation. In the carereicver application, an address book is used as a starting point for communication. When adding other U-Care users to the address book, the necessary fields are automatically retrieved, in other cases they have to be added. On certain devices it is possible to automatically start voice conversations from the address book in the browser, using the skype:// URI. Alas this is not possible on all brands of tablet computers. Because of privacy concerns, the community service also contains a profile page to set, delete or hide personal information, further described in the next paragraph. 


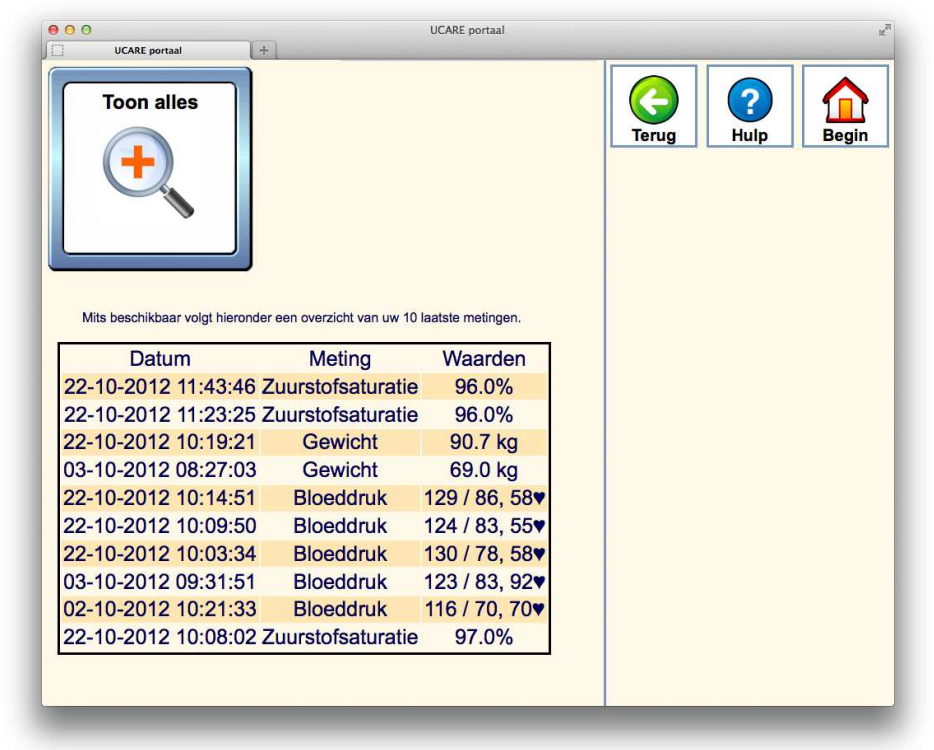

Figure 4.11: Review measurements

\subsubsection{Privacy measures}

Measures to protect privacy deserve attention as they are important for scaling up the usage of the system after lab testing. In all communication with external services and between tiers, communication is based of SHA-256 hashed and salted patient identifiers to prevent disclosure of identities. Also, authentication information is encrypted. In every tier, operation is possible based only an ID, so without using actual personal information (such as name) of users. Care receivers or their caregivers can choose not to include or store any personal information within their account.

\subsubsection{API implementation}

Leveraging the Metro API in J2EE and the annotation facility @WebService, which converts singleton beans into web services, we obtain generated WS Definition Language (WSDL) descriptions and servlets to test web service implementations. This allows fast creation and editing of the web-exposed API, or WebAPI. The WebAPI implements the methods for the services discussed above: scheduling, managing agenda items, notifications, messages and alerts, managing labels and personalisation settings, and for testing. On the reference side, a web service client is used to notify the integration tier about scheduled events, medication intake confirmations and to request vital sign measurements. The functions are listed in Appendix D. 


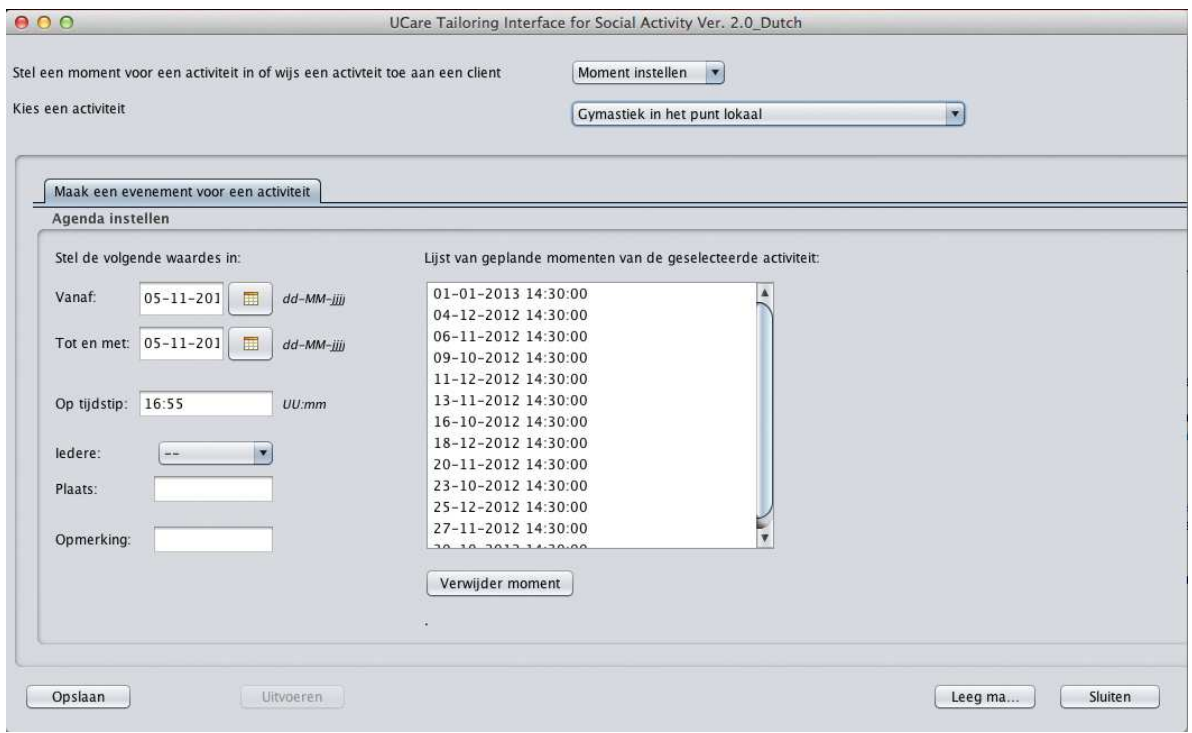

Figure 4.12: Caregiver tailoring software interface for defining social activity related service plans

\subsubsection{Persistence implementation}

The system uses Java Persistence API (JPA) 2.0 to enable persistence by providing the ORM principle described above. As JPA allows for the various multiplicities and inheritance relations between object, it enables a pure OObased information model to be automatically mapped to a database scheme.

The actual database is a MySQL 5.1 database, and the J2EE built-in Derby database is used for the scheduler service.

\subsection{Discussion}

This section finally discusses the mapping of requirements onto the service components using a traceability table, and design and implementation choices that have been made. The usage of the system is also evaluated, but will be discussed in Chapter 5 .

\subsubsection{Traceability Table}

Table 4.3 is a traceability table to show the requirements-realisation mapping. The requirements stated in Section 2.5 are repeated below, and for each of the four services discussed in that section the implementation details and discussion paragraph is given. 
Table 4.3: Traceability table: requirements-realisation mapping

\begin{tabular}{|c|c|c|c|}
\hline Nr. & Requirement & Realisation & Discussion \\
\hline 2.5 .1 & \multicolumn{3}{|c|}{ Social Interaction } \\
\hline SI 1 & Content management & Agenda & 4.4 .3 \\
\hline SI 1 & Video communication & VoIP & 4.4 .7 \\
\hline SI 2 & Authorisations & Authentication mechanism & 4.4 .1 \\
\hline SI 3 & Encouters & Social Activity Management & 4.4 .6 \\
\hline SI 4 & Matchmaking & Addressbook & 4.4 .7 \\
\hline SI 5 & Delegates & Credential sharing & - \\
\hline SI 6 & Contact Family/friends & Messages, VoIP & 4.4 .7 \\
\hline 92.5 .2 & \multicolumn{3}{|c|}{ Social Activities } \\
\hline SA 1 & Reminders & Escalation path & 4.3 .1 \\
\hline SA 2 & Reminder tailoring & Tailoring interface & 4.3 .1 \\
\hline SA 3 & Measuring & Push facility & 4.4 .2 \\
\hline $\mathrm{SA} 4$ & Intrusiveness levels & Push facility & 4.4 .2 \\
\hline SA 5 & Registration & Agenda & 4.4 .3 \\
\hline \multirow[t]{2}{*}{$\mathrm{SA} 6$} & Input & Agenda & 4.4 .3 \\
\hline & & Tailoring interface & 4.4 .6 \\
\hline 2.5 .3 & \multicolumn{3}{|c|}{ Medication Monitoring \& Compliance } \\
\hline Med 1 & Dispense reminder & Escalation path & 44.3 .1 \\
\hline Med 2 & Assistance & Tailoring interface & 4.3 .1 \\
\hline Med 3 & Guidance & Medication diary & 4.3 .1 \\
\hline Med 4 & Intake scheme & Medication diary & 4.3 .1 \\
\hline Med 5 & Sampling & Coupled Third party dispenser & 4.4 .4 \\
\hline Med 6 & Compliance measure & Medication classification & 4.3 .1 \\
\hline 22.5 .4 & \multicolumn{3}{|c|}{ Health monitoring } \\
\hline HM 1 & Monitoring & Third party service & 44.4 .5 \\
\hline HM 1.1 & Feedback & Tailoring interface & 4.2 \\
\hline HM 1.2 & Measures & Third party service & 4.4 .5 \\
\hline HM 1.3 & Mobility & Device choice & 4.3 .3 \\
\hline HM 1.4 & Feedback & Tailoring interface & 4.2 \\
\hline HM 2 & Presentation & Health info & 4.4 .5 \\
\hline HM 3 & Measures & Third party service & 4.4 .5 \\
\hline
\end{tabular}




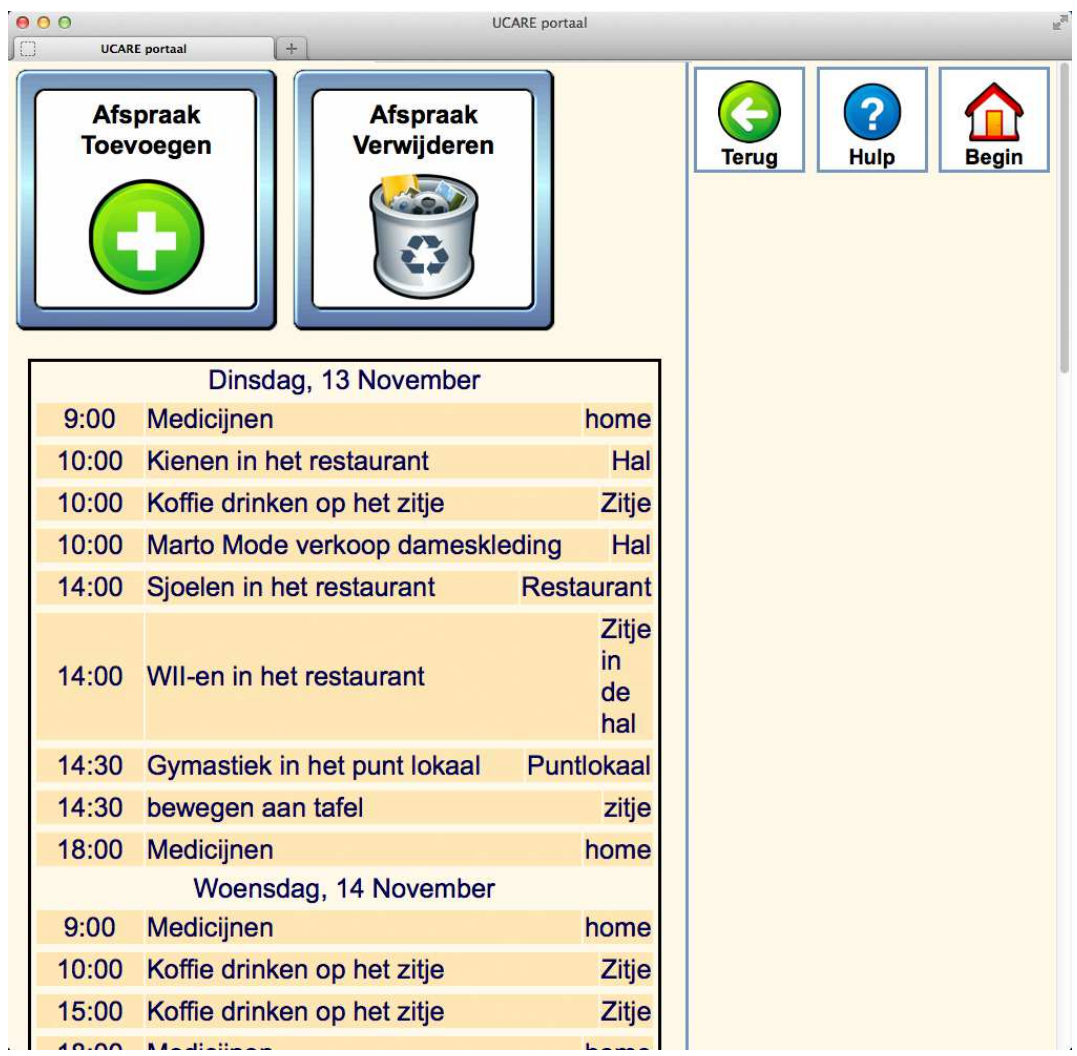

Figure 4.13: Care receiver activity software interface showing actual activities.

\subsubsection{Design and implementation Choices}

The choice of J2EE enables a great deal of scalability and fail-over as load balancing and pooling are available. Though current usage levels do not yet need it, this could be useful for later application scenarios. On the other hand, the fact that the Integration Tier and Carereceiver Tier are currently physically separated is a source of possible runtime errors. It would be better to provide the system in duplo, moving those 2 physical tiers into virtual ones, distributed over multiple physical locations. Also, the Convention Over Configuration paradigm adopted in J2EE allows for scalability, as it forces to develop in modules thereby separating concerns.

The choice of developing a WebAPI to use between system parts seemed also accurate, as it allows for easy development and separation of concerns. On the other hand, delay and over-use of notification features within the API are improvable when scaling up.

The push mechanism that displays notifications and alerts is accurate but 
limited to the physical capabilities of the device that renders the alert (w.r.t sound volume and clear visibility on the screen). A potential improvement could be to use a physical device that is better able to communicate alerts by means of a combination of clear audible and visible signalling, especially considering the target audience and the fact that the devices currently used (tablet computers, smartphones) are not designed for delivery of alerts. 
Chapter 5

\section{Testing User-Tailored E-Health Services in Practice: Results and Lessons Learned}

\subsection{Introduction}

This chapter discusses the evaluation of the home care services platform. A pilot study has been conducted in 2012 to evaluate both technical and user aspects.

Because it is a platform that should be tailored by its users, it it useful to evaluate it in practice: in that way, the tailorability of the system can be verified in real use cases. Moreover, the availability of a trial location in a nursing home in Sittard, the Netherlands, enables much more realistic testing than lab testing or tests using controlled simulations. The research project aims to include a validation of the platform as a proof of concept using this location.

The motivation to test the system in a real-life pilot, with a limited number of users, stems from the fact that the development is in a stage in which the platform works, but it is too early for large scale testing. It still is a research prototype and resources for large scale testing are not available. On the other hand, just testing the result in a lab, or living lab situation is undesirable: that does not provide real usage results or feedback [5, 8, The end users who are testing the system are aware that they are using a working prototype, yet they can assume a working system that has been tested.

The overall goal of the pilot is to demonstrate that ICT applications support the wellbeing and independent living of elderly in the care domain. From this general goal, sub-goals related to both the user perspective and the system perspective are drawn: 
- To be able to consume viable U-care services in a user-friendly and usable way;

- To demonstrate a feasible application infrastructure that supports usertailored e-health services.

The relevant pilot evaluation questions are defined as follows:

1. Is the system usable in day-to-day care situations?

2. Compared to care as-is, does it provide added value?

3. Is the system user-friendly?

4. Should the technical aspects of the system be improved?

5. What is the effectiveness of the various system parts?

These are usage-related (1,2 and 3) and system-related (4 and 5) research questions. If the first three answers are positive, the first goal is met. Questions 4 and 5 are studied to pursuit the second goal. To obtain the necessary answers, this chapter describes the evaluation process, results and a conclusion referring back to the evaluation questions. The rest of this chapter is structured as follows. Section 5.2 discusses the methods used in the evaluation, including the pilot study design and the outcome measures that are used. Section 5.3 presents the results of the pilot. In section 5.4 these results are discussed and reviewed. Section 5.5 refers back to the evaluation questions mentioned above, and presents concluding remarks.

\subsection{Methods}

\subsubsection{Pilot study design}

Before the actual pilot, a focus group of elderly have tested various interface designs. This way we come up with a design that is justified. The different designs are shown in Appendix A.

In the pilot, we evaluate the 4 services whose requirements were elicited and described in Section 2.4 social interaction, social activities, medication intake and compliance, and health monitoring.

Before the pilot, caregivers and care receivers are instructed using both workshops and written documentation. The caregivers are trained by the developers. The care receivers are trained by the caregivers using workshops (simultaneous training) and individual training. These are not performed by the developers because of familiarity and privacy reasons.

The pilot is conducted as follows:

1. Pilot preparation; 
2. Pilot phase 1;

3. Adjustment;

4. Pilot phase 2;

5. Evaluation.

The pilot preparation involves lab-testing the developed services (integration testing) and configuring all the necessary hardware components, network and software settings. The pilot itself is divided in two phases. In this setup, both unexpected circumstances can be dealt with, and desired new functionalities that arise in the first phase, can be realised in between the two phases. Finally, an evaluation is held which is discussed in the following of this chapter.

The first phase lasted from week 19 till week 26 (7 May - 25 June) 2012. The second phase lasted from week 40 till week 47 (1 October - 19 November) 2012. Eight female care receivers of nursing home Hoogstaete (aged 74-98) are voluntarily selected to participate in either of these phases, or both. Due to age and nursing home location characteristics, no male persons were available. They are asked (i) to learn to operate the system, (ii) perform tasks according to different usage scenarios as defined in Table 5.1. and (iii) participate in questionnaires and interviews. The scenarios tested in the pilot are executed using stratification. This is because of the limited number of sensors and actuators available. Also different combinations could be tested this way. The tested scenarios cover a range of the possible service plans (see Section 4.1 for the definition and an example of a service plan) possible with the system. These service plans and the pilot user characteristics are listed in Table 5.2

The social activities are entered in the system as soon as the schedule is defined by the caregivers responsible for activities. The activities that are entered are the same for all the participants, and equal to the activities that are announced to the inhabitants that don't use the system.

The social interaction, as described in Section 4.4.7, is set up using Skype. Skype accounts for all care receivers are configured on tablet computers, and a Skype account for the caregivers is set up on a separate laptop. Also, family and relatives of care receivers can interact with the care receivers.

\subsubsection{Evaluation methods}

When evaluating the proposed system, both the usage of the system and the technical aspects of the system need to be evaluated. This is because the goals and research questions presented in 5.1 relate to indeed both the user and the system perspective. Indicators related to the perception of the system by its users in real life should therefore be assessed, but also the engineering quality of the system.

In order to measure the user and system perspective, both quantitative and qualitative methods are used. 
Table 5.1: Pilot study scenarios

\begin{tabular}{|c|c|}
\hline Service plan & Description \\
\hline $\begin{array}{l}\mathrm{MD}_{m}+\mathrm{BP}+ \\
\text { Weight }\end{array}$ & $\begin{array}{l}\mathrm{MD}_{m} \text { is a manual medication dispenser. Care receivers } \\
\text { are asked to take medication. BP and Weight services } \\
\text { are used to monitor blood pressure and body weight } \\
\text { respectively, based on plan created by caregivers. }\end{array}$ \\
\hline $\begin{array}{l}\mathrm{MD}_{m}+\mathrm{BP} \\
\mathrm{BP}+\text { Weight }\end{array}$ & $\begin{array}{l}\text { Same as above but without measuring body weight. } \\
\text { care receivers are asked to monitor their blood pressure } \\
\text { (BP) and body weight. }\end{array}$ \\
\hline $\begin{array}{l}\mathrm{OX}+\mathrm{BP}+ \\
\text { Weight }\end{array}$ & $\begin{array}{l}\text { care receivers are asked to monitor their blood pressure } \\
(\mathrm{BP}) \text {, Oxygen Saturation }(\mathrm{OX}) \text {, and body weight. }\end{array}$ \\
\hline $\mathrm{MD}_{e}+$ & $\mathrm{MD}_{e}$ is an electronic medication dispenser. It is used \\
\hline Weight + & $\begin{array}{l}\text { for routine medication; with monitoring body } \\
\text { weight and blood pressure }(\mathrm{BP}) \text {. }\end{array}$ \\
\hline $\mathrm{SA}$ & $\begin{array}{l}\text { Caregivers enter social activities (SA) organised in the } \\
\text { nursing home. Care receivers are notified about } \\
\text { these activities. }\end{array}$ \\
\hline SI & $\begin{array}{l}\text { Caregivers, care receivers and family have social inter- } \\
\text { action (SI) using the system. }\end{array}$ \\
\hline
\end{tabular}

The quantitative techniques are executed using logging and tracing facilities of the application server and the database server.

The qualitative techniques are based on the IBM Computer Usability Satisfaction Questionnaire [52, the Unified Theory of Acceptance and Use of Technology (UTAUT) 77] questionnaire, and a questionnaire with augmented, semistructured interviews based on the ISO 25010 framework [55]. This way, three things are measured: the usability, the perceived ease of use, and the software quality characteristics.

\subsection{Results}

This section discusses the results of the pilot study. First, the results gathered with the four user-facing services (Activities, Social Interaction, Monitoring of Health Status, Medication Intake) are discussed. For each of those, results of the first phase, improvements, and results of the second phase are discussed. Then, the usability study results are presented, related to both care receivers and caregivers. Finally, hardware and infrastructure related issues are discussed. 
Table 5.2: Pilot study details and number of users (\#)

\begin{tabular}{ll}
\hline Item & Description \\
\hline \# care receivers & 8 \\
Age & $86 \pm$ 12 years (All female) \\
\# caregivers & 4 \\
Gender & 3 female, 1 male \\
Trial location & Nursing home, Sittard, NL \\
Duration & 7 May -25 June 2012; \\
& 1 October -19 November 2012 \\
Services & Social Activities $(8,8)$ \\
(\# users phase 1,2 $)$ & Social Interaction $(8,8)$ \\
& $\mathrm{MD}_{m}+$ BP + Weight $(1,1)$ \\
& $\mathrm{MD}_{m}+\mathrm{BP}(1,1)$ \\
& $\mathrm{BP}^{+}$Weight $(2,1)$ \\
& $\mathrm{OX}^{+} \mathrm{BP}+$ Weight $(1,1)$ \\
& $\mathrm{MD}_{e}+$ Weight $+\mathrm{BP}(0,1)$ \\
\hline
\end{tabular}

\subsubsection{Services}

\section{Activities}

In total, 56269 activities for care receivers activities have been registered in the system during the complete pilot. 53851 of them are social activities, the others appointment for other service plans. Over 200 different social activity types have been registered, most of them are organised on a recurring basis. Figure 5.1 splits the frequent ones (occurrence more than 100) to type; Appendix C shows the complete list of activities. Drinking coffee occurs not only multiple times a day for all care receivers, but is also recurring, including during the weekend. Hence it is much more frequent.

Since the software that enables the creation of personal service plans is indeed designed for care receiver-specific plans, it was not completely suited for assigning activities to groups of people. This is possible, but it is essentially a quadratic growing process: both recurrence over users and activities. As the persistence of these activities involves operations that cost time in the order of tenths of seconds, it can result in slowness from a perception perspective in case of large operations.

Providing tailored activity schedules for care receivers was valued as time consuming for the caregivers involved, because it was extra work (entering in two systems) and it was not yet arranged substitution. The numbers of activities given above, shows that it is used heavily by the caregivers. Hence, the usability of the software for managing the activities is of great importance.

Currently, only a limited number of care receivers indeed profited from the availability of this online agenda. In larger settings, the benefit as replacement 
would be bigger, as entering (recurrent) activities then only once yields more gain.

It was valuable that the care receivers got a notification of the activities, and activities that are repeated often, such as coffee drinking, only have to be registered once for all care receivers and scheduled moments, instead of again for every care receiver paper print. Also, it was valued that entered activities immediately are available on the system, which aided verification of the scheduled activities.

Before the second phase started, the system has been improved to increase the speed of saving activities. This was noticed by one caregiver:

"It costs less time than before. If I enter activities and assign to inhabitants, I'm finished earlier than before. It reliefs that the inhabitants get notifications of certain activities."

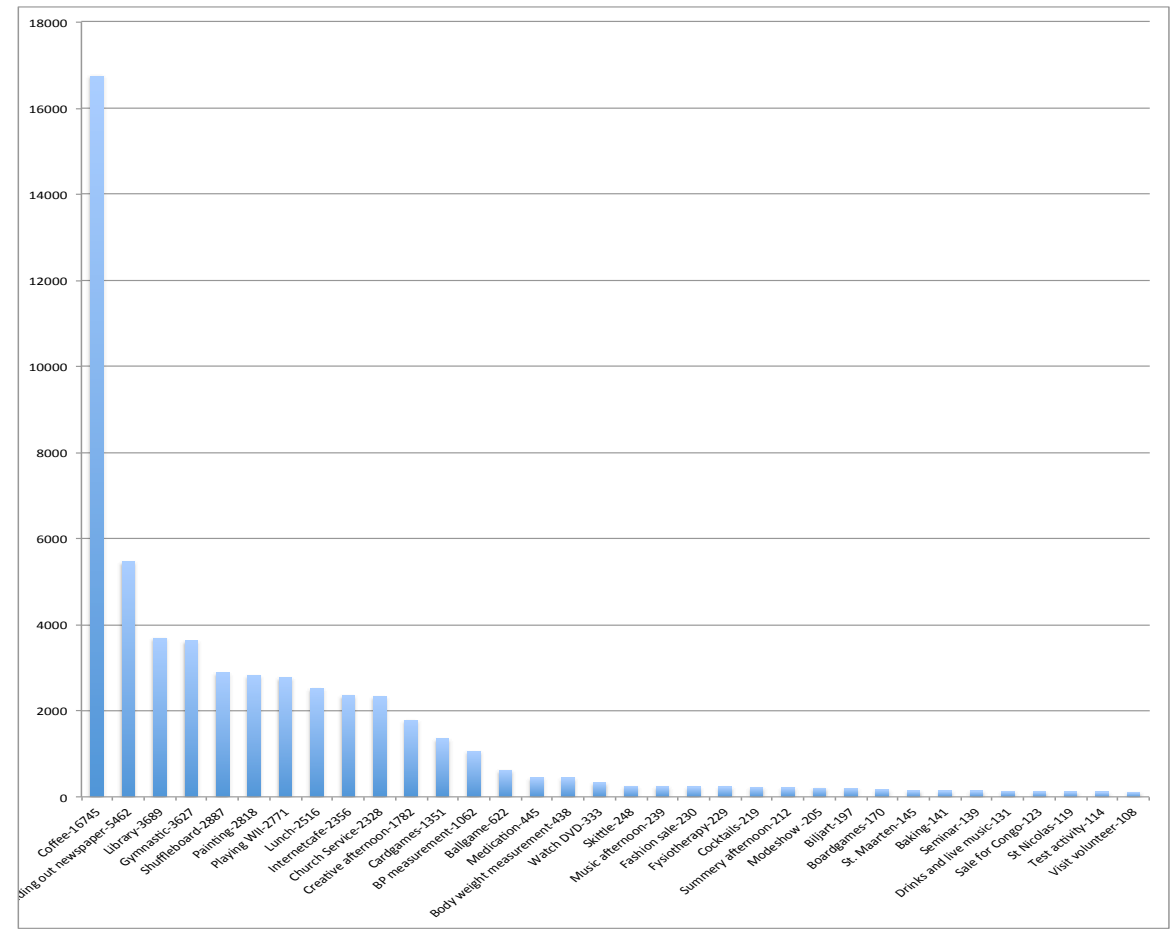

Figure 5.1: Activities entered.

\section{Social Interaction}

The following social interaction services are available to the end users: 
- Text-based messaging between care receivers and caregivers;

- Video-based communication between care receivers, their family, and caregivers.

The text-based messaging uses a Mailbox ('Postvak') application within the end-user system (see Figure 4.8). Latest messages are shown on the right above the calendar. Instant messaging is possible, as new messages are automatically pushed (delivered) to the recipient device.

The social interaction facility was preconfigured on the tablet devices, such that it was directly possible for caregivers and care receivers to use video communication. Using the tablet home screen this could be initiated.

The main use of the text interaction were one-way; i.e. only towards the care receivers to inform and remind about activities or measurements. The main video interaction was between family and care receivers. Occasionally, the video possibility was used by caregivers used as replacement for visits.

In the pilot, the walking distance between the work place of the caregivers and care receivers was in the order of 10 to 50 meter only. If the walking distance would have been bigger, the advantage of this service would obviously be greater. That has also been found in home care projects were video communication was implemented [20].

\section{Health Monitoring}

During the pilot, care receivers performed more then 200 self-measurements using the platform. They used sensing devices capable of measuring weight, oxygen saturation (including heart rate) and blood pressure (including pulse rate).

Creating the service plans to schedule these tasks was an easy task for the caregivers involved, because the service plans were explicitly tailored to their needs and they were designed in a simple to use wizard format. In these service plans, the caregivers set which care receiver needs to measure what, personal boundaries for the values measured, and the escalation path, i.e. what to do in case of forgotten measurements, or measurement values outside the set boundaries.

Creating service plans offers a lot of freedom as many parameters can be set. The program, which functions like a step-by-step wizard, was received well. One caregiver noticed:

"Creating service plans for measurements is accurate and fast. This really saves us time."

Regarding the question if this service enlightens the tasks of caregivers, this caregiver noticed:

"Yes, especially with respect to the measurements performed by the people themselves. They also got a greater feeling of empowerment 
and autonomy. Despite the age, this is the concept that worked best. It saves us time, walking, and performing operations. Because of that we can help other care receivers better."

The escalation path feature, i.e. warning the selected caregiver if measurement values exceeded set bounds, functioned properly. Only one time a warning was not delivered to the caregiver' cell phone due to one server tier being offline for unluckily planned software upgrade. After this upgrade, the warnings included the measured value that caused the alert. This was regarded as a great improvement, because the caregiver now has information to judge the exceeding of the threshold directly and act accordingly:

"I was pleased to see that the measurement results were directly visible on the smartphone of the caregiver."

As said, in total over 200 measurements were performed during the pilot. One day of measurement failed due to improper device configuration -it is necessary to couple the measurement devices to care receiver IDs in the rest of the system, and this has to be modified in case a care receiver with a different care receiver ID starts using the devices.

In fact, the number of measurements grew so large that it did not fit on the screen any more. In the second pilot phase, therefore a button was added to show older, archived measurements, and the main health information overview only shows the latest measurements.

\section{Medication compliance}

As found in Table 5.1 both electronic and manual medication dispenser were tested. The 'Smint' used as medication is delivered on rolls of pouches. Care receivers received a service plan in which they had to take them according to the defined schedule, from either a manual box or electronic dispenser.

The electronic device was received much better. One caregiver said: "I absolutely have a preference for the electronic dispenser." It gave much better compliance results because it was more user-friendly: the electronic device produces a loud noise when medication is due; it already cuts of the medication pouches for easy intake and it registers intake times itself. The manual box on the other hand is just a storage place. The reminder to take the medication and the acknowledgement are available through a tablet computer only, whose sound is not loud enough and which requires more steps to be taken.

The medication classification that has been designed (see 4.3.1) in cooperation with the nursing home was intuitive and was received well. The coloring scheme makes it easy to directly see which care receivers are incompliant on which days.

The electronic device was tested in the second pilot phase. Notably, compliance (defined as the ratio of number of timely taken medication to the total number of medication prescribed) was much better with the electronic dispenser. Although both are tested using only one care receiver for one week 
with the medication prescribed twice a day, electronic dispenser compliance was $89 \%$ vs. $30 \%$ for the manual dispenser.

Because of the loud noise the electronic dispenser makes when medication is due, people rather stay home and wait to take the medication, as doing so makes the noise stop. Even though the device allows to prematurely dispense a pouch in case of eg. appointments outside. On the other hand, the manual dispenser makes no noise when medication is due, although there is the (as mentioned) less loud notification on the tablet. Moreover, it does not automatically record intake times, as it is just a simple medication box. This makes it less user friendly.

\subsubsection{Usability}

\section{Care receivers}

In this section, we investigate perceived ease of use of the system as we want to assess the usability.

Figure 5.2 shows perceived ease of use among the care receivers. It is based on the UTAUT questionnaire. Perceived ease of use is measured using 5 effort expectancy statements answered on a Likert scale of 1 (totally disagree) to 5 (totally agree).

1. Learning to operate the application is easy for me;

2. I find the application easy to interact with;

3. I find it easy to get the application to do what I want;

4. It is easy for me to become skilful at using the application;

5. My interaction with the application is clear and understandable.

The results of this evaluation among 8 users of the system are shown in Figure 5.2. It was executed after the users got familiar with the system, i.e. halfway during the first pilot phase. On the upper part, a large spread in the answers is noticeable. This stems from the difference in how the system is valued by the users. Some are quite positive, but some are quite pessimistic. This variety is clearly visible in the lower part of the figure, which shows a histogram with the answers per user.

The variation among the users is also seen in the remarks they gave. They are listed in Table 5.3. Care receiver 3 mainly has negative remarks. 


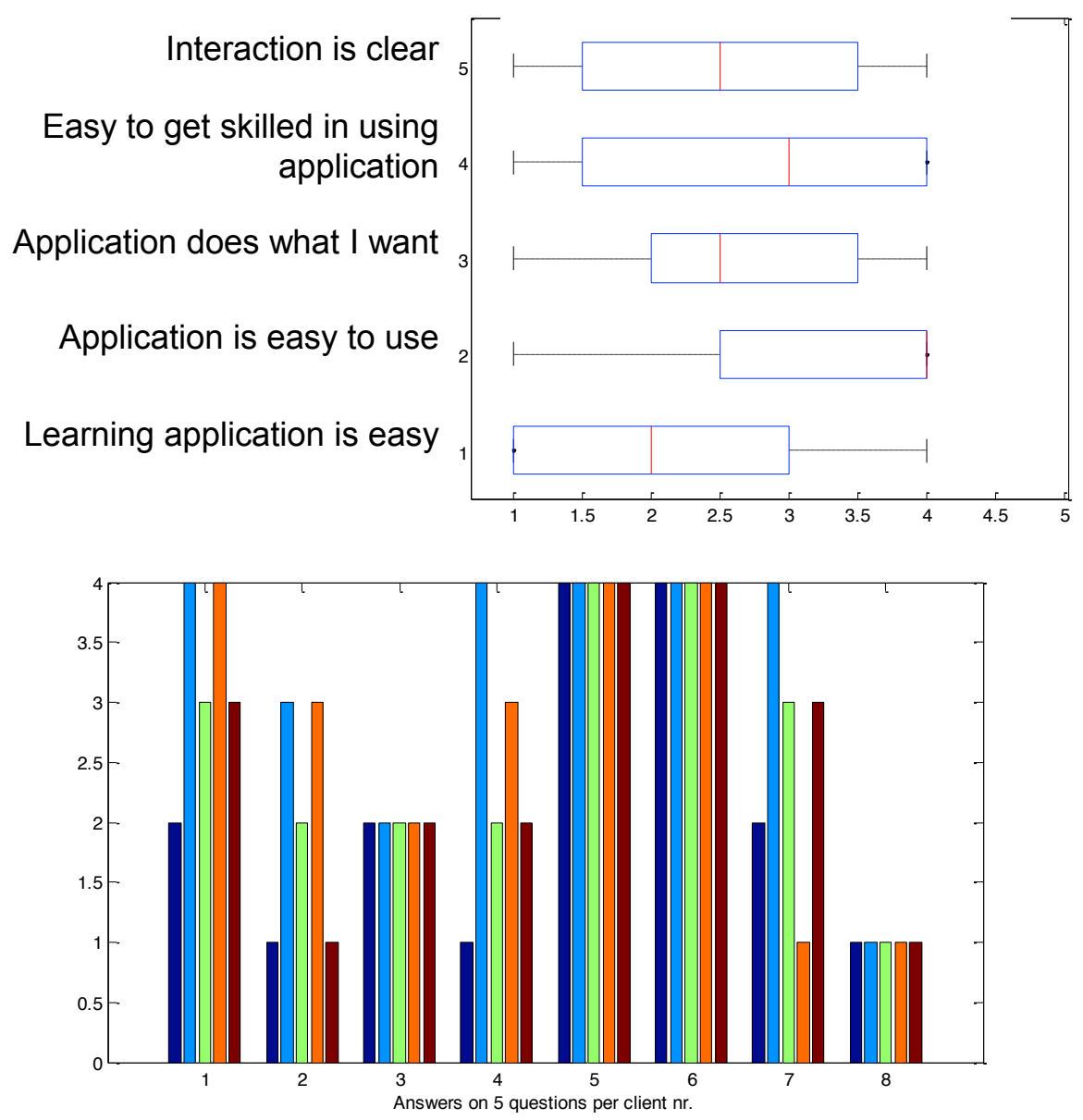

Figure 5.2: Care receivers results. In the higher part, the box plot shows the dispersion of answers. In the lower part, the histogram shows per-user answers. 
Table 5.3: Positive and negative points mentioned by care receivers. \# = care receiver number.

\begin{tabular}{|c|c|c|c|c|c|c|}
\hline \multirow{2}{*}{\begin{tabular}{l|}
$\#$ \\
1 \\
\end{tabular}} & \multicolumn{4}{|c|}{ Negative } & \multicolumn{2}{|c|}{ Positive } \\
\hline & & & & & & \\
\hline 2 & $\begin{array}{l}\text { difficult to } \\
\text { learn }\end{array}$ & $\begin{array}{l}\text { I have other } \\
\text { interests }\end{array}$ & & & $\begin{array}{c}\text { more } \\
\text { independence } \\
\text { through self- } \\
\text { measurements }\end{array}$ & \\
\hline 3 & $\begin{array}{c}\text { cannot handle } \\
\text { it }\end{array}$ & $\begin{array}{l}\text { I'm not very } \\
\text { interested in } \\
\text { using it }\end{array}$ & $\begin{array}{c}\text { explanation } \\
\text { was too little, } \\
\text { too rapid and } \\
\text { too much at } \\
\text { once }\end{array}$ & $\begin{array}{c}\text { I prefer } \\
\text { measurements } \\
\text { by caregiver }\end{array}$ & & \\
\hline 4 & & & & & & \\
\hline 5 & & & & & $\begin{array}{c}\text { can use it } \\
\text { reasonably well }\end{array}$ & $\begin{array}{l}\text { I like the } \\
\text { interface }\end{array}$ \\
\hline 6 & $\begin{array}{l}\text { understanding } \\
\text { the signs }\end{array}$ & $\begin{array}{l}\text { it takes a while } \\
\text { before } \\
\text { measurements } \\
\text { are read }\end{array}$ & & & $\begin{array}{l}\text { weighing and } \\
\text { taking blood } \\
\text { pressure is easy }\end{array}$ & $\begin{array}{c}\text { ideal for at } \\
\text { home }\end{array}$ \\
\hline 7 & $\begin{array}{l}\text { difficult to } \\
\text { learn how to } \\
\text { use it }\end{array}$ & & & & $\begin{array}{l}\text { nice device if } \\
\text { you know how } \\
\text { it works }\end{array}$ & \\
\hline 8 & $\begin{array}{l}\text { difficult to } \\
\text { learn how to } \\
\text { use it }\end{array}$ & & & & $\begin{array}{l}\text { would like to } \\
\text { learn but need } \\
\text { explanation }\end{array}$ & \\
\hline
\end{tabular}




\section{Caregivers}

Also the caregivers (who had to train the care receivers in using the system) were inquired regarding their perceived ease of use of the system. Figure 5.3 shows their perceived ease of use. A more optimistic result is found in comparison to the care receivers. This may relate to better familiarity with technology in general and ICT in particular. Even though some of the caregivers never used a tablet computer before.

There are also complaints. From the Computer Usability Satisfaction Questionnaire and the interviews it is clear that there are 2 eminemt problems: if the system does not respond as supposed, it is unclear what the cause of the problem is. If the system reacts slow, it is also unclear what is the cause. The first problem has to do with the unclarity of error and exception messages, which were not always understood or understandable by the users. The second problem relates to internet connection, and will be discussed in the Section 5.3 .3 .

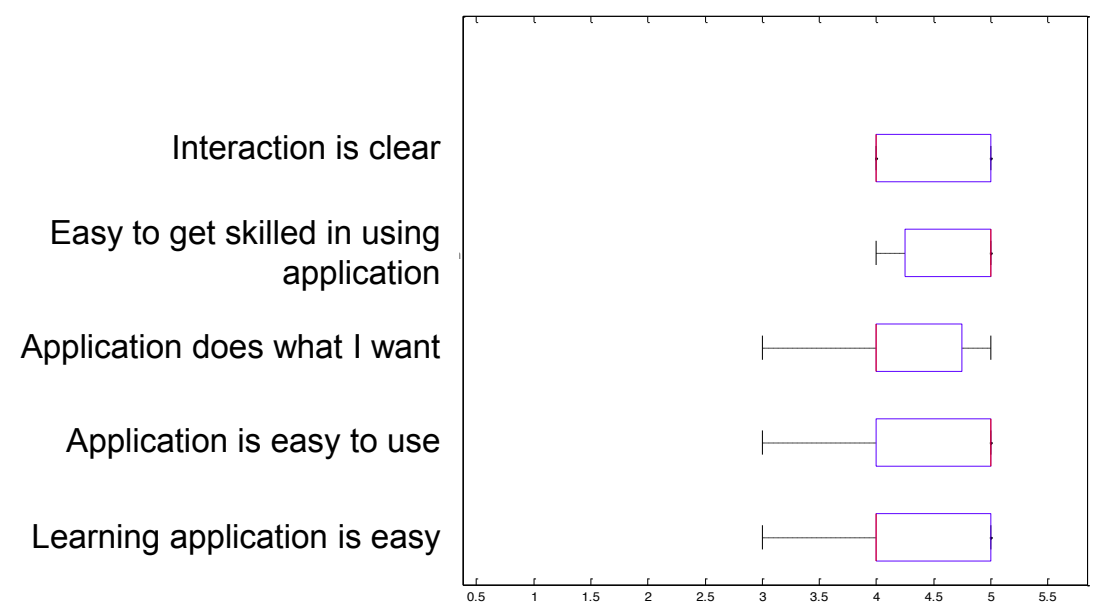

Figure 5.3: Caregiver results.

\section{Comparing care receivers and caregivers}

Table 5.4 shows the results of the Computer Usability Satisfaction Questionnaire 52 . The 4 caregivers and the 8 care receivers answered the questions (on interval scale $1-7$ ) related to system use, information quality, interface quality and overall satisfaction.

Again, the results show a positive score for the caregivers and an average score for the care receivers. Notably, the standard deviation $(\sigma)$ measured in caregivers is lower in all parts of the questionnaire than it is in care receivers: 
again, this questionnaire shows more spread in the answers from care receivers, and less spread in the answers from caregivers.

The largest differences between caregivers and care receivers are found in understanding the information (information quality) and system use. Understanding the information is more difficult for the care receivers. The use of the system, including facets as speed, effectiveness and efficiency, scored low especially in some care receivers. The interface quality on the other hand is received positively.

Table 5.4: Computer Usability Satisfaction Questionnaire mean and standard deviation $(\sigma)$ scores ( 8 care receivers and 4 caregivers, interval scale $1-7)$

\begin{tabular}{lcccc}
\hline Score Name & \multicolumn{2}{c}{ Care receivers } & \multicolumn{2}{c}{ Caregivers } \\
& Mean & $\sigma$ & Mean & $\sigma$ \\
\hline Overall & 3,7 & 1,3 & 4,8 & 0,62 \\
System Use & 3,2 & 1,8 & 4,4 & 0,76 \\
Information Quality & 3,5 & 0,95 & 4,9 & 0,66 \\
Interface Quality & 4,7 & 1,6 & 5,3 & 0,81 \\
\hline
\end{tabular}

\subsubsection{Technical aspects}

This section discusses the main experiences with the technical facilities during the pilot. First the infrastructural aspects are covered, followed by the experiences with hardware components.

\section{Infrastructure}

The infrastructural facilities needed to be improved somewhat during testing. The three main issues are discussed below: network availability, power and wireless signal strength.

In the pilot, a dependency between the integration tier and the application tier showed up, not found in prior lab testing. This resulted in application response being very slow in one case of a network outage of the integration tier server, which was located in a different network than the application tier. The blocking connection was removed the same day after this was found, to improve the independency of the components.

A power outage due to construction works also resulted in a short unavailability. For the second pilot phase it was hence decided to move the servers to better protected server rooms.

In the nursing home where the tests took place, a WiFi network was installed prior to the tests. However, coverage needed to be improved as some 
inhabitants of the nursing home had very poor connection on their measurement and tablet devices.

In conclusion, the infrastructural aspects such as power, network availability and wireless signal strength played a crucial role during the evaluation. Hence it was important to be able to react quickly for not having end users lose trust in the developed technology.

\section{Hardware}

The sensors performed well during the pilot. The most important remark was that it takes a long time before measured values using the sensors become visible on the tablet. This is due to different tiers and web service interconnections involved. Nevertheless, measured values are directly visible on the sensor itself. One care receiver started writing down all measured values, but after a few days she noticed that they were indeed sent correctly to the system.

Between the manual and electronic medication dispenser there was a great preference for the latter one, despite the higher cost of ownership. The ability to notify care receivers and the integration with the rest of the system to review compliance is valued by the caregivers.

The Android tablets used were considered 'not ideal' for the care receivers. There are too many buttons, it is too sensitive to operate and notifications are not produced loud enough. One caregiver noticed regarding this piece of hardware:

"Informing the care receivers was difficult. Most users did not know how to deal with the messages. The standardised notification font size also was too small. It was not the ideal way to inform. Despite various attempt with different notification sounds and setting the maximum volume, it was not a reason to hold the tablet to see what the notification is about. These are material limitations."

\subsection{Discussion}

Frequently, introducing complex innovations on goes hand in hand with some growing pains. These growing pains do not necessarily show up during lab-only testing, yet they can be very valuable when they occur during testing in daily life. This section discusses some of the interesting moments and lessons learned during the pilot testing.

\subsubsection{User outcomes discussion}

We start discussing with the target audience. One caregiver noticed:

"This is really a generation of people that is afraid to press a button, afraid to do something wrong. So it can result into frustration, a feeling of powerlessness." 
This could indeed be true for the current generation of care receivers. On the other hand, it is wise to test such systems after development on small scale, to be prepared for when they can be used on larger scale in the near future. Also, technical stability has to be verified when developing such a middleware platform. Verification in practice is then preferable over lab testing only, because it is more realistic. Moreover, organisations become better aware of and get experience with technological (in)possibilities through such pilot studies.

Executing such pilot studies in different phases means that the time in between can be used beneficially: for improvements and to react on unforeseen events. Of course, one has to take care when performing controlled trials to keep the interventions the same in both phases. In this study that was not relevant because there were only different cohorts of tests.

As said, the users involved are aware of the fact that the tests are preliminary tests. Nevertheless, we asked how they thought about the platform. One caregiver envisions:

"For use in home care situations, where caregivers are not in the neighbourhood directly, it is very suitable. Especially the measurements. For example when a care receiver does not feel well (and knows how the system works), he/she can arrange a voice connection with the caregiver. This way he/she can get the tasks to measure certain values and get adequate and fast follow-up to the problem. E.g. calling the general practitioner, 112, no action, a sign of comfort, or the announcement how long it will take a caregiver to reach the care receiver."

\section{Graphical User Interface}

In general, the design of the GUI did not receive much criticism, because it was tested beforehand regarding both various technical and usage scenarios. In the care receivers, the interface quality components was scored the highest in the CSQ evaluation (see Table 5.4).

One interesting issue in fact was that the interface was designed to work best in portrait mode, but due to protective covers added, the device was mostly hold in landscape, at the loss of having the overview of all items on one page. Another issue was that the goal of the home-icon (go back to the start screen of the system) in the application was not reached in full: the Android tablets chosen for the pilot also have a home button with a physical home icon. Not surprisingly, this leaded to occasional confusion.

Android in that sense also caused inconvenience regarding the lack of being able to start a Skype VoIP session to another person, based on a URI in the web browser. Nevertheless, some care receivers enjoyed video contact with both family and caregivers. 


\section{Application logic}

The application logic controls the actual content visible in the graphical user interface. It provides the logic necessary for the services to work, but is not directly visible as it resides 'under the hood'. The functionalities offered by the application logic in the different services have been described in 5.3.1, here we will focus on the important logic aspects that were tested but have not yet been covered: session management, publish/subscribe, and scheduling.

The session management was set up in such a way that care receivers, once identified, did not have to enter passwords again. This is important because entering information on tablets is more difficult than just viewing information, and for the care receivers the latter was the main intent. This way, authentication remains but becomes more user-friendly.

Publish/subscribe was introduced to update the views on the system directly in case of new events. This is of importance it reflects the ad-hoc aspects of care: it must be possible to issue alerts or reminders as necessary, and not only on scheduled or request-response basis. We notice that this kind of logic is crucial in this kind of platform.

Scheduling on the other hand is important because many care tasks are recurrent, such as activities of daily life. Functionality that allows scheduling and initiates action whenever scheduled items are due, is important for support of the task and the escalation path in case the task is not well fulfilled.

\section{What's in it for me?}

Figure 5.2 clearly shows the variety of attitudes within this test group. If the care receivers are not motivated to learn the innovation they do not like to use it and as a consequence do not use it a lot. On the other hand, motivated care receivers felt there was something in it for them so they spent time in learning the system and tried to perform the tasks asked. One care receiver asked if she could keep the sensors and tablet in between the two phases of the pilot. This was because self-measurements gave her clear personal advantages:

- She did not have to get up anymore at fixed times in the morning;

- She did not have to get dressed and then wait for the measurements to be taken anymore;

- The system gave her more independence; it improved her self-management. She had better overview over her own health condition using the system.

The tailoring was set, such that in case of abnormal measurement values a caregiver would come by anyway. This still gave her the feeling of security.

Another care receiver was motivated to use the tablet due to the new possibility to read ebooks on the tablet. Not the first application intended, but nevertheless very useful: due to her paresis it was much more difficult to read normal books. 


\subsubsection{Technical aspects}

In the pilot, a dependency between the integration tier and the application tier became noticeably. If a lightweight reasoning engine could be used to replace the heavyweight one used now in the integration tier, it is possible to combine the integration and application tier. It would be good to assure redundancy in case of scaling up. This is technically possible through the availability of pooling in the application servers currently used.

Using Web Services proved to offer reliable inter-tier connections. However they are quite slow because of the large protocol overhead. In retrospective, less usage of web service calls would be recommendable. If they need to be made, it is good to aggegrate the calls as much as possible. (E.g., not a WS call for every agenda item, but one call for the entire schedule.) This is what was done in the second phase of the pilot. It was more pleasant for the end users as well. Both for the caregivers when they had to enter service plans, as well as for the care receivers when they wanted to check their measurements or medication records.

In some of the workshops organised by the caregivers to instruct care receivers simultaneously, it was noticed that the WiFi signal was too poor to handle multiple tablets in one location. Users found this demotivating, because it prevented them from learning to operate the system. It is difficult to eliminate such problems, but testing beforehand helps. In this pilot testing a priori was not possible, because the $\mathrm{WiFi}$ was set up especially for this very pilot. After the first pilot phase the network problems were completely fixed, so having 2 separate phases definitively helped here.

It was noticed that the maximum sound level of the tablets was not loud enough to be very effective. hence to users could not always successfully be notified. The hardware has its limits here. In the given timeframe this could not be solved. Solutions may be found in the usage of other, custom devices to attract users' attention, including for example smart watches, speakers and / or lamps.

Software-related issues were found in the handling of URIs by the browser, especially discrepancies between $\mathrm{iOS}$ and Android. The first allows (IANAregistered [39]) VoIP URIs such as e.g. skype:// and callto:// to initiate video sessions from an (embedded) browser, but the latter (used in the pilot) doesn't.

As discussed in Section 4.4.6, both policy-based and cryptography-based measures were taken to protect user privacy. No privacy infringements occurred during the pilot. It proved recommendable to agree with the stakeholders involved on this matter, and to restrain communication of user identification data if not necessary.

In case of technical issues, it is important to be able to react quickly. Of course, using different services, sensors and actuators from different vendors in one study makes solving more challenging. On the other hand, troubleshooting now goes through one channel which is more convenient for end users. 


\subsection{Conclusion}

Section 5.1 listed research questions that were used in the evaluation described here. In this last section, we summarise our answers.

1. Is the system usable in day-to-day care situations? The system is usable in day-to-day care, especially when tailored by caregivers to situations in which care benefits from the services provided by the system. The services include medication dispense and compliance monitoring, and telemonitoring of vital signs. For social interaction, the system is not usable for all users involved because operating the devices can be too complex to learn and to do.

2. Compared to care as-is, does it provide added value? Dependent on how the system is tailored, the monitoring and escalation path features of the system provide added value for caregivers. For some care receivers, the system provides added value for information gathering, self management and social interaction.

3. Is the system user-friendly? Caregivers were generally satisfied with the user-friendliness of the system. They are able to use the system. Satisfaction in care receivers varied. They have difficulties learning and operating the new technology. A part of the users persisted in learning to operate the device, and got attracted to it. They found it user-friendly. But others got demotivated and frustrated. They did not find it user-friendly.

4. Should the technical aspects of the system be improved? In between the pilot phases it was rendered necessary to improve some of the services and to improve the technical stability of the pilot. During the second pilot phase, only speed improvements were needed to improve the user experience.

5. What is the effectiveness of the various system parts? In sum, the health monitoring and medication services showed to be effective. The social interaction and activity services showed to be not very effective at this moment. Nevertheless, these functionalities are in part necessary for the health monitoring and medication services. The architectural decision to separate integration issues from user-application is adequate, and the web-based interconnections are reliable, albeit from time to time perceived somewhat slow.

If we look back to the goals that are drawn in Section 5.1, we notice the following. The system developed worked in everyday care practice. It has shown to be a feasible application infrastructure. It aided in saving caregivers' time in aspects related to medication and health monitoring. In general, usability was considered positive by the 4 caregivers that used the system, and neutral 
with more deviation by the 8 care receivers. Though there were some technical issues (discussed in paragraph 5.3.3) that caused frustration among the 12 users, the system worked most of the time as expected.

In future, it can be recommended to fine-tune the system performance, and then test it on larger scale in home care settings, focused on health monitoring and medication support. Focus on training and learning to operate the devices is very important. For social interaction and activity management the system is less suitable because it is not effective; they do not have enough advantages over current practice. Nevertheless, these services are anyway necessary for the working of the other services, because of agenda and notification requirements. 


\section{Decision Support in E-Health Services using b-coloring of graphs, k-medoids based clustering and logistic regression}

Aging populations and increasing healthcare costs motivate the search for ways to increase care efficiency. Smart resource scheduling and informed decision making play key roles in the solution. They benefit from modelling of care processes and patient profiles. In this chapter, we present a novel unsupervised data mining approach using data collected by care services, to create care decision support systems. Two actual cases demonstrate the use of this approach: medication compliance modelling to manage medication intake using the system discussed throughout this thesis, and patient profile clustering, to group patients with similar health situations. The results show that it is possible to classify health-related situations in elderly healthcare, and to schedule resources according to expected health problems. Concretely, the presented cases demonstrate a decision support system to monitor medication compliance, health-related problems and to schedule resources such as staff, time and budget.

\subsection{Introduction}

The aging population is an omnipresent problem in western countries. For example in the Netherlands, one of 4 to 5 working class people would need to work in healthcare in 2040 to provide the current level of care [22. As 
this is undesirable from an economic and social perspective, it is important to innovate care and to put clients more into a self-management position, using ICT to support them in their daily life and only call for professional aid in case of necessity. This is also desired by most elderly as they express to age as independent as possible.

Clearly, (electronic) care services can contribute to this desire and this problem but in general they are expensive, they are not well integrated and not well tailored to specific needs [25, 50, 71. Healthcare institutions should systematically acquire the information needed to make decisions and to react quickly. If we focus our interest on nursing homes, pathology development in elderly people induces healthcare and social needs, and involves problems of management. These problems include organising, leading, acquisition and allocating resources, but also controlling and managing activities. Resource allocation (material, human and financial) and the obligation to react quickly can however be improved by ICT services. However, though current methods acquire data that can be used for such allocation, this barely happens and should be improved to increase efficiency, to improve resource planning and to face future efficiency gain demands.

In this chapter, we propose a Decision Support System (DSS) based on a data mining approach, in order to support operational and tactical decisions. The DSS is tested using both a case study and a validation. The goals of of the DSS vary for different stakeholders. For caregivers the goal is to monitor client classifications, so they are informed on client well-being. For planning and logistic purposes, it is of interest to see prediction estimates, to forecast the class of new clients; to have time-based forecasts and to find rules that explain behaviour. Clients themselves use it for self-management and awareness. Finally for management, it is relevant to find patterns among care consumption, available from the care services.

The structure of the rest of this chapter is as follows: Section 6.2 gives an overview of the contribution of data mining. Section 6.3 presents related work. Section 6.4 shortly discusses the data aspects of the case study. Section 6.5 discusses the data mining methods and the rationale for using these methods. Section 6.6 presents the results of a simulation study. Then a validation of the method using existing data from French nursing homes is performed. These data are the results of staff assessments, rather than measured by an electronic care (e-care) system, but the same methodology is still suitable because both sources concern the same domain and data are in the same format. Conclusions and an outlook are finally presented in Section 6.8

\subsection{Contribution of data mining}

\subsubsection{Data mining in general}

The aim of data mining is to automatically find useful information in large quantities of data. Data mining can be both predictive and descriptive: in 
the first case, the objective is to predict the value of a particular attribute given existing data, in the latter case the objective is to derive patterns that summerize the underlying relationships in the data. Data mining hence is an integral part of knowledge discovery, which is the overall process of converting raw data into knowledge through obtaining useful information from the data.

In 66, four core data mining tasks are identified:

1. Predictive modelling. The task is to build a predictive model for a target variable, based of explanatory variables. Classification and regression are methods to predict a discrete outcome (eg. whether or not somebody will do something) cq. an extrapolation of continuous output (eg. what the future value of a measurement will be).

2. Association analysis. The goal is to discover patterns that describe strongly associated features in the data. Typically, one tries to find implication rules $(a \rightarrow b)$. An example application is understanding relationships between different goods bought simultaneously in a supermarket, e.g. the pattern that people buying milk also buy bread, or people buying beer also buy snacks.

3. Cluster analysis. The goal is to group similar observations such that observations within one group are more similar to each other, and observations of different groups are less similar to each other. For example, this way it is possible to find groups of customers with related behaviour.

4. Anomaly detection. The task is to detect outliers, i.e. whose characteristics are significantly different from the rest of the data. A good anomaly detector should have a low error rate and a high detection rate. An example application domain is the detection of spam email.

The first task can be solved using supervised techniques, as the goal is to infer a function from labelled data using training examples. The latter three are referred to as unsupervised, as their aim is to find hidden structure in the data.

\section{Contribution of datamining in healthcare}

In healthcare, the four abovementioned tasks can be used as follows.

1. Clustering to cluster patient data. Groups of patients with similar behaviour are found in this way.

2. Predictive modelling to find the probability that new patient measurements fit in one of the found clusters. The goal is to enable prediction.

3. Association mining to find relations between input variables. This enables to find the most prominent associations in the measured data.

4. Anomaly detection to find (urgent) anomalies in measured patient data. 
In this Chapter, we limit ourselves to the first three tasks. The fourth task is already covered using the escalation path feature in the tailoring system: if patient measurements of abnormal values occur, then a caregiver is warned. Hence it is more interesting to focus on clustering of patients, predictive modelling and association mining. Summarizing the above mentioned tasks, Figure 6.1 shows the discussed data mining techniques and their process steps steps from left to right 13 .

\begin{tabular}{|c|c|c|c|c|}
\hline Data preparation & & Method selection & $\begin{array}{l}\text { Method } \\
\text { Evaluation }\end{array}$ & Model deployment \\
\hline \multirow{5}{*}{$\begin{array}{l}\text { Data collection } \\
\text { Data preparation } \\
\text { Data visualization } \\
\text { Dimension } \\
\text { reduction }\end{array}$} & \multirow{3}{*}{ 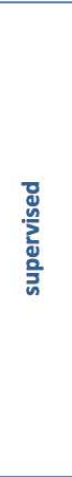 } & $\begin{array}{l}\text { Prediction } \\
\text { Linear regression } \\
\text { K-nearest neighbors } \\
\text { Regression models } \\
\text { Neural networks }\end{array}$ & \multirow{3}{*}{$\begin{array}{l}\text { Performance } \\
\text { evaluation }\end{array}$} & \multirow{5}{*}{$\begin{array}{l}\text { Application to new } \\
\text { data } \\
\text { KPI displaying } \\
\text { Warning issuing }\end{array}$} \\
\hline & & $\begin{array}{l}\text { Classification } \\
\text { k-nearest neighbors } \\
\text { Naïve Bayes } \\
\text { Classification trees } \\
\text { Logistic classification } \\
\text { Neural nets } \\
\text { Discriminant analysis }\end{array}$ & & \\
\hline & & $\begin{array}{l}\text { Time series forecasting } \\
\text { Progression-based } \\
\text { Smoothing methods }\end{array}$ & & \\
\hline & \multirow{2}{*}{ 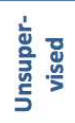 } & Association / Affinity & \multirow[b]{2}{*}{ Insight derivation } & \\
\hline & & $\begin{array}{l}\text { Segmentation } \\
\text { Cluster analysis }\end{array}$ & & \\
\hline
\end{tabular}

Figure 6.1: Data mining flow and steps. Data is collected, prepared in the right format, eventually previsualised and fit to right dimension. Based on objective, super- or unsupervised data mining method is selected and evaluated. Finally it can be applied to new data and used to display key performance indicators or to issue appropriate warnings.

First, the data is collected, prepared in the right format, eventually previsualised and fit to appropriate dimensions. Based on objective, super- or unsupervised data mining methods are selected and evaluated. Finally, the process is applied to new data and used to display key performance indicators (KPIs) or to issue appropriate warnings.

\subsection{Related work}

Data mining in healthcare has been applied in various settings to create DSSs, 12. especially applied to medical cases [21, despite patient privacy concerns 48. Research in support for long term care has been less popular but serves as interesting case for clustering due to its nature: it often concerns variability [15] 
among large data and automated support can be a benefit in analysing it. Clustering is an important unsupervised learning method for dividing data into a set of disjoint groups with high intra-cluster similarity and low inter-cluster similarity 43. Most clustering algorithms assume a single affinity matrix recording pairwise similarity between data. Possible improvements to this include increasing the amount of affinity matrices to be able to detect multiple useful features [37, automating the number of clusters to be found [23] (topic in this chapter) and coping with large-scale clustering using e.g. big data available from the web [16]. In relation to care, now Healthcare Information Systems have started to be adopted on large scale [5] after just being administrative support tools, and are now also being connected to actual patient measurements and status information [76, it becomes important to improve planning, to provide patient-specific care tailored to the patient's needs [25] and to support care efficiency using the available information in such systems. Also association analysis has found its way to healthcare to aid in finding unexpected patterns, e.g. in diabetes care 63 . This chapter focuses on how support care efficiency, thereby making use of automated data mining techniques to achieve that goal.

\subsection{Case study description}

Figure 6.2 shows the data flow architecture of the developed care system as described in Chapter 4. The system is fed with information about vital signs, medication, activities and interactions from either the database of the patient system or web services interfaces with third party services. This information is used to inform clients and caregivers.

As described in Chapter 4, the system has a set of adapters to connect to third party services via webservices (WSDL) technology. This way not only built-in service data can be used for knowledge extraction but data can also be collected from third party services.

Two examples are shown in Figure 4.7, the A\&D device of MobiHealth B.V.'s telemonitoring service, and the electronic medication dispenser, which enable classification of health measurements.

Figure 6.1 summarises these process steps steps from left to right, including relevant data mining techniques involved [13. Data is collected, prepared in the right format, eventually previsualised and fit to appropriate dimensions. Based on objective, super- or unsupervised data mining method is selected and evaluated. Finally it is applied to new data and used to display key performance indicators (KPIs) or to issue appropriate warnings.

\subsection{Methods}

To explain the data mining methods used, it is best to take a generated dataset and discuss the subsequent steps. First the dataset characteristics are described. Consecutively the data mining methods for clustering and regression 


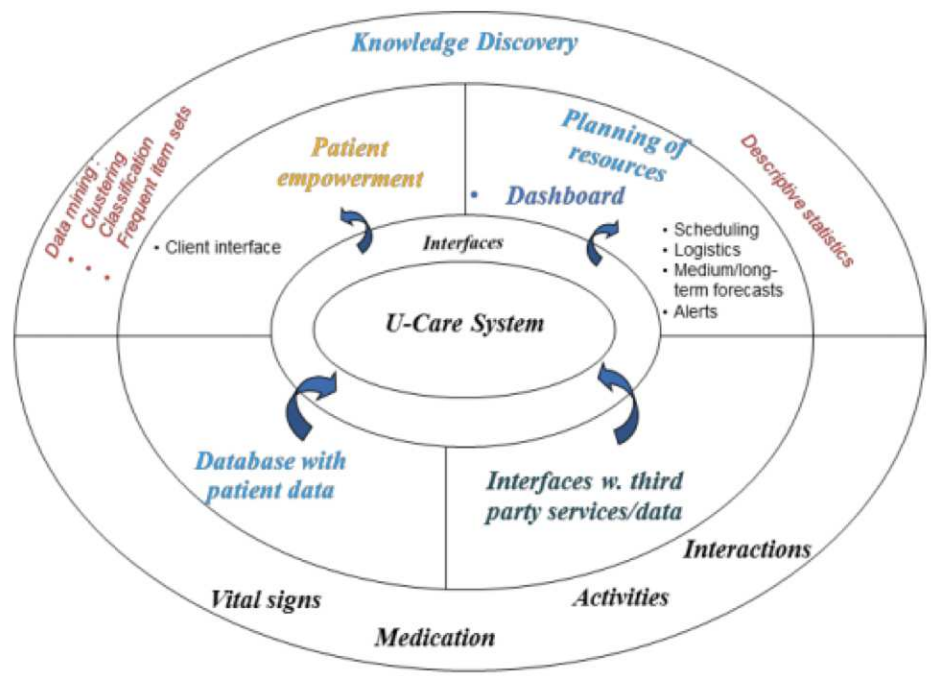

Figure 6.2: Data flow architecture. The system has interfaces to be fed with third party services and a database with patient data. They provide data related to medication, health measurements, activities and interactions. Using these sources, both patients and caregivers are informed based on data mining techniques described in this chapter.

purposes are covered, as corresponding to the formulated goals in section 6.1 .

\subsubsection{Dataset characteristics}

Let $a$ be a day $\in\{$ Monday,..., Sunday $\}$. Medication compliance is introduced as follows: the compliance $c(i, a)$ of patient $i$ on day $a \in\{0,1,2\}$, i.e. bad, improvable, or good compliance for that day. Boundaries for these ordinal values may be set in the system by the responsible caregiver per client. It is important to notice that we use ordinal values. Although this certainly limits the possible data mining methods, and we have to take the distance measure into account, we can now work with terms such as good compliance and bad compliance based on what caregivers define.

For the generated dataset, we introduced uniformly random behavior for Monday and Thursday and introduced the notation of 4 types of compliance bahaviors: average patients, good compliant patients, good-minus compliant patients, and weekend-minus compliant patients. For the 4 patient types, we varied weekend-data uniformly varied between 0,1 and 2 . The weekend days were hence instantiated orthogonal, i.e. for each patient $i$ type, all $c_{i, s a t} *$ $c_{i, \text { sun }}=9$ combinations are simulated. 


\subsubsection{Data Mining Steps}

This paragraph discusses the three data mining steps executed:

1. Clustering to find similarities within the medication data. Groups of patients with similar compliance are found in this way.

2. Regression to find the probability that new patient measurements fit in one of the found clusters. The goal is to enable prediction.

3. Association mining to find relations between input variables. This enables to find the most prominent associations in the compliance data, e.g. between the weekend days.

\subsubsection{Clustering}

Patient clustering using PCA has among others been proposed in 15. The principle of PCA is to compute the matrix $O$ which corresponds to the centred and reduced data from the matrix $O^{\prime}$ (obtained by subtracting the corresponding mean and by dividing by the corresponding standard deviation of each variable). Afterwards, we compute the correlation matrix $C$ from $O$ and compute its eigenvectors and the eigenvalues. From the first two eigenvectors we verify if there exists a linear correlation, i.e. the characteristics of the two first component diagram is that we observe parallel lines (visual analysis concerning the first two principal components) implying that the first two principal components have a high cumulative correlation in order to retain the maximum amount of information. Afterwards, we execute the partition algorithm based on the first two eigenvectors. We compute the $P_{i}$ coordinates of the first two components $\left(p_{i 1}, p_{i 2}\right)$ and we apply rotation and projection on the corresponding axis. Afterwards, we compute $d_{k}$, the Euclidian distance from each $q_{k}$ to its successor depending on the sorting and each bisector of the line segment corresponding to $n-1$ longest distances is the cutting between two clusters.

If there is no linear correlation between two first two variables, it is not possible to use this algorithm because we have to take into account more than the first two components. In this case, we have the same problem as with the kmeans approach. We have to correctly identify the kernels of each cluster, and PCA clustering becomes similar to k-means clustering 19. We try to explore it by using connected components or the k-medoids algorithm (a clustering algorithm related to the $\mathrm{k}$-means algorithm, dedicated to ordinal data).

Clustering based on coupling b-coloring of graphs [14, 33. and k-medoids [13] is executed to find patient clusters and extract knowledge on resources (e.g. medication intake supervision) planning. This method consists of bcoloring the most distant nodes in the vector space in order to estimate the number of clusters. Next, k-mediods is performed based on the number on the dominant colors in this graph. It gives better results than PCA- (Principle Component Analysis) based clustering if the data is more unrelated. In our case study the data is unrelated, so k-mediods better represents the actual patient 
measurements and hence patient performance. The inconvenient drawbacks 13. of $\mathrm{k}$-means and k-mediods (I: initialization-sensitivity, parameter setting affect outcome, II: possibility to converge to local optimum, III: desired number of clusters has to be given (supervised method)) are tackled by performing graph b-coloring first, in order to identify the number of clusters as input to $\mathrm{k}$-mediods. The method is discussed in the next section.

\subsubsection{Coupling of b-Coloring of Graphs and K-Mediods on All Variables}

If the data is relatively uncorrelated concerning all the variables, PCA clustering is not appropriate. Hence we use a new approach based on coupling b-coloring of graph and k-medoids algorithm. This approach has been proposed in [14].

The principle is the following. Graph coloring is a special case of graph labelling. The proper b-coloring problem 42 is an assignment of colors to the vertices of one graph with two conditions:

1. Adjacent vertices have different colors. This means there is a proper coloring of the graph;

2. There exists at least one vertex having its neighbouring vertices in all the other colors used. This vertex is called a dominating vertex.

From the dissimilarity or distance matrix, the complete graph $G=(V, E, w)$ is defined by:

- a finite set $V=\left\{v_{1}, \ldots, v_{n}\right\}$ of vertices with $\left|v_{i}\right|=n$ observations, $v_{i}$ corresponds to observation $o_{i}$;

- a finite set $E=\left\{e_{1}, \ldots, e_{m}\right\}$ of edges over $V \times V$;

- a weight function $w: E \rightarrow \mathbb{R}$ with $w\left(v_{i}, v_{i}\right)=D\left(o_{i}, o_{j}\right)$, the distance or dissimilarity between observations $i$ and $j$. We use the Euclidian distance as a distance metric for calculating the distance matrix.

Starting from $G$, the partial threshold graph $G^{\prime}$ corresponds to the graph associated with threshold value $s$, where:

$$
s=\min \left\{\max _{j}\left\{d_{i j}=D\left(o_{i}, o_{j}\right), i \neq j\right\}\right\}
$$

We remove all edges with weight $\geq$ threshold values $s$. Consequently, we obtain a filtered graph $G^{\prime}=\left(V, E_{\geq s}, w\right)$ called the threshold graph. We verify if this threshold graph is connected.

The proper coloring op the graph $G^{\prime}=\left(V, E_{\geq s}, w\right)$ consist of assigning colors to all vertices such that adjacent vertices have different colors. 
The coloring is called a b-coloring if for each color $C_{k}$ there is $\geq 1$ vertex $v_{i}$ in this color, having its neighbours in all different colors. This vertex is a dominating vertex.

The proposed algorithm aims to obtain a partition of the filtered graph $G^{\prime}$ into disjoint colors $C_{1}, \ldots, C_{k}$ that represent $k$ clusters. There are 2 parts: first, a proper coloring of $G^{\prime}$ is obtained. Then, $G^{\prime}$ is re-colored such that is becomes b-colored 42 .

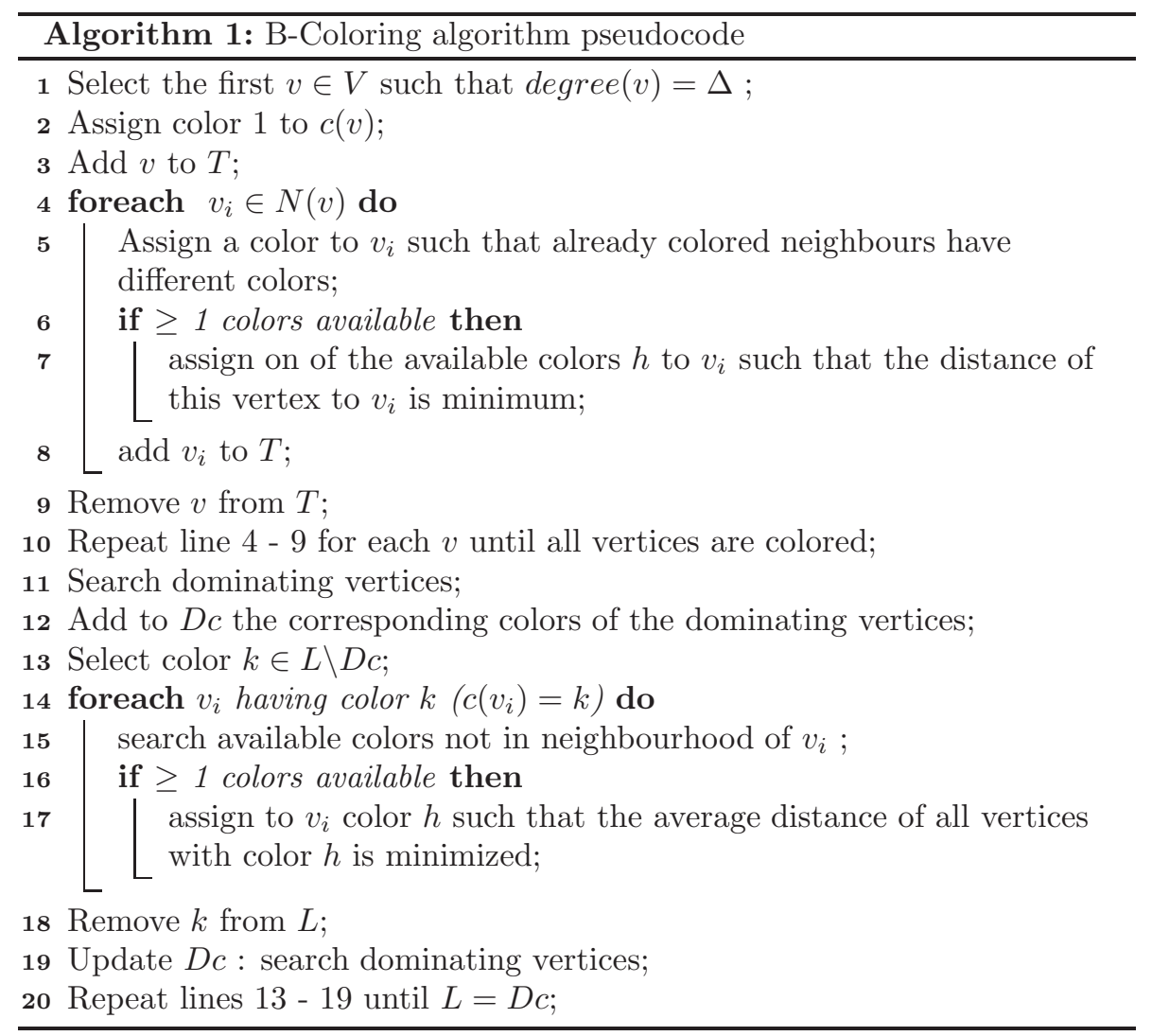

Next, we discuss the steps for the b-coloring algorithm that colors the partial threshold graph. First some definitions are given, which are used in the procedure "b-coloring algorithm pseudocode" shown hereafter.

- Let $\Delta$ be the maximum degree of $G^{\prime}$ obtained by the function degree $\left(v_{i}\right)$ which allows to calculate the degree of vertex $v_{i} \in V$.

- Let $c(v)$ be the color of vertex $v$ in graph $G^{\prime}$.

- For every $v, N(v)$ is the set of adjacent vertices to $v$.

- The set of colors of $N(v)$ is $N c(v)$. 
- $L$ is the color set used in the graph $G^{\prime}$ with $L=\{1,2, \ldots, \Delta+1\}$ corresponding to the color numbers.

- Let $D c$ be the set of dominating colors. A dominating color corresponds to the color of $\geq$ dominating vertex. Initially, $D c=\varnothing$.

- Let $T$ be an ordered set of vertices, sorted by decreasing degree. Initially, $T=\varnothing$.

The principle of the proposed algorithm based on b-coloring of graph is given in procedure "B-Coloring algorithm pseudocode".

When $L=D c,|L|$ gives the number of dominating colors and hence the number of clusters as input to $\mathrm{k}$-mediods. The $\mathrm{k}$-mediods pseudocode is given in algorithm "K-Medoids algorithm pseudocode".

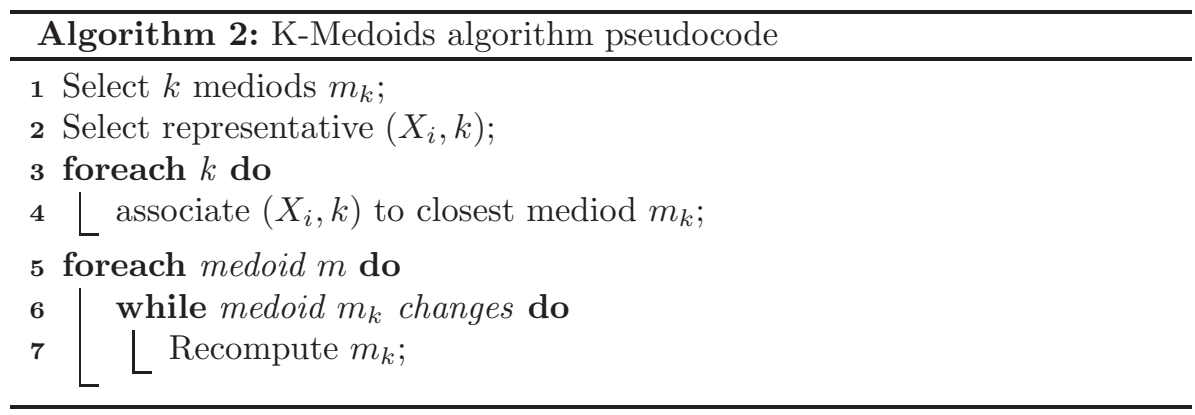

An example of the b-coloring based clustering approach is given in Appendix E.

\subsubsection{Logistic Regression}

Logistic regression models [51] enable to find probabilities for labelled class membership. As such, it predicts binary outcomes (as opposite to continuous output prediction in linear regression). In this case, the aim is to accurately find the probability that new patients fit in one of the clusters that have been discovered. So once the clustering is obtained, we can use logistic classification [61] to reveal the rules to match existing and new patients into the found clusters, and to find the most contributing variables. These contributions are given as a number of $\beta \mathrm{s}$ in the logit, the linear predictor function for a particular data point $i$ :

$$
\operatorname{logit}\left(p_{i}\right)=\beta_{0}+\beta_{1} x_{1, i}+\ldots+\beta_{n} x_{n, i}
$$

yields us the likelihood of a new instance of measured compliance values belonging to the found cluster and the contribution of each variable $x_{i}$ to the decision what the most suited cluster of a new instance is. 
We are able to predict the label $C_{i}$ of a set of observations $x_{1, i} \ldots x_{n, i}$ using the following formula:

$$
P\left[Y=C_{i} \mid x_{1}, \ldots, x_{n}\right]=\frac{1}{1+\exp \left(-\left(\beta_{0}+\sum_{i=1}^{n} \beta_{i} x_{i}\right)\right)}
$$

\subsubsection{Association Mining}

Finally, we performed frequent item-set analysis to find the most prominent associations in the compliance data. This way, it becomes clear if there are associations between certain (mis)compliance on days, e.g. throughout the weekend.

We used Tanagra to find association rules using the apriori algorithm . As the Apriori algorithm only works with Boolean values for each variable, we have to recodify the 3 -valued variable $c$ into 3 Boolean valued variables $c^{\prime}$, e.g. for $x$ being a day $a$ :

$$
\left\{c_{x}=2\right\} \equiv\left\{c_{x, 0}^{\prime}=0, c_{x, 1}^{\prime}=0, c_{x, 2}^{\prime}=1\right\}
$$

\subsection{Results}

As stated, we want to find the actual patterns hidden in the medication data. In the studied case, we find using PCA that only $52,6 \%$ of the variability is explained in the first two components. So there is no good linear correlation and PCA-based clustering does not yield valuable results. (In fact this is not surprising as 2 out of 7 variables are filled random, and 2 are orthogonal for all instances.) The results of the new method, consisting of b-coloring of graphs followed by K-Mediods, are discussed below. After that, the regression model and patterns found using frequent itemset analysis are shortly discussed.

The advantage of prepending the b-coloring procedure to $\mathrm{k}$-medoids is that we automatically obtain the number of clusters - it corresponds to the number of different colors of the dominating vertices. We can also identify the best representative object of each cluster regarding the vertices having the same color. That way, we optimize the choice of these medoids with respect to kmedoids choosing datapoints as centers. Moreover we obtain the number of clusters (this input number is necessary for the k-medoids algorithm) instead of trying manually. The approach is tested on the simulated data concerning medication. Table 6.1 shows the results of the clustering and a short description of each of the clusters found.

\subsubsection{Logistic Regression}

We used Weka 34 to search a classifier for all variables. The classifier is listed below. A maximum of 5 days is needed to predict the class so based on the training set it is possible to anticipate resources on expected compliance issues 
Table 6.1: Clustering of $126 * 4=504$ patient medication intake weeks. $\mathrm{N}=$ cluster size.

\begin{tabular}{cccr}
\hline Cluster & $\mathrm{N}$ & $\{$ Mo...Su $\}$ & Patient performance description \\
\hline 0 & 96 & $\{1,1,1,1,1,1,1\}$ & Average \\
1 & 47 & $\{2,2,2,2,2,2,2\}$ & Compliant \\
2 & 82 & $\{2,2,2,2,2,2,1\}$ & Compliant $\backslash$ Sunday \\
3 & 62 & $\{2,2,2,1,2,2,2\}$ & Compliant $\backslash$ Thursday \\
4 & 46 & $\{2,1,2,2,2,2,2\}$ & Compliant $\backslash$ Tuesday \\
5 & 60 & $\{1,2,2,2,2,2,2\}$ & Compliant $\backslash$ Monday \\
6 & 51 & $\{1,2,2,2,2,2,1\}$ & Compliant $\backslash$ Monday, Sunday \\
7 & 27 & $\{2,2,2,2,2,0,0\}$ & Weekend incompliant \\
8 & 33 & $\{2,2,2,0,2,1,1\}$ & Varying \\
\hline
\end{tabular}

likely to occur later in time (stratified 10x cross validation: 100\% accuracy). The confusion matrix belong to the found regression model is listed in Tabel 6.2

Class $0: 38.06+[T U E] *-2.5+[W E D] *-7.56+[T H U] *-1.75+[F R I] *$ $-8.86+[S A T] *-5.53$

Class $1:-34.85+[M O N] * 5.58+[T U E] * 2.5+[T H U] * 4.28+[S U N] * 6.95$

Class $2:-15.44+[M O N] * 6.71+[T H U] * 1.37+[S A T] * 2.31+[S U N] *-2.87$

Class $3:-10.73+[M O N] * 0.34+[T U E] * 0.41+[T H U] *-5.1+[S A T] *$ $0.7+[S U N] * 8.64$

Class $4:-11.33+[T U E] *-8.57+[T H U] * 6.11+[S U N] * 6.71$

Class $5:-16.27+[M O N] *-5.51+[T U E] * 0.85+[T H U] * 2.94+[S U N] * 8.84$

Class $6: 3.04+[M O N] *-4.72+[T H U] * 1.09+[S A T] * 1.7+[S U N] *-2.68$

Class $7: 4.35+[M O N] * 1.12+[T U E] * 1.35+[T H U] * 0.73+[S A T] *-14.46+$ $[S U N] *-1.1$

Class $8: 10.62+[M O N] * 1.34+[W E D] * 1.34+[T H U] *-9.41+[S A T] *$ $-4.21+[S U N] *-0.76$

\subsubsection{Pattern Finding}

Table 6.3 gives some examples of patterns found using the Tanagra software program. Using this algorithm, it is possible to find patterns among measured data and the significance of these patterns. 
Table 6.2: Confusion matrix

\begin{tabular}{cccccccccc}
\hline $\mathrm{a}$ & $\mathrm{b}$ & $\mathrm{c}$ & $\mathrm{d}$ & $\mathrm{e}$ & $\mathrm{f}$ & $\mathrm{g}$ & $\mathrm{h}$ & $\mathrm{i}$ & Classified as \\
\hline 96 & 0 & 0 & 0 & 0 & 0 & 0 & 0 & 0 & $\mathrm{a}=$ Class 0 \\
0 & 47 & 0 & 0 & 0 & 0 & 0 & 0 & 0 & $\mathrm{~b}=$ Class 1 \\
0 & 0 & 82 & 0 & 0 & 0 & 0 & 0 & 0 & $\mathrm{c}=$ Class 2 \\
0 & 0 & 0 & 62 & 0 & 0 & 0 & 0 & 0 & $\mathrm{~d}=$ Class 3 \\
0 & 0 & 0 & 0 & 46 & 0 & 0 & 0 & 0 & $\mathrm{e}=$ Class 4 \\
0 & 0 & 0 & 0 & 0 & 60 & 0 & 0 & 0 & $\mathrm{f}=$ Class 5 \\
0 & 0 & 0 & 0 & 0 & 0 & 51 & 0 & 0 & $\mathrm{~g}=$ Class 6 \\
0 & 0 & 0 & 0 & 0 & 0 & 0 & 27 & 0 & $\mathrm{~h}=$ Class 7 \\
0 & 0 & 0 & 0 & 0 & 0 & 0 & 0 & 33 & $\mathrm{i}=$ Class 8 \\
\hline
\end{tabular}

An example of frequent itemset analysis, showing the most evident pattern. These are the patterns found between intake compliance on Tuesday, Wednesday and Friday. For the caregivers, this algorithm is used to show the most significant patterns found.

The pattern shown in Table 6.3 are obtained using Apriori algorithm. The first two columns denote the association found, the support shows the rule's ratio of support count versus total number of items in the set. The lift is the ratio between the rule's confidence and the support of the itemset in the rule's consequent. The confidence is the support for rule divided by the support for the antecedent.

Table 6.3: Association rules found

\begin{tabular}{lllll}
\hline Antecedent & Consequent & Support & Lift & Confidence \\
\hline FRI $=$ true & WED = true & 0.952 & 0.976 & 0.976 \\
WED $=$ true & FRI = true & 0.952 & 0.976 & 0.976 \\
WED = true & TUE = true & 0.952 & 0.976 & 0.976 \\
TUE $=$ true & WED = true & 0.952 & 0.976 & 0.976 \\
FRI $=$ true & TUE $=$ true & 0.952 & 0.976 & 0.976 \\
TUE $=$ true & FRI = true & 0.952 & 0.976 & 0.976 \\
\hline
\end{tabular}

\subsubsection{Discussion}

From the simulated data of medication, we can find some interesting properties. Clearly there are some patients that need supervision every day: Cluster 0 (See Table 1) represents one fifth of the population. Cluster 1 in the simulated population does not need attention. Cluster 5 should be checked Mondays. Cluster 7 needs supervision in the weekend and cluster 3 needs supervision on Thursday. Using the regression model built, we see that is possible to 
anticipate of compliance problems that are, based on the training data, likely to occur later in time (as its possible to know the corresponding class). Of course in practice, new data should be added continuously to reinforce the classifier and the regression model and take into account changes in profile over longer time. In the studied case, we also investigated PCA and conducted a cluster visualisation on all the days in the week, seeing that the first two component explain $52,6 \%$ of correlation. So there is not a good linear correlation and PCA-based clustering does not yield us valuable results. In fact, it is not surprising as 2 days in the dataset are filled random, and the 2 weekend-days are orthogonal for all instances. As the tools used can be integrated in a service oriented architecture (SOA) environment such as Java 2 Enterprise Edition, it is possible to chain the presented data mining actions. In that way, the results can be displayed to the end users in the home care system in a web-based realtime monitoring tool.

\subsection{Validation}

We compared simulation data with data recorded from real patients from AGGIR, (Autonomy-Gerontology-Group- Iso-Resources) a French codification system to assess patients health status in nursing homes. We performed the same cluster analysis using this data (discussed in the next sections). Additionally we tried to compare medication data, which was not possible as $99 \%$ of the patients in the AGGIR database were given medication, and therefore there was no distribution among this variable. This is explained in the following 2 sections.

\subsubsection{Case 2: comparison study}

Long-term care is needed in patient suffering from chronic illness or disability. These conditions lead to a need for assistance in Activities of Daily Living, such as help for washing, dressing, using the toilet, eating, transferring, etc.

Dependence evaluation in France is carried out using a specific scale called the AGGIR scale. Figure 1 presents the AGGIR scale. It is a scale which is based on a set of items in order to determine the autonomy-disability for each individual in Activities of Daily Living. In nursing homes, only the first eight items are observed: (1) Coherence, (2) Orientation, (3) Washing, (4) Dressing, (5) Food, (6) Toilet, (7) Transferring, (8) Moving. It is shown in Figure 6.3.

The evaluations are made by the resident doctor in collaboration with the nursing staff. An item can be evaluated using one or more of the four adverbs:

1. Spontaneously;

2. Usually;

3. Entirely; 


\section{Correctly.}

The codification is the following (see Figure 6.3):

- If no adverbs are applicable, the code is A;

- If $>0$ adverbs are applicable, the code is B;

- If all adverbs are applicable, the code is $\mathrm{C}$.

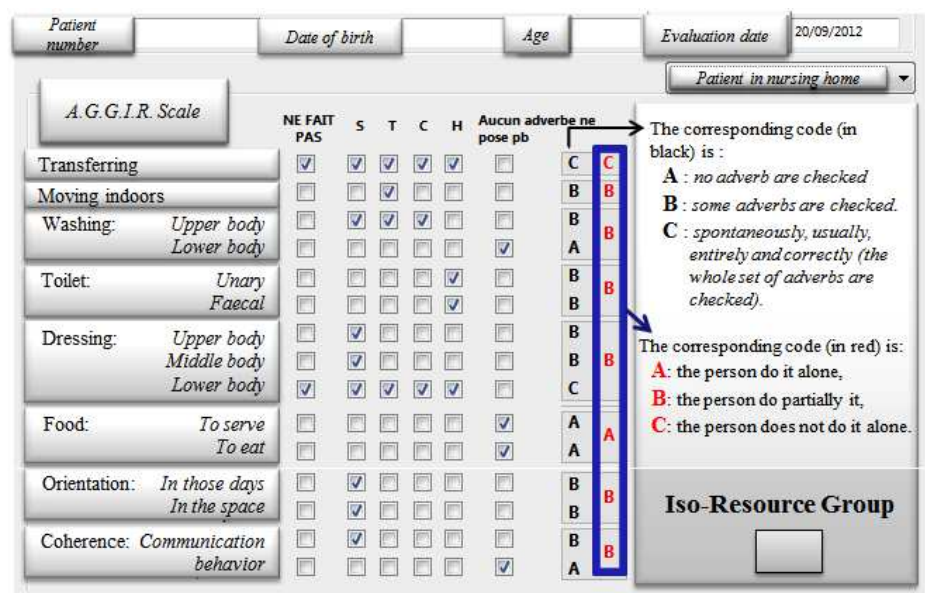

Figure 6.3: Patient dependence evaluation using AGGIR.

The aim of this second case study is to find feature-patterns related to the autonomy- disability level of elderly people from the data clustering: a common technique for data analysis.

\subsubsection{Experiment}

The aim of the study is, again, to identify differences between feature-patterns related to the autonomy-disability level of elderly people in the different clusters obtained from residents suffering from dementia syndromes (2211 observations) related to cognitive problems and to apraxia. The same method (b-coloration of graphs and k-medoids) as described above is used on these data, which is again codified in 0, 1, 2 (corresponding to the scoring of resp. A, B, C).

Clustering is performed on residents living in nursing homes. The results are shown in table 6.4, revealing that this method succeeds in clustering in real life cases [15]. 


\subsection{Conclusions and future work}

\subsubsection{Conclusion}

We showed that different data mining techniques can be used beneficially in the analysis, classification, prediction and association of patient information using data mining on nursing home data.

The system that acquires this information was discussed in Chapter 4.

We simulated 126 patients using this system regarding their medication compliance. On this simulation, we performed clustering, model-making and pattern finding. The clustering clearly indicates patient classes with patients that need extra supervision on certain days. A regression model was constructed to categorise new compliance information as it becomes available. Finally, we demonstrated that patterns can be found in this data using frequent item set mining.

The novel clustering method that was utilised in the simulation was validated with a second case, consisting of the AGGIR data from a French nursing home. Given the presented care system and the data mining methods that have been presented, it is possible to present the clustering, prediction and pattern finding results in an intelligent web environment, such as an online web based monitoring tool. In this way, it supports caregivers and care management in their decision making and efficient resource allocation. Hence this chaper has demonstrated how to increase care efficiency and resource planning by using already available healthcare data in an intelligent way.

\subsubsection{Future work}

This chapter has shown how data mining based decision support systems advances healthcare systems. Three issues are interesting to proceed in advancing this direction: a practical one, and two research issues.

Firstly, real data should be gathered from multiple patients to implement the proposed system, using this approach beyond solely medication compliance measures. In analysing the data, different dissimilarity measures should be tested to see which gives best clustering results.

Secondly, this data should be used for longitudinal monitoring. For this, the proposed dashboard needs to be tested and it should include the regression model and best suggestions based on a fine-tuned Frequent Item-Set Mining to show suggestions to the caregiver based on the client performance. The Apriori algorithm is useful to find the frequent item sets on these measured variables in the system. It is interesting to retrieve frequently occurring relations among the different health parameters. A selection is then to be displayed in the proposed dashboard.

Thirdly, on a longer timescale, we can theoretically predict if patients will move to a different class using a Markov Modelling approach. This should result in suggestions for caregivers on what to do in these cases. 
Table 6.4: Clustering of 2211 patient profiles. $N=$ cluster size.

\begin{tabular}{|c|c|c|}
\hline Cluster & $\mathrm{N}$ & $\begin{array}{l}\text { \{ coherence, orientation, toilet, habillage, } \\
\text { alimentation, elimination, transfer, moving }\}\end{array}$ \\
\hline 0 & 287 & $\{2,2,2,2,2,2,2,2$ \\
\hline 1 & 33 & $1,1,2,2,2,2,2,2$ \\
\hline 2 & 79 & $\{1,0,1,1,0,0,0,0$ \\
\hline 3 & 131 & $\{0,0,0,0,0,0,0,0$ \\
\hline 4 & 179 & $\{2,2,2,2,1,2,2,2$ \\
\hline 5 & 66 & $\{2,2,2,2,1,2,0,1\}$ \\
\hline 6 & 60 & $\{1,0,1,1,0,0,1,1\}$ \\
\hline 7 & 95 & $\{0,0,2,2,1,2,2,2\}$ \\
\hline 8 & 43 & $\{2,2,2,2,1,2,2,1\}$ \\
\hline 9 & 110 & $\{1,1,2,2,1,2,2,2$ \\
\hline 10 & 133 & $\{1,1,1,1,0,0,0,0$ \\
\hline 11 & 65 & $1,0,0,0,0,0,0,0$ \\
\hline 12 & 63 & $\{1,1,1,1,0,2,0,0\}$ \\
\hline 13 & 72 & $1,1,2,2,1,2,1,1\}$ \\
\hline 14 & 81 & $\{2,2,1,1,1,1,0,1\}$ \\
\hline 15 & 58 & $\{2,2,1,0,0,0,0,0$ \\
\hline 16 & 61 & $\{2,2,2,2,1,2,0,0\}$ \\
\hline 17 & 17 & $\{2,2,2,2,1,2,1,1\}$ \\
\hline 18 & 100 & $\{0,0,1,1,0,0,0,0\}$ \\
\hline 19 & 34 & $\{2,2,2,2,2,2,1,1\}$ \\
\hline 20 & 83 & $\{1,1,1,1,1,2,1,1\}$ \\
\hline 21 & 60 & $\{1,1,1,0,0,0,0,0\}$ \\
\hline 22 & 67 & $\{2,2,1,1,1,0,0,1\}$ \\
\hline 23 & 78 & $\{0,0,1,0,0,0,0,0\}$ \\
\hline 24 & 30 & $\{2,2,2,2,2,2,2,1\}$ \\
\hline 25 & 45 & $\{1,0,1,0,0,0,0,0\}$ \\
\hline 26 & 81 & $\{0,0,1,1,1,2,2,1\}$ \\
\hline
\end{tabular}




\section{Chapter 7}

\section{Conclusions and Directions for Further Research}

This chapter first summarises the conclusions we draw from the research described in this thesis. Then, the general contributions of this research are described. Finally, some directions for further research are suggested.

\subsection{Conclusions}

The user-tailored e-health services platform that is described in this thesis, enables integration and personalisation of care services from multiple vendors and technological origins. The data used and collected within the platform is an important enabler for patient modelling and decision support. Adequate personalisation of selected care services saves time, can empower clients and make them aware of their health situation, and facilitates communication between caregivers, caretakers and family.

\subsection{Reflection on the Research Questions}

Section 1.2 presented the research questions for this study. We will revisit them one by one.

1. How to adequately elicit requirements from the different stakeholders involved in such a system?

In Chapter 2, a user-based requirements engineering process has been described that involves end-users in the requirements elicitation process. Requirements elicitation for e-health services should involve end-users in all design phases to gather the requirements in an adequate way. End users were involved using interviews, workshops, visualisation-supported demonstrations and discussions. When the system was implemented, it 
was again discussed with stakeholders. Finally, requirements elicited were mapped to the implemented functions and components using a traceability table (Section 4.5).

2. How to effectively gather comments and critique from stakeholders on the platform in an early stage of the design process?

This question was studied in Chapter 3 Interactive scenario visualisation (ISV) is proposed to create visualisations of concrete usage scenarios. This was done using state-of-art software that enables quick creation of visualisations. An evaluation showed that scenario visualisation aids in the design process. ISV helps to clarify to-be-designed care systems, aids in gathering feedback and gives insight into proposed functionalities.

Scenario-based design is also part of the framework that sequences userbased design, PACT and FICS analyses, and UML-based design of MVC service components into one methodology. This framework couples user need assessment to the development of web-based systems. Indeed, webbased systems are nowadays often built using MVC frameworks (e.g. Ruby-on-Rails and JSF).

\section{To what extent are service oriented techniques beneficial to de-} velop this platform?

Architectural principles like SOA (Service Oriented Architecture) enable flexible web-based system designs that offer services in a loosely coupled, reconfigurable manner. Services are abstracted on levels of organisational processes, application level functionalities, and technologies that support these services. From a communication point of view, specific attention is necessary for request/response and publish/subscribe based messaging in such environments. Often, an ESB (Enterprise Service Bus) is used to provide an infrastructure for push- or request based services communication.

SOA is increasingly popular among enterprises. In the care sector, the combination of loosely coupled services and the ability to publish and subscribe to ad-hoc events (e.g. in the case of alarms) is promising but still needs to be adopted on a larger scale. The platform described in Chapter 4 of this thesis nevertheless, shows that these loose coupling, service tailoring and publishing of notifications are relevant and technologically possible using SOA.

\section{Is the system usable in daily care and is it effective?}

In Chapter 5, we systematically evaluated the system using two-phased trial approach from an end user and a technology perspective. The system is usable in daily care. The largest gains occur, when the system is tailored by caregivers to support daily care processes. These services include medication dispense and compliance monitoring, and telemonitoring of vital signs. For social interaction, the system is not usable 
for all users involved, because operating the devices can be too complex to learn and perform.

Dependent on how the system is tailored, the monitoring and escalation path provide added value for caregivers. The caregivers were relatively satisfied with the user-friendliness of the system; they were able to use the system. Some of the care receivers were unsatisfied with the system as they found it difficult to operate, and did not have the motivation to learn using the devices. Other care receivers were more satisfied with the increase in self-management and possibilities the system provided.

In sum, the health monitoring and medication services seem effective. The social interaction and activity services seem not very effective at this moment. Nevertheless, the functionalities are partly necessary for other services, such as the health monitoring and medication services.

\section{How to leverage the data used in such a system to model patient behaviour and to provide decision support?}

Chapter [6] described how the data within the system can be used for monitoring, data analysis and decision support. To this end, a module based on data mining approaches has been developed. We showed that different data mining techniques can be used beneficially in the analysis, classification, prediction and association of patient information.

For data mining being able to work in practice, a lot of data is necessary. Actual data was not available from the context of the U-Care project. Hence, the validation of this module has been performed using simulations and using data available from French nursing homes. We showed that, given the presented e-health system and the data mining methods, it is possible to support caregivers and care management in their decision making and in resource allocation.

\subsection{Research Contributions}

This research has contributed in both applied and fundamental areas of the development of healthcare technologies.

The practical contribution is the realisation (Chapter 4) and evaluation (Chapter 5) of a care services platform that integrates services from different vendor and can be tailored by caregivers to fit individual care receiver needs. Moreover, the research shows that SOA is beneficial to achieve this goal.

The fundamental contribution of the research is twofold:

In the first place, we have conducted and presented research on methodological aspects of requirements elicitation (Chapter 2) and service design (Chapter 3). A framework is proposed which sequences user-based design involving scenarios, PACT and FICs analyses, and UML-based design of MVC service components into one methodology. The contribution of this PACT- 
FICS-MVC approach is a user-based design process usable in web-based and SOA-based systems.

In the second place, it has been shown in this thesis, that healthcare middleware platforms integrating multiple services, benefit from data mining based decision support. To this end, medication compliance classification has been implemented and novel data mining methods have been researched and discussed in Chapter [6] Data mining methods have been evaluated using both the e-health services platform and using nursing home data available from the French AGGIR database.

\subsection{Directions for Further Research}

The platform described in this thesis can be furthered into different directions. This section discusses some of the research challenges and opportunities.

- The current platform enables user tailoring of a set of care service plans related to activities, interaction, medication management and vital sign monitoring. It involves third party services for text-based messaging, VoIP, medication services and telemonitoring. It would be very interesting to develop a solution that enables the realisation of user-defined templates for new service plans. Using such a service, new service plan templates can be created by trained key users, that enable caregivers to tailor the service plans for their care receivers. Especially when key users create such templates, validity checking is a key issue.

- The number of pluggable services could also be increased, to make it applicable on wider scale. This would involve extending the number of actual wrappers in the wrapper component of the platform. Also, access to the platform by professionals or family to view information can be developed. Again, this should be validated in a different real life testbed. The platform API itself can be enhanced using those validation results. This is a step important to create a configurable, multi-user and usertailored services platform. Making it open source is a logical next step to foster adoption.

- The decision support component in the system enables analysis of multiple sources. In this research, it has been demonstrated for medication classification purposes, for user-specific escalation paths, and for patient profile modelling and clustering. Using the methods described in chapter 4 and 6. a generic web-based framework can be established to enable tailored decision support based on case-relevant measurement data.

- The escalation path processes currently require a heavyweight, commercial, stand-alone reasoning engine. It would be better to replace it by a lightweight and web-based runtime reasoning component. It should be able to reason the escalation path for events based on the actual service plans. 
- The framework for user-based service design has been used, and is currently being used, in different research projects. Meta analysis and extension to model-driven engineering is a challenging next step. It benefits from using behaviour-driven development techniques. When this framework can successfully be extended to the implementation (and testing) phases, it will lead to much more agile creation, reconfiguration and adoption of adequate e-health services. 


\section{Bibliography}

[1] Ian Alexander and Neil Maiden. Scenarios, stories, use cases : through the systems development life-cycle. Wiley, 2004.

[2] Alice. http://www.alice.org, January 2013.

[3] D. Benyon and C. Macaulay. Scenarios and the HCI-SE design problem. Interacting with computers, 14(4):397-405, 2002.

[4] M. Berg. Patient care information systems and health care work: a sociotechnical approach. International Journal of Medical Informatics, 55(2):87-101, 1999.

[5] M. Berg. Implementing information systems in health care organizations: myths and challenges. International Journal of Medical Informatics, 64:143-156, 2001.

[6] M. Bishop. Introduction to computer security. Addison-Wesley Professional, 2004.

[7] ICF Research Branch. Icf core sets project, 2012.

[8] Tom H.F. Broens, Rianne M.H.A. Huis in 't Veld, Miriam M.R. Vollenbroek-Hutten, Hermie J. Hermens, Aart Halteren van, and Lambert J.M. Nieuwenhuis. Determinants of successful telemedicine implementations: a literature study. Journal of Telemedicine and Telecare, 13(6):303-309, September 2007.

[9] J.M. Carroll. The Scenario Perspective on System Development. In: Scenario-Based Design: Envisioning Work and Technology in System Development. John Wiley \& Sons, 1995.

[10] J.M. Carroll. Five reasons for scenario-based design. Interacting with Computers, 13:43-60, 2000.

[11] Eveline Castelijns, Annick van Kollenburg, and Wine te Meerman. De Vergrijzing Voorbij. Stichting Fundatie Berenschot, 2013. 
[12] Young M Chae, Hye S Kim, Kwan C Tark, Hyun J Park, and Seung H Ho. Analysis of healthcare quality indicator using data mining and decision support system. Expert Systems with Applications, 24(2):167 - 172, 2003. Intelligent Electronic Commerce.

[13] Krzysztof J. Cios, Witold Pedrycz, Roman Swiniarski, and Roman Swiniarski. Data mining methods for knowledge discovery. Springer, 2008.

[14] C. Combes and J. Azema. Graph based clustering with b-coloring to identify the number of clusters. Technical report, University of Jean Monnet Saint-Etienne, 2012.

[15] Catherine Combes and Jean Azema. Clustering using principal component analysis applied to autonomydisability of elderly people. Decision Support Systems, 1(0):-, 2012.

[16] R. Cooley, B. Mobasher, and J. Srivastava. Web mining: information and pattern discovery on the world wide web. In Tools with Artificial Intelligence, 199\%. Proceedings., Ninth IEEE International Conference on, pages $558-567$, nov 1997.

[17] A. Cooper. The Inmates Are Running the Asylum Why High-Tech Products Drive Us Crazy and How to Restore the Sanity. Sams Publishing, Indianapolis, USA., 2004.

[18] J. Corbin and A. Strauss. Grounded theory research: Procedures, canons, and evaluative criteria. Qualitative Sociology, 13(1):3-21, 1990.

[19] Chris Ding and Xiaofeng He. K-means clustering via principal component analysis. Proc. of Int'l Conf. Machine Learning (ICML 2004), pages 233$240,2004$.

[20] D. Dohmen. De e van e-Health Juiste energie voor optimale implementatie van moderne technologie in de zorg thuis. $\mathrm{PhD}$ thesis, Universiteit Twente, 2013.

[21] L. Duan, W. N. Street, and E. Xu. Healthcare information systems: data mining methods in the creation of a clinical recommender system. Enterprise Information Systems, 5(2):169-181, 2011.

[22] Schippers E.I. and Veldhuijzen van Zandten M.L.L.E. Brief aan de tweede kamer der staten generaal. In Arbeidsmarktbrief, 2011.

[23] H. Elghazel, V. Deslandres, M.S. Hacid, A. Dussauchoy, and H. Kheddouci. A new clustering approach for symbolic data and its validation: Application to the healthcare data. proceedings of 16th International Symposium on Methodologies for Intelligent Systems (ISMIS 2006), pages 473482, 2006. 
[24] E. Jendrock et al. The java ee 6 tutorial. Technical report, Oracle Corp., 2012 .

[25] N. Genet et al. Home care in europe: a systematic literature review. BMC Health Services Research, 11:207, 2011.

[26] Peter Paul Borg et al. Active ageing and solidarity between generations. A statistical portrait of the European Union 2012. Eurostat, 2011.

[27] P.T. Eugster, P.A. Felber, R. Guerraoui, and A. Kermarrec. The many faces of publish/subscribe. ACM Computing Surveys, 35(2):114-131, 2003.

[28] G. Eysenbach. What is e-health? Journal of Medical Internet Research, $18(3): 2,2001$.

[29] G. Eysenbach, J. Powell, M. Englesakis, C. Rizo, and A. Stern. Health related virtual communities and electronic support groups: systematic review of the effects of online peer to peer interactions. British Medical Journal, 328:11-66, 2004.

[30] E. Gamma, R. Helm, R. Johnson, and J. Vlissides. Design patterns: Elements of reusable object-oriented software. Addison-Wesley, USA, ISBN 0-201-63361-2., 1994.

[31] Konstantinos Giannakouris. Population and social conditions. ageing characterises the demographic perspectivesof the european societies. Eurostat, 72,2008 .

[32] B.G. Glaser and A.L. Strauss. The discovery of grounded theory: Strategies for qualitative research. Aldine, Chicago, 1967.

[33] K. Benabdeslem H. Elghazel and A. Dussauchoy. Constrained graph bcoloring based clustering. Proceedings of the 9th International Conference on Data Warehousing and Knowledge Discovery (DAWAK 2007), LNCS Nr 4654:262-271, 2007.

[34] Mark Hall, Eibe Frank, Geoffrey Holmes, Bernhard Pfahringer, Peter Reutemann, and Ian H. Witten. The weka data mining software: an update. SIGKDD Explor. Newsl., 11(1):10-18, November 2009.

[35] M. Hettinga. Understanding evolutionary use of groupware. PhD thesis, Telematica Instituut Fundamental Research Series, vol. 007. Enschede, the Netherlands: Telematica Instituut, 2002, 2002.

[36] P. Hsia, J. Samuel, J. Gao, D. Kung, Y. Toyoshima, and C. Chen. Formal approach to scenario analysis. IEEE Software, 11(2):33-41, 1994.

[37] Chu-Song Chen Hsin-Chien Huang, Yung-Yu Chuang. Multiple kernel fuzzy clustering. IEEE TFS, 1:1-15, 2012. 
[38] M. H. A. Huis in 't Veld, I. A. Widya, R. G. A. Bults, L. Sandsjo, H. J. Hermens, and M. M. R. Vollenbroek-Hutten. A scenario guideline for designing new teletreatments: a multidisciplinary approach. Journal of telemedicine and telecare, 16(6):302-307, 2010.

[39] IANA. https://www.iana.org/assignments/uri-schemes.html, 20132.

[40] IceSoft AJAX Push Framework. http://www.icesoft.org/java/projects/ICE faces/ajax-push.jsf, September 2012.

[41] R. Ichikari, K. Kawano, A. Kimura, F. Shibata, and H. Tamura. Mixed reality pre-visualization and camera-work authoring in filmmaking. In Mixed and Augmented Reality, 2006. ISMAR 2006. IEEE/ACM International Symposium on, pages 239 -240, oct. 2006.

[42] W. Irving and D.F. Manlove. The b-chromatic number of a graph. Discrete Applied Mathematics, 91:127-141, 1999.

[43] Anil K. Jain. Data clustering: 50 years beyond k-means. Pattern Recognition Letters, 31(8):651 - 666, 2010. Award winning papers from the 19th International Conference on Pattern Recognition (ICPR).

[44] M. Jarke. Scenarios for modelling. Communications of the ACM, 42:47-48, 1999.

[45] K. Shelley J.M. Taekman. Virtual environments in healthcare: Immersion, disruption, and flow. International anesthesiology clinics [0020-5907], 48(3):101-120, 2010.

[46] H. Kaindl. A design process based on a model combining scenarios with goals and functions. IEEE Transactions on Systems, Man and Cybernetics, 30(5):537-551, 2000.

[47] S. Kripalani and R. B. Haynes. Interventions to enhance medication adherence in chronic medical conditions: A systematic review. Archives of Internal Medicine, 167(6):540-549, 2007.

[48] Krzysztof, Cios, and Moore. Uniqueness of medical data mining. Artificial intelligence in medicine, 26:1-24, 2002.

[49] O. Kulyk, R. Kosara, J. Urquiza, and I. Wassink. Human-Centered Aspects. In Human-Centered Visualization Environments. Springer Verlag, Berlin, ISSN 0302-9743, ISBN 978-3-540-71948-9, 2007.

[50] G. Lafortune and G. Balestat. Trends in severe disability among elderly people: Assessing the evidence in 12 oecd countries and the future implications. Report of Directorate For Employment, Labour And Social Affairs Health Committee, 2007. 
[51] Niels Landwehr, Mark Hall, and Eibe Frank. Logistic model trees. In $M a-$ chine Learning: ECML 2003, volume 2837 of Lecture Notes in Computer Science, pages 241-252. Springer Berlin Heidelberg, 2003.

[52] J.R. Lewis. Ibm computer usability satisfaction questionnaires: Psychometric evaluation and instructions for use. International Journal of Human-Computer Interaction, 7:57-78, 1995.

[53] P.D.Gray M.R. McGee-Lennon. Including stakeholders in the design of homecare systems: Identification and categorisation of complex user requirements. In Proceedings of the INCLUDE Conference, 2007.

[54] I. Mulder, Y. Schikhof, M. Vastenburg, A. Card, T. Dunn, A. Komninos, M. McGee-Lennon, M. Santcroos, G. Tiotto, M. van Gils, J. W. J. R. van 't Klooster, A. Veys, and M. Zarifi Eslami. Designing with care: The future of pervasive healthcare. Pervasive Computing, 8(4):85-88, October 2009 .

[55] International Standards Organisation. ISO/IEC 25010:2011. systems and software engineering - systems and software quality requirements and evaluation (square) - system and software quality models. Technical report, http://www.iso.org/iso/iso_catalogue/catalogue_tc/catalogue_detail.htm? csnumber $=35733,2010$.

[56] Cesare Pautasso, Olaf Zimmermann, and Frank Leymann. Restful web services vs. "big" web services: making the right architectural decision. In Proceedings of the 17th international conference on World Wide Web, WWW '08, pages 805-814, New York, NY, USA, 2008. ACM.

[57] P. Pawar, J. Subercaze, P. Maret, B. J. Van Beijnum, and D. Konstantas. Towards business model and technical platform for the service oriented context-aware mobile virtual communities. In IEEE 13th Symposium on Computers and Communications, 2008.

[58] J. Pruitt and J. Grudin. Personas: practice and theory. In Proceedings of the 2003 conference on Designing for User Experiences. ACM, New York, 2003.

[59] T.M.H. Reenskaug. Thing-model-view-editor. an example from a planningsystem. Technical report, Xerox PARC, 1979.

[60] S. Robertson. Scenarios, Stories, Use Cases: Through the Systems Development Life Cycle, chapter Scenarios in Requirements Discovery, pages 39-59. Wiley, Chichester, 2004.

[61] L. Rouviere. Regression sur variables categorielles. Technical report, University of Rennes 2, 2008.

[62] Marieke Scholten. The user-centred design of a social communication system for the elderly. Master's thesis, University of Twente, 2010. 
[63] S. Stilou, N. Maglaveras, and C. Pappas. Mining association rules from clinical databases: An intelligent diagnostic process in healthcare. Studies in Health Technology and Informatics, pages 1399-1403, 2001.

[64] A. Stucki, T. Stoll, A. Cieza, M. Weigl, A. Giardini, D. Wever, N. Kostanjsek, and G. Stucki. Icf core sets for obstructive pulmonary diseases. Journal of Rehabilitation Medicine, 36(4):114-120, 2004.

[65] A. Sutcliffe. Scenario-based requirements engineering. In Requirements Engineering Conference, 2003. Proceedings. 11th IEEE International, pages $320-329$, sept. 2003.

[66] Pang-Ning Tan, Michael Steinback, and Vipin Kumar. Introduction to Data Mining. Pearson Education, 2006.

[67] Hseyin Tanriverdi and C. Suzanne Iacono. Diffusion of telemedicine: A knowledge barrier perspective. Telemedicine Journal, 5:223-244, 1999.

[68] Unity3D. http://www.unity3d.com, January 2013.

[69] J. W. J. R. van 't Klooster, C. Combes, and B. J. F. van Beijnum. Towards decision support for a homecare services platform. In Proceedings of the 4th International Workshop on Web Intelligence 8 Communities, Lyon, France, pages 48-54, New York, April 2012. ACM.

[70] J. W. J. R. van 't Klooster, C. Combes, B. J. F. van Beijnum, and H.J. Hermens. Decision support in nursing home care services using b-coloring of graphs, k-medoids based clustering and logistic regression. Int. J. Web Intelligence and Agent Systems, 2013. Submitted.

[71] J. W. J. R. van 't Klooster, P. Pawar, B. J. F. van Beijnum, C. B. Dulawan, and H. J. Hermens. Perspectives on the viable mobile virtual community for telemedicine. In Encyclopedia of E-Business Development and Management in the Global Economy, Advances in E-Business Research (AEBR) Book Series, pages 824-835. IGI Global, Hershey, USA, 2010.

[72] J. W. J. R. van 't Klooster, B. J. F. van Beijnum, A. P. W. Eliëns, and H. J. Hermens. Interactive scenario visualization for user-based service development. In Proceedings of the 2012 International Conference on Collaboration Technologies and Systems (CTS 2012), Denver, USA, pages 498-503, USA, May 2012. IEEE Computer Society.

[73] J. W. J. R. van 't Klooster, B. J. F. van Beijnum, and H. J. Hermens. Ucare: Requirements elicitation for ambient assisted living. In Proceedings of the IEEE-EMBS Benelux Chapter Symposium, Enschede, pages 127127, Enschede, November 2009. MIRA, University of Twente.

[74] J. W. J. R. van 't Klooster, B. J. F. van Beijnum, and H. J. Hermens. Experiences in testing personalized care systems in nursing home. Proceedings - BME 2013, 2013. 
[75] J. W. J. R. van 't Klooster, B. J. F. van Beijnum, and H. J. Hermens. Testing user-tailored e-health services: Results and lessons learned. In Proceedings of the IADIS International Conference on e-Health 2013, 24 26 July, Prague, Czech Republic, 2013.

[76] J. W. J. R. van 't Klooster, B. J. F. van Beijnum, P. Pawar, K. Sikkel, L. O. Meertens, and H. J. Hermens. Virtual communities for elderly healthcare: User-based requirements elicitation. International Journal of Networked 83 Virtual Organizations, 9(3):214-232, October 2011.

[77] Viswanath Venkatesh, Michael G. Morris, Gordon B. Davis, and Fred D. Davis. User acceptance of information technology: Toward a unified view. MIS Quarterly, 27(3):pp. 425-478, 2003.

[78] WHO. International classification of functioning, disability and health. Technical report, World Health Organization, 2001.

[79] WHO. Icd: International statistical classification of diseases, 10th revision. Technical report, World Health Organization, 2004.

[80] I. A. Widya, R. G. A. Bults, B. J. F. van Beijnum, L. Sandsjö, L. Schaake, M. H. A. Huis in 't Veld, V. M. Jones, and H. J. Hermens. Requirements elicitation in a telemedicine pain-treatment trial. In K. Ryan and W. Robinson, editors, 17th IEEE International Requirements Engineering Conference, Atlanta, GA, USA, pages 309-314, Los Alamitos, 2009. IEEE Computer Society.

[81] A. Zarghami, M. Zarifi Eslami, B. Sapkota, and M.J. van Sinderen. Dynamic homecare service provisioning architecture. In IEEE International Conference on ServiceOriented Computing and Applications (SOCA 2011), 12-14 Dec 2011, Irvine, USA. pp. 213-220. IEEE Computer Society. ISBN 978-1-4673-0319-4, 2011.

[82] M. Zarifi Eslami. Service Tailoring: A Method and Tool for User-centric Creation of Integrated IT-based Homecare Services to Support Independent Living of Elderly. PhD thesis, University of Twente, 2013.

[83] E. Zudilova-Seinstra, T. Adriaanse, and R. van Liere. Trends in interactive visualization : state-of-the-art survey. Springer London Ltd., 2008. 


\section{Appendix A}

\section{Graphical designs end-user interface}

This Appendix presents the different graphical user interface designs that have been developed and tested in focus groups.

The upper 4 designs in Figure A.1 are the different designs tested during a mockup development phase 62. They have been presented to a focus group of elderly users in a nursing home. The left lower 'combination' version is the prototype version, based on that selection. The right lower version is the implemented version based on the prototyped version. 

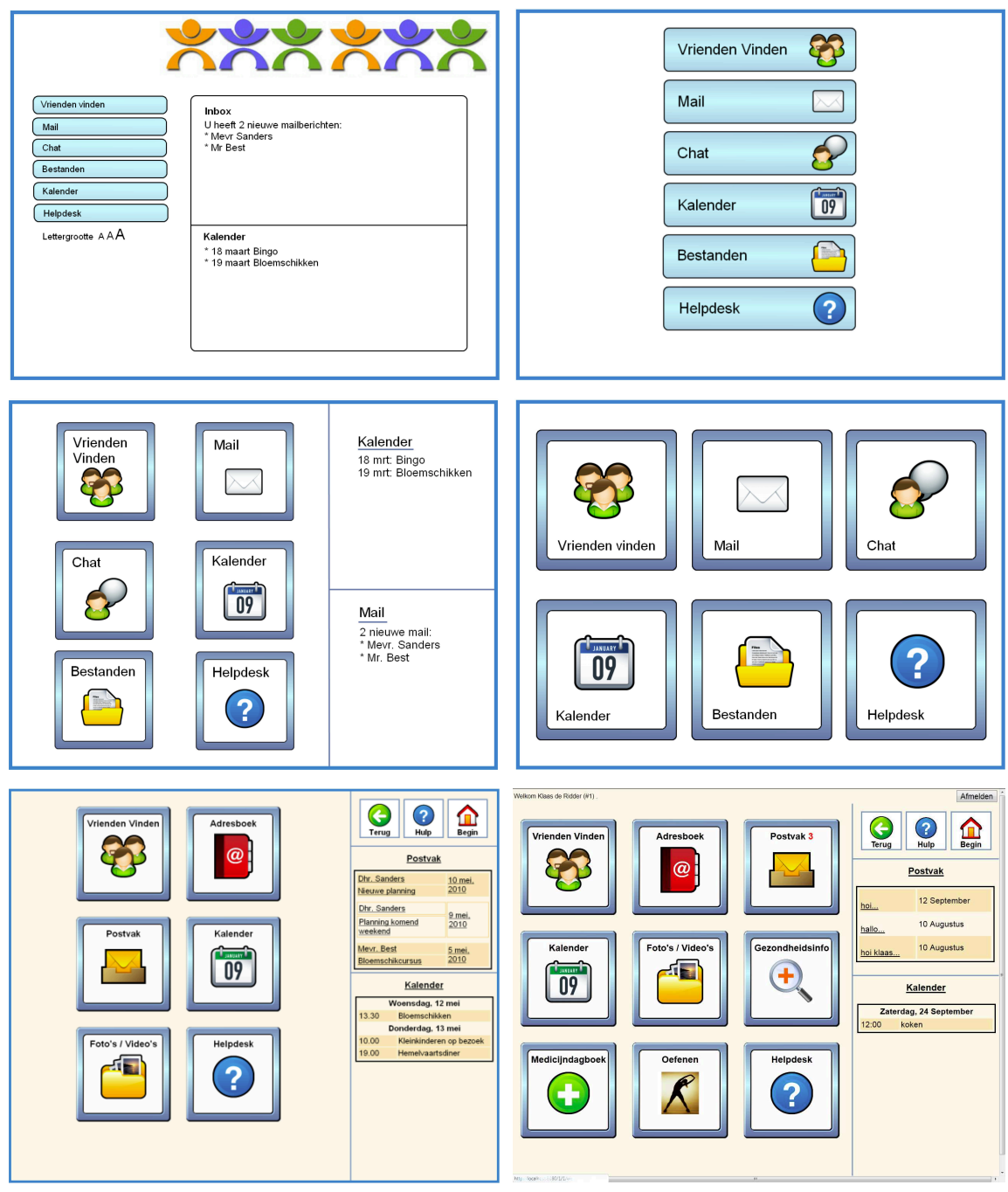

Figure A.1: Impressions of the different interface designs 


\section{Appendix B}

\section{Interview questions}

\section{Opzet en Script voor interviewsessies}

Doel: helder beeld krijgen van doelgroep en beeld krijgen van gezondheidstoestand. ICF categorieën zijn tussen [] vermeld.

Opzet:

1. korte ijsbreekperiode om geinterviewde op gemak te stellen

2. vertellen doel onderzoek, samenwerkingsverband ucare

3. vragen gezondheidssituatie, ICF

4. vragen leefsituatie en externe factoren

5. afsluiting bezoek

Letten op:

- antwoorden partner

- verwachte (te) lange antwoorden in verband met beschikbare tijd

- open vs. gesloten vragen

- opname met geluidsdrager

\section{IJsbrekers}

- woont u hier alleen?

- hoe lang woont u hier al? hoe bevalt het?

- wat doet $\mathrm{u}$ in het dagelijks leven? wat deed u hiervoor? 


\section{Inleiding}

Vertel dat antwoorden anoniem behandeld worden en de informatie alleen binnen het kader van het onderzoek gebruikt wordt. Als u bepaalde antwoorden niet wilt geven is dat zeker in orde.

Geef evt. flyer met achtergrondinfo.

Vertel dat komende vragen betrekking hebben op: 1) gezondheid, 2) leefomstandigheden. 3) Gezondheidssituatie

- Kunt u ons vertellen over uw gezondheidssituatie? (bij geen antwoord, vraag naar problemen, chronische aandoeningen)

- Wat verwacht u daarin aan verandering? Verbetering, verslechtering?

- Krijgt u hulp van anderen, en waar bestaat deze hulp uit ? (NB dit staat ook in het indicatiebesluit), vraag ook naar: familie / vrienden (mantelzorg) / professionele hulp

- Anders: Heeft u een zorgindicatie?

\section{ICF gedeelte gezondheidssituatie}

Bij het bekijken van de gezondheidssituatie een van persoon kijken we naar het menselijk lichaam, en wat hiermee wordt gedaan. Over deze 2 onderwerpen gaan de volgende vragen.

- Als we kijken naar de opbouw van uw lichaam kijken, kunt u ons vertellen of er bij u bijzonderheden of gebreken zijn? (Lichaam Structuur) Oog oor Mond / tong Cardiovasculair (Hart en bloedvaten) Spijsverteringsstelsel Uitscheidings/ voortplantingsorganen Bewegingsapparaat Huid Zenuwstelsel Anders handen, armen, benen, voeten

- En als we kijken naar het functioneren van het lichaam? Zijn er hier gebreken? Mentaal Sensorisch Stem en spraak Functioneren cardiovasculair, immuun- en ademhalingssysteem Spijsvertering Uitscheiding voortplanting Beweging Huidgerelateerd Anders

(Korte vragen) De volgende korte vragen gaan over wat er met het lichaam wordt gedaan.

- Kunt $\mathrm{u}$ iets vertellen over zaken die u doet (Activiteiten) en deelname aan de volgende situaties (Participatie)?

- Welke activiteiten of zaken waaraan $\mathrm{u}$ deelneemt kunt $\mathrm{u}$ niet meer doen of met moeite?

- Welke zou u graag willen doen?

- Welke missen? 
- Aanvullingen?

In hoeverre doet $\mathrm{u}$ het volgende uberhaupt, bent $\mathrm{u}$ betrokken in het volgende? (meet de performance - P-restriction)

- Leren / kennis vergaren

- Communicatie

- Mobiliteit

- Zelfverzorging

- Huishoudelijke taken

- Onderhouden van relaties met anderen

- Sociale verkeer, uw functioneren in deze omgeving Uitvoeren iha van algemene en complexe taken

In hoeverre ben u zonder hulp staat dit te doen met uw gezondheidssituatie? (meet de ability - A-limitation)

- Leren / kennis vergaren

- Communicatie

- Mobiliteit

- Zelfverzorging

- Huishoudelijke taken

- Onderhouden van relaties met anderen

- Sociale verkeer, uw functioneren in deze omgeving Uitvoeren iha van algemene en complexe taken

\section{Leefsituatie}

Tot slot volgen enkele vragen over uw leefsituatie.

- In hoeverre zijn er in uw huis aanpassingen aan de woning gedaan?[e5-e1] Apparatuur, drempels, elektronica, handvaten, keuken. etc.

- In hoeverre moeten deze nog worden gedaan?

- Gebruikt u alle aanpassingen?

- Denkt u aan aanvraag van aanpassingen?

- Zijn er hierom, of vanwege uw situatie, redenen om te verhuizen? 
- Hoe erg bent u gesteld op uw woonomgeving, groenvoorzieningen en het klimaat?[e2]

- Hoe ervaart $\mathrm{u}$ de sociale voorzieningen in uw omgeving?[e5]

- Wenst u meer of anders?

- Hoe is de informatievoorziening? Maakt u hier veel gebruik van?

- In hoeverre bent u bekend met apparatuur, zoals elektronica, dvds, mobiele telefoon, afstandbedieningen, computer, internet? [e1]

- Gebruikt u het veel?

- Hoe is de relatie met naasten, vrienden, verplegend personeel, doktoren (evt. collega's)? [e3-e4]

- Krijgt u voldoende ondersteuning van deze mensen?

Tot slot nog een paar kleine vragen.

- Uw leeftijd?

- Uw hoogst genoten opleiding?

\section{Afsluiting}

- Bedank voor interview

- Benadruk anonieme behandeling nogmaals

- Wijs nogmaals op flyer

- Vraag of geinterviewde op de hoogte wil blijven -Ruimte voor opmerkingen geinterviewde op achterzijde. 


\section{Appendix C}

\section{Activities list}

Below, an anonymized list of activities organised during the evaluation is shown (Dutch).

Accordoen concert

Activiteit met vrijwilligster activiteit ...

Avondmaaltijd theehuis

Benadering door de wandelclub

Benadering door wandelclub

bewegen aan tafel

bezoek van vrijwilliger

Bibliotheek in de hal

Biljarten

bloeddruk opmeten

Bloemschikken

Boek lezen

Borrelen

Borrelen met live muziek

bowlen

Broodje knakworst

Broodje knakworst met zuurkool

Buren op bezoek

busuitstapje

Carnavalszitting

Cocktailmiddag

Creamiddag in het restaurant

Creme brulee

Dag van de ouderen

Diner

Drinks
DVD bekijken op het zitje

dvd kijken Bartje

DVD kijken op het zitje

DVD kijken op zitje

dvd kijken: Drie is te veel

Fietsen

Film

Frederique op bezoek

fysiotherapie

gesprek over Sint Nicolaas vroeger

Gewicht

Groentesoep maken

Gymastiek in het punt lokaal

H.Mis in het restaurant

H.Mis met dameskoor Nieuwstad

Hapjes en drankje

Hapjes en drankjes

Hard gekookte eieren eten

Internetcafe

Kapper

Kegelen

Kegelen /jeu de boules

Kegelen op het zitje

Kegelen/ jeu de boules

kegelen/jeu de boules

Kerk dienst

kerstconcert 
Kerstdiner

Kerstgebak bij zitgemak

kerstliedjes zingen

Kerstmarkt

Kerstverhaal

Kerstversiering etage

kienen

Kienen in het restaurant

kienen op het zitje

Kleinkinderen op bezoek

Koersbal

Koersbal in het restaurant

koffie drinken

Koffie drinken op het zitje

Koffie zetten

Kookactiviteit

krant voorlezen

Krant voorlezen op het zitje

Kroedwusj zegening in het restaurant

Kun je Zingen, zing dan mee

laatste

Lasagne essen

leuk evenement

Lezing

Lezing over Vergeten groenten

Lilian fashion Modehuis

Line-dance middag

Lunch

lunchtime!

Marto Mode verkoop dameskleding

medicatie innemen

Medicijnen

Memory

Middageten in het restaurant

Modeshow

Muziek met Huub Merkelbach

Muziek middag met DJ Bas

Muziek quiz

Muziekavond met het Muze koor

Muziekmiddag

Muziekmiddag Balkan duo.

Muziekmiddag Balkan-duo

Muziekmiddag/zangkoor in het res- taurant

naar bed

Naar schouwburg

Naar verjaardag

Nagel en handverzorging

Nagelverzorging

Nationale buitenspeeldag

Ontbijt

Optreden in het restaurant

Pannenkoeken bakken

Pepernoten bakken

Quiz

Sacramentsprocessie

schaken met John

Schilderclub

shopping

Sint Maarten optocht

Sint Nicolaasmiddag zitje

Sinterklaas kienen

Sinterklaas show

Sjoelen

Sjoelen in het restaurant

Spelactiviteit op het zitje

spellenmiddag

spellenmiddag stagiaires

Spelletjes spelen

sport en spelmiddag

sport/spel ...

Uitstapje met het busje

Uurmode show

Verjaardag Mevr. ...

Verkoop voor Congo

Versieren zitje Carnaval

Volksdans

wafels bakken

Weight

wekker

WII-en in het restaurant

Zingen op het zitje

Zitje versieren Sint Nicolaas

Zomerse middag

Zoon op bezoek

zuurstofverzadiging 


\section{Appendix D}

\section{API reference}

Below the list of functions available from the application tier API is given. For details on the data structures and parameter settings used, we refer to the software documentation. Note: where Ids are mentioned, they are accepted and sent in encrypted format (hashed) as discussed in paragraph 4.3.1.

\section{Web Service API functionalities exposed}

addAgendaItem adds an Agenda item. Once the item expires, the integration tier is notified.

addUserToAct stores an Act for a given User.

agendaDemo demos Agenda functionality.

editAgendaItemById edit Agenda item by Id.

getActList get list of all Acts users could be labeled with.

getActListOfUserById gets Act List Of User by Id.

getDateAndTime gets server Date And Time.

getGroupList gets list of available Groups.

getUserById gets User profile information By its hashed id.

getUserList gets User List.

removeAct removes an Act.

removeAgendaItemById removes Agenda item by Id.

removeUserActById removes a labelling of a user to an Act.

sendMessage sends a Message to a User. 
sendReminder sends a Reminder to User

setKeyValueByUserId set a key-value pair for a User.

voidOperation a void web service call.

\section{Web Service API calls made}

The following web service calls are made from the application tier to the integration tier:

UcareCalenderNotify called when Agenda item expires.

getVitalSignRecords requests latest vital sign data.

getVitalSignArchiveRecords requests archived vital sign data.

getMedication requests latest medication compliance data.

setMedicationAck Registers medication taken time (for manual intake confirmation). 


\section{Appendix E}

\section{B-coloring example}

Below, a clustering example is given to illustrate the b-coloring algorithm presented in Section 6.5. based on 14. The steps mentioned correspond to the line numbers of Algorithm 1: B-Coloring algorithm pseudocode.

\section{Distance and threshold}

Table E.1 is a distance matrix between 6 observations.

Table E.1: Distance matrix

\begin{tabular}{lcccccc}
\hline $\mathrm{D}(.,)$. & $\mathrm{a}$ & $\mathrm{b}$ & $\mathrm{c}$ & $\mathrm{d}$ & $\mathrm{e}$ & $\mathrm{f}$ \\
\hline $\mathrm{a}$ & 0 & & & & & \\
$\mathrm{~b}$ & 0.05 & 0 & & & & \\
$\mathrm{c}$ & 0.15 & 0.05 & 0 & & & \\
$\mathrm{~d}$ & 0.10 & 0.10 & 0.10 & 0 & & \\
$\mathrm{e}$ & 0.25 & 0.075 & 0.05 & 0.05 & 0 & \\
$\mathrm{f}$ & 0.075 & 0.10 & 0.20 & 0.15 & 0.25 & 0 \\
\hline
\end{tabular}

The threshold distance $s$ is calculated according to

$$
s=\min \left\{\max _{j}\left\{d_{i j}=D\left(o_{i}, o_{j}\right), i \neq j\right\}\right\}
$$

In Table E.2 $\max _{j}\left\{d_{i j}=D\left(o_{i}, o_{j}\right), i \neq j\right\}$ are given, the minimum (0.10) is emphasised:

Table E.2: Max distances

\begin{tabular}{ccccccc}
\hline & $\mathrm{a}$ & $\mathrm{b}$ & $\mathrm{c}$ & $\mathrm{d}$ & $\mathrm{e}$ & $\mathrm{f}$ \\
\hline $\max$ & 0.25 & $\mathbf{0 . 1 0}$ & 0.20 & 0.15 & 0.25 & 0.25 \\
\hline
\end{tabular}


The corresponding threshold graph $G_{\geq 0.10}$ is given in Table E.3 and visualised in Figure E.1.

Table E.3: Threshold graph

\begin{tabular}{lcccccc}
\hline $\mathrm{D}(.,)$. & $\mathrm{a}$ & $\mathrm{b}$ & $\mathrm{c}$ & $\mathrm{d}$ & $\mathrm{e}$ & $\mathrm{f}$ \\
\hline $\mathrm{a}$ & 0 & & & & & \\
$\mathrm{~b}$ & 0 & 0 & & & & \\
$\mathrm{c}$ & 0.15 & 0 & 0 & & & \\
$\mathrm{~d}$ & 0.10 & 0.10 & 0.10 & 0 & & \\
$\mathrm{e}$ & 0.25 & 0 & 0 & 0 & 0 & \\
$\mathrm{f}$ & 0 & 0.10 & 0.20 & 0.15 & 0.25 & 0 \\
\hline
\end{tabular}

Step 1: The maximum degree of the threshold graph is $\Delta=4$. Vertices $d$ and $f$ have a degree of 4 . One of them must be used to start coloring in the next step. The color set $L$, corresponding to the color numbers, is $L=\{1,2, \ldots, \Delta+1\}=\{1,2,3,4,5\}$.

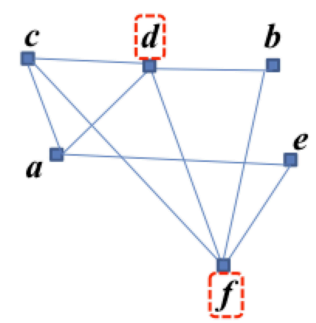

Figure E.1: Threshold graph.

\section{Color assignment}

Step 2: We choose to start from $d$, colour $c(d)=1$.

Step 3: $\{d\}$ is added to $T$.

Step 4-7: All nodes adjacent to $d$ are colored differently. $N(d)$, the neighbourhood of $d$ becomes $\{a, b, c, f\}$. The colored neighbourhood of $d$ becomes $N c(d)=\{2,3,4,5\}$.

Step 8, 9: $T$, the set of vertices ordered by decreasing degree, becomes $T=$ $f, a, c, b$ after $d$ is removed from $T$. The result is shown in Figure E.2.

Step 4: The next vertex from $T$ is $f$.

Step 5: Only neighbour $e$ is not yet colored, as seen in Figure E.2

Step 6: As $e$ is connected to $a$ and $f$, the other colors $L \backslash N c(e)=\{1,3,4\}$ are available. 


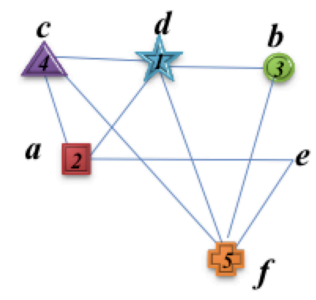

Figure E.2: Initial threshold graph coloring.

Step 7: We search the minimum distance from nodes in these colors to $e$ in the distance matrix:

- color 1: Vertex $d$ has this color. $D(e, d)=0.05$;

- color 3: Vertex $b$ has this color. $D(e, d)=0.075$;

- color 4: Vertex $c$ has this color. $D(e, d)=0.05$.

We choose to select color 1 and color $e$ with color 1 as shown in Figure E.3. Step 8,9: $e$ is added to $T$, and $f$ is removed from $T$, hence $T=\{a, c, b, e\}$.

Step 10: Now it is easy to verify that threshold graph $G_{\geq 0.10}$ has a proper coloring.

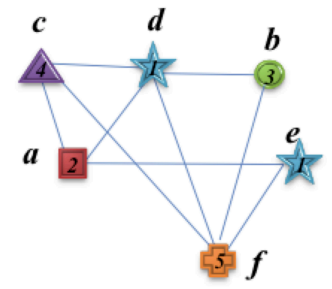

Figure E.3: Threshold graph coloring: proper coloring reached.

\section{Searching dominating vertices}

Recall from paragraph 6.5.4 that a dominating vertex is a vertex with its neighbouring vertices in all other colors used.

Step 11: In figure E.3 we see only vertex $d$ with color 1 is dominating. $\{2,3,4,5\}$ are non-dominating colors.

Step 12: The set of dominating colors $D c=\{1\}$.

Step 13: Among the non-dominating colors $\{2,3,4,5\}$ we pick a $k$, e.g. color 5 . 
Step 14: All vertices having $c\left(v_{i}\right)=5$ must be recolored. In our case this is vertex $f$.

Step 15: Colors of neighbours of $f$ (again, see Figure E.3) are $N c(f)=\{1,3,4\}$. Step 16: The set of available colors is $\{2\}=L \backslash(N c(f) \cup\{5\})$.

Step 17: $f$ is recolored with color 2. The result is Figure E.4. (If there were more options, color $h$ would be chosen such that the average distance of all vertices with color $h$ is minimised).

Step 18: remove $k$ from $L$, then $L=\{1,2,3,4\}$.

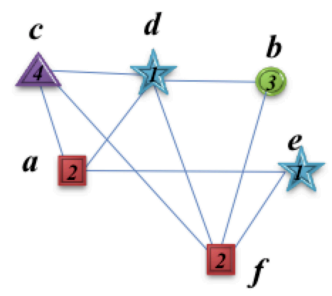

Figure E.4: Threshold graph coloring: recoloring vertex $f$.

Step 19: we have to identify if there are new dominating colors. Initially, $D c=\{1\}$. We verify if there are dominating colors $\in\{2,3,4\}$ (can be checked in Figure E.4):

- color 2: dominating if there is a vertex with neighbours in all other colors. The neighbours of vertex $f$ are in all other colors $L \backslash\{c(f)\}$. Hence, color 2 is a dominating color.

- color 3: vertex $b$ has this color. $b$ has no neighbour in color 4 , hence 3 is not a dominating color;

- color 4: vertex $c$ has this color. $c$ has no neighbour in color 3 , hence 4 is not a dominating color.

Now, the set of dominating colors becomes $D c=\{1,2\}$ and the set of non-dominating colors becomes $L \backslash D c=\{3,4\}$.

\section{Iterating step 13-19}

Step 13: $k$ is chosen among $\{3,4\}$. We pick a $k$, e.g. color 4 .

Step 14: All vertices having $c\left(v_{i}\right)=4$ must be recolored. In our case this is vertex $c$.

Step 15: Neighbouring colors of $c$ are $N c(c)=\{1,2\}$.

Step 16: Available color is $\{3\}=L \backslash(N c(c) \cup\{4\})$.

Step 17: $c(3)=3$. The result is shown in Figure E.5.

Step 18: remove $k$ from $L$, then $L=\{1,2,3\}$. The result is Figure E.4. 


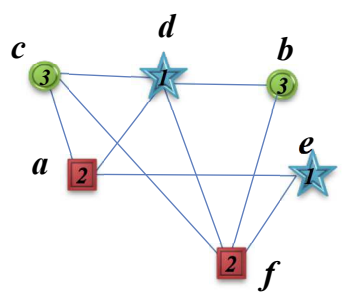

Figure E.5: Threshold graph coloring: recoloring vertex $c$.

Step 19: again, we have to identify if there are new dominating colors. Initially, $D c=\{1,2\}$. We verify if there are dominating colors $\in\{3\}$. This is true for both $c$ and $b$. The set of dominating colors becomes $D c=\{1,2,3\}$.

\section{Convergence}

Step 20. Now, $L=D c=\{1,2,3\}$. So there are 3 clusters. The corresponding partition $P=\left\{C_{1}, C_{2}, C_{3}\right\}$. An observation is that an observation $o_{i}$ is in the class $C_{1}$ if $c\left(v_{i}\right)=1$. 


\section{Dankwoord}

De volgende personen wil ik graag bedanken.

Allereerst een groot woord van dank aan mijn dagelijks begeleider dr.ir. BertJan van Beijnum en promotor prof.dr.ir. Hermie Hermens.

Bert-Jan, iets meer dan vier jaar geleden bood je me de keuze uit meerdere, misschien wel 5 aio-plaatsen. Dat is al meer dan een groot dankwoord waard. Je bood veel ruimte in het zelfstandig doen van onderzoek maar had bijtijds ook uitstekende suggesties en ideeën.

Hermie, bedankt voor de tips en adviezen, voor de feedback en het vertrouwen. En vooral ook de mogelijkheden die je me bood in het geven van onderwijs en het schrijven van een subsidieaanvraag. Ik heb er twee prachtbanen aan overgehouden.

Mijn dank gaat ook uit naar alle collega's van de vakgroep. De veelzijdige groepsbijeenkomsten en discussies staan mij bij, maar zeker ook de lunchwandelingen met collega's door het prachtige landgoed het Wageler. In het bijzonder wil ik vakgroepvoorzitter prof. dr. ir. Peter Veltink bedanken bij BSS te hebben mogen werken en Wies wil ik bedanken voor alle ondersteuning daarbij. Miriam, Ing, Val, Richard, Lamia, Hailiang, Pravin, Bart, Nick e.a. wil ik bedanken voor de prettige werkomstandigheden.

Je voudrais remercier prof. dr. Pierre Maret et dr. Catherine Combes de le CNRS en Saint-Étienne. Mer ci pour m'inviter de travailler à vous. J'ai appris beaucoup de data mining, plus que possible ailleurs. Je voudrais aussi remercier Chahrazed, Johan et Juri pour leur hospitalité à Saint-Étienne.

Afdelingshoofd Evelien Kamp-Poorthuis en lokatiedirecteur Robert Goossens van het Bonhoeffer College van der Waalslaan wil ik bedanken voor alle begrip, vrijheid en flexibiliteit die het me mogelijk maakten een groot onderzoek in Frankrijk te doen en voor het feit dat het lesrooster tot haast op het uur aangepast was op mijn onderzoek. Fantastisch. 
De projectcollega's, in het bijzonder bij Orbis Hoogstaete in Sittard wil ik bedanken voor alle energie en moeite die in het project zijn komen te zitten gedurende meer dan vier jaar. Maarten, John, Lilian, Cindy en collega's hartstikke bedankt. Ook Tom en Marten wil ik bedanken. Shahin, Mohammed en Lucas, bedankt voor alle bijdragen aan het project. It was great working with you.

Mijn afstudeerders Linda, Fred, Fabian, Tom en in het bijzonder Marieke wil ik ook bedanken voor alle bijdragen. De CreaTe studenten wil ik bedanken voor een aantal prachtige demo's.

Tabea, meer dan vier jaar heb je mij gesteund ondanks het verre reizen, late thuiskomen, als het liep en ook als het niet liep. Dankjewel.

Mijn familie wil ik bedanken voor alle ondersteuning en in het bijzonder voor het bij toerbeurt fungeren als taxichauffeur van en naar Schiphol - niet alleen op gebruikelijke, maar zeker ook op ongebruikelijke tijdstippen.

De collega's van de Healthcare tak van Nedap N.V. wil ik bedanken voor de bijdrage aan het proefschrift.

Els wil ik bedanken voor de omslag. Ik ben blij dat we innovatie en de kunsten enigszins samen hebben kunnen brengen.

Jan-Willem van 't Klooster

Enschede, Juni 2013 


\section{Biography}

Jan-Willem van 't Klooster was born in Leidschendam, The Netherlands, in 1984. He went to the Stedelijk Gymnasium Leiden (1996-2002) before studying Telematics (BSc and MSc, 2002-2008) and Computer Science Education (MSc; 2009-2010) in Enschede at the University of Twente.

From 2008 till 2013, Jan-Willem worked at the University of Twente as a research assistant in Telemedicine in pursuit of his $\mathrm{PhD}$ in user-tailored e-health services. A part of the work has been executed in France, in the Centre National de la Recherche Scientifique in Saint-Étienne.

From 2009 onwards, he works part-time at the Bonhoeffer College Enschede as a qualified teacher in Computer Science. From 2013 onwards, Jan-Willem has been working as a product owner at Nedap N.V.'s healthcare division in Groenlo, The Netherlands.

The research interests of Jan-Willem include healthcare decision support, service oriented computing and, in more general, e-health and design methodologies. These topics did not only find their way into the research presented here, but also in the teaching performed at secondary school, BSc and MSc levels and in healthcare product development at Nedap.

Since 2007, Jan-Willem has been hired as ERP and ICT consultant. Spare time attention goes to his old-timer, guitar and flying gliders. 


\section{List of publications}

1. J. W. J. R. van 't Klooster, C. Combes, B. J. F. van Beijnum, and H. J. Hermens. Decision support in nursing home care services using b-coloring of graphs, k-medoids based clustering and logistic regression. International Journal of Web intelligence and Agent Systems. Submitted.

2. J. W. J. R. van 't Klooster, B. J. F. van Beijnum, P. Pawar, K. Sikkel, L. O. Meertens, and H. J. Hermens. Virtual communities for elderly healthcare: User-based requirements elicitation. International Journal of Networked \& Virtual Organizations, 9(3):214-232, Inderscience, October 2011.

3. I. Mulder, Y. Schikhof, M. Vastenburg, A. Card, T. Dunn, A. Komninos, M. McGee-Lennon, M. Santcroos, G. Tiotto, M. van Gils, J. W. J. R. van 't Klooster, A. Veys, and M. Zarifi Eslami. Designing with care: The future of pervasive healthcare. Pervasive Computing, 8(4):85-88, IEEE Computer Society, October 2009.

4. J. W. J. R. van 't Klooster, B. J. F. van Beijnum, and H. J. Hermens. Testing user-tailored e-health services: Results and lessons learned. In Proceedings of the IADIS International Conference on e-Health 2013, 24 26 July, Prague, Czech Republic, 2013.

5. J. W. J. R. van 't Klooster, B. J. F. van Beijnum, A. P. W. Eliëns, and H. J. Hermens. Interactive scenario visualization for user-based service development. In Proceedings of the 2012 International Conference on Collaboration Technologies and Systems (CTS 2012), Denver, USA, pages 498-503, IEEE Computer Society, USA, May 2012.

6. J. W. J. R. van 't Klooster, C. Combes, and B. J. F. van Beijnum. Towards decision support for a homecare services platform. In Proceedings of the 4th International Workshop on Web Intelligence $\&$ Communities, $W W W$ conference 2012, Lyon, France, pages 48-54, ACM, New York, April 2012.

7. J. W. J. R. van 't Klooster, B. J. F. van Beijnum, P. Pawar, K. Sikkel, L. O. Meertens, and H. J. Hermens. What do Elderly desire? A case 
for Virtual Communities. International International Workshop on Web Intelligence and Virtual Enterprises, 9th IFIP working conference on Virtual Enterprises (Pro-VE), Thessaloniki, Greece, October 7-9, 2009.

8. J. W. J. R. van 't Klooster, B. J. F. van Beijnum, and H. J. Hermens. Putting the patient at the centre: Making telemedicine services personal again. In Proceedings of the 3rd International Conference on Pervasive Computing Technologies for Healthcare, Pervasive Health 2009, London, page 6071, ICST, March 2009.

9. J. W. J. R. van 't Klooster, P. Pawar, B. J. F. van Beijnum, C. B. Dulawan, and H. J. Hermens. Perspectives on the viable mobile virtual community for telemedicine. In Encyclopedia of E-Business Development and Management in the Global Economy, Advances in E-Business Research (AEBR) Book Series, pages 824-835. IGI Global, Hershey, USA, 2010.

10. J. W. J. R. van 't Klooster, B. J. F. van Beijnum, and H. J. Hermens. Ucare: Requirements elicitation for ambient assisted living. In Proceedings of the IEEE-EMBS Benelux Chapter Symposium, Enschede, pages 127127, MIRA, University of Twente, Enschede, November 2009.

11. J. W. J. R. van 't Klooster, B. J. F. van Beijnum, and H. J. Hermens. Experiences in testing personalized care systems in nursing home. Proceedings of the 2013 IEEE BME Benelux conference, IEEE Benelux Chapter, 2013.

12. J. W. J. R. van 't Klooster. Context, design and implementation of a control system for ring resonator-based optical beam forming networks. LAP Lambert Academic Publishing AG \& Co. KG, Saarbrucken, 2010.

13. J. W. J. R. van 't Klooster and M. L. T. Janssen. Ervaringen met het gebruik van sociale media in het voortgezet onderwijs. In Proceedings NIOC 2011, Heerlen, pages 122-126, Open Universiteit, Heerlen, April 2011.

14. J. W. J. R. van 't Klooster, C. G. H. Roeloffzen, A. Meijerink, L. Zhuang, D. A. I. Marpaung, W. C. van Etten, R. G. Heideman, A. Leinse, H. Schippers, J. Verpoorte, and M. Wintels. Design of a ring resonator-based optical beam forming network for phased array receive antennas. In 30th ESA Antenna Workshop on Antennas for Earth Observation, Science, Telecommunication and Navigation Space Missions, ESA/ESTEC, Noordwijk, the Netherlands, pages 403-406, Noordwijk, The Netherlands, May 2008 . 